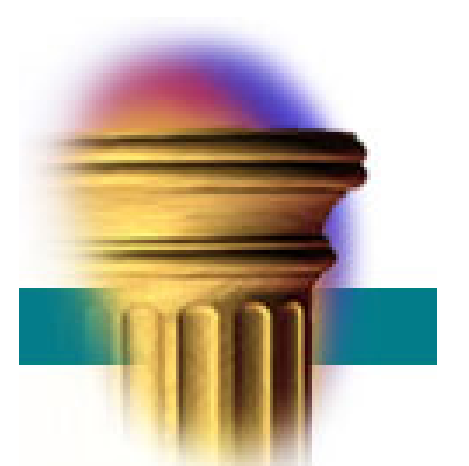

\title{
8 \\ Asymmetric Information, Dynamic Debt Issuance, and the Term Structure of Credit Spreads
}

$\frac{\tilde{U}}{0}$

\author{
Luca Benzoni, Lorenzo Garlappi, \\ and Robert S. Goldstein
}

\section{September 2019}

\section{WP 2019-08}

https://doi.org/10.21033/wp-2019-08

${ }^{*}$ Working papers are not edited, and all opinions and errors are the responsibility of the author(s). The views expressed do not necessarily reflect the views of the Federal Reserve Bank of Chicago or the Federal Reserve System. 


\title{
Asymmetric Information, Dynamic Debt Issuance, and the Term Structure of Credit Spreads*
}

\author{
Luca Benzoni $^{\dagger}$ \\ Chicago Fed
}

\author{
Lorenzo Garlappi ${ }^{\ddagger}$ \\ UBC
}

\author{
Robert S. Goldstein ${ }^{\S}$ \\ University of Minnesota
}

September 20, 2019

\begin{abstract}
We propose a tractable model of a firm's dynamic debt and equity issuance policies in the presence of asymmetric information. Because "investment-grade" firms can access debt markets, managers who observe a bad private signal can both conceal this information and shield shareholders from infusing capital into the firm by issuing new debt to service existing debt, thus avoiding default. The implication is that the "asymmetric information channel" can generate jumps to default (from the creditors' perspective) only for those "high-yield" firms that have exhausted their ability to borrow. Thus, our model deepens the "credit spread puzzle" for investment-grade firms.
\end{abstract}

JEL Classification Codes: G12; G32; G33

Keywords: Credit spreads; Capital structure; Corporate Default; Jumps to Default

\footnotetext{
*We thank Olena Chyruk, Greg Duffee, Pierre Collin-Dufresne, Murray Frank, Marco Grotteria, Jiri Knesl, David Lando, Yi Li, Kristian Miltersen, Richard Rosen, Fabrice Tourre, Josef Zechner, and seminar participants at Copenhagen Business School, Humboldt University, UC Riverside, Vienna Graduate School of Finance, the 2018 NBER SI Asset Pricing Meeting, the 2019 AFA meeting, the 2018 SFS Cavalcade, and the 2018 CFE meeting for comments and suggestions. David Kelley, Scott Lee, Andy Polacek, Zachry Wang, and Dan Weiss provided excellent research assistance. All remaining errors are our own. The views expressed herein are those of the authors and not necessarily those of the Federal Reserve Bank of Chicago or the Federal Reserve System.

${ }^{\dagger}$ Federal Reserve Bank of Chicago, 230 S. LaSalle Street, Chicago, IL 60604, USA. E-mail: lbenzoni@frbchi.org

${ }^{\ddagger}$ Sauder School of Business, University of British Columbia, 2053 Main Mall, Vancouver, BC V6T 1Z2, Canada. E-mail: lorenzo.garlappi@sauder.ubc.ca

$\S$ University of Minnesota, Carlson School of Management, and NBER, 321 19th Ave South Minneapolis, MN, 55455, USA. E-mail: golds144@umn.edu
} 
"How did you go bankrupt?"

"Two ways. Gradually, then suddenly."

- Ernest Hemingway, The Sun Also Rises

\section{Introduction}

Most of the literature on debt issuance and optimal capital structure assumes that corporate bond investors observe a noiseless signal of firm value when determining the fair market price of debt. In practice, however, investors typically must rely on imperfect accounting statements and other public information to infer firm value. Aware that managers have inside knowledge of a firm's value, creditors will account for this informational disadvantage when they price debt. The presence of such asymmetric information in debt markets could potentially expose investors to unanticipated credit events in that, from the perspective of their information set, a firm may unexpectedly "jump to default." 1

In this paper, we propose a tractable model of a firm's dynamic choice of equity and defaultable debt in the presence of asymmetric information. In this setting, we demonstrate that managers of firms with access to the debt markets (which we refer to as "investmentgrade" (IG) firms) conceal any bad private signal by servicing existing debt through the issuance of new debt. Because this debt issuance shields shareholders from infusing capital into the firm, it is in their best interest for the firm not to default at this time. Thus, jumps to default can occur only after a firm has exhausted its ability to borrow, and thus has dropped to "fallen angel" status. We conclude that IG spreads cannot be explained by credit-event premia associated with asymmetric information, because the probability of a credit event through this channel is zero. An implication of our model is that other channels, such as asymmetries in state and federal taxes, market imperfections (e.g., illiquidity), and jumps in asset value due to public information, are needed to explain the large spreads on short-maturity IG debt identified by the empirical credit risk literature.

The notion of jump-to-default (or credit-event) risk arises naturally in reduced-form

\footnotetext{
${ }^{1}$ This type of default contrasts with defaults observed in standard diffusion-based structural models of default (Merton (1974)), in which firm value dynamics are assumed to be observed by all agents. In these models, default is "predictable," in that all agents observe firm value diffuse toward the (known) default boundary.
} 
credit-risk models (e.g., Duffie and Singleton (1997); Jarrow, Lando, and Turnbull (1997)), in which default is an unpredictable jump event. In their seminal paper, Duffie and Lando (2001) provide an economic justification for reduced-form models. Specifically, they investigate the optimal behavior of the manager of a firm that can issue only equity to service debt in place. They show that if this manager receives a sufficiently bad private signal, then it will be in the best interest of shareholders for the manager to declare default, rather than have them continue to service debt payments. From an outsider's information set, such a default is unexpected and can be characterized by a default intensity process similar to that specified in reduced-form models.

Building on the insights of Duffie and Lando (2001), we study a firm in which a manager with private information can issue new debt to service existing debt, at least until the firm exhausts its debt capacity. In contrast to Duffie and Lando (2001), our model predicts that IG firms will never jump to default due to a bad private signal. Since shareholders receive zero payoff in the event of a default, it is optimal for a manager acting on shareholders' behalf to avoid an immediate default by issuing new debt in order to service existing debt. Because IG firms have residual debt capacity, their managers pursue this strategy even if they receive a bad private signal about the firm's value, in the hope that asset valuations will improve before debt capacity is exhausted. Because IG debt does not jump to default in our model, it does not command a jump-to-default premium, and thus short-maturity spreads are essentially zero. However, creditors rationally account for their informational disadvantage when pricing the firm's debt, resulting in higher spreads at longer maturities. Only after the firm has reached "fallen angel" status, implying it has lost its ability to tap the credit market, is a jump to default possible in our framework. ${ }^{2}$

In some respects, our model's predictions for IG bonds are the opposite of those of Duffie and Lando (2001). By precluding the manager from accessing the credit market after the initial debt offering, Duffie and Lando (2001) show that firms can jump to default due to asymmetric information even if the underlying asset value dynamic follows a diffusion process. In contrast, by allowing the manager of IG firms to issue debt in the future, such firms would not immediately jump to default after a bad private signal even if the asset value

\footnotetext{
${ }^{2}$ The prediction that high-yield bonds can jump to default is consistent with the empirical findings of Strebulaev and Zhao (2012), who report that the default event of speculative-grade debt is associated with significant unanticipated losses in firm value. See also Clark and Weinstein (1983), Giesecke (2006), Jarrow and Protter (2004), Lang and Stulz (1992), and Warner (1977).
} 
follows a jump process that drops below a default threshold.

Our paper contributes to two strands of the literature. ${ }^{3}$ The first is the extensive body of work that studies structural models of capital structure choice and leverage dynamics. ${ }^{4}$ Unlike most papers in this literature, we allow for information asymmetry between the manager and creditors. The combination of dynamic debt issuance and the presence of information asymmetry between the manager and creditors provides a framework that nests most of the models studied in the literature. We exploit this generality to compare the implications of our model for optimal capital structure choice, credit spreads, and default frequencies to the predictions of previous studies. Specifically, by restricting the manager to issue only equity after the initial debt offering, our setting reverts to Duffie and Lando (2001). If we assume that the manager and creditors are equally informed, we obtain a model of optimal capital structure dynamics with complete information (e.g., Fischer, Heinkel, and Zechner (1989)). By removing both the ability to issue debt and the presence of informational asymmetry, we recover a version of the Leland (1994) model.

The second strand of literature to which we contribute investigates credit spreads in reduced-form frameworks. In particular, we build on the body of work that focuses on decomposing credit spreads into components of expected loss, risk premia, liquidity premia, and taxes. ${ }^{5}$ In this literature, there is disagreement on the magnitude of the jump-to-default premium. At opposite ends of the spectrum, Driessen (2005) estimates the ratio of riskneutral to actual default intensity, $\lambda^{\mathbb{Q}} / \lambda^{\mathbb{P}}$, to be 2.3 , while Bai, Collin-Dufresne, Goldstein, and Helwege (2015) argue that, if jump risk is priced due to a contagious response, then the ratio $\lambda^{\mathbb{Q}} / \lambda^{\mathbb{P}}$ has an upper bound of approximately 1.1. In contrast, in our paper we claim

\footnotetext{
${ }^{3} \mathrm{~A}$ third literature, less directly linked to our work, studies voluntary disclosure of managerial information, e.g., Shin (2003), and the roll-over of short-maturity debt, market runs, and market freezes, e.g., Diamond and Dybvig (1983), Acharya, Gale, and Yorulmazer (2011), He and Xiong (2012), Schroth, Suarez, and Taylor (2014), Dang, Gorton, and Holmström (2015), and Carré (2016).

${ }^{4}$ An incomplete list of contributions to this literature includes Merton (1974); Black and Cox (1976); Fischer, Heinkel, and Zechner (1989); Leland (1994); Goldstein, Ju, and Leland (2001); Dangl and Zechner (2004, 2016); Hennessy and Whited (2007); Abel (2016, 2017); DeMarzo and He (2018); Admati, DeMarzo, Hellwig, and Pfleiderer (2017). Our work is also related to the previous literature that models firms' earnings or assets with complete information via jump-diffusion processes (e.g., Zhou (2001); Gorbenko and Strebulaev (2010)). These specifications, however, do not give rise to a stochastic intensity for default unless the only variation in asset levels is through jumps. Finally, Chernov, Schmid, and Schneider (2017) study endogenous debt capacity in a model of sovereign debt issuance.

${ }^{5}$ See, e.g., Elton, Gruber, Agrawal, and Mann (2001), Longstaff, Mithal, and Neis (2005), Chen, Lesmond, and Wei (2007), Feldhütter and Schaefer (2018), and Culp, Nozawa, and Veronesi (2018).
} 
that the actual default intensity $\lambda^{\mathbb{P}}$ is tiny for IG firms, especially at very short horizons. Firms holding an IG status tend to gradually move toward their default boundary, and can jump to default only thereafter.

Most empirical studies of corporate bonds report evidence of a "credit-spread puzzle," in that it is difficult to explain observed spreads between corporate bond yields and Treasury yields in terms of expected losses and standard measures of risk. Our analysis is most relevant for IG spreads of short-maturity debt where the credit-spread puzzle is prevalent. Indeed, a growing literature ${ }^{6}$ argues that IG spreads for maturities greater than a few years can be explained by combining pricing kernels that capture time-varying Sharpe ratios over the business cycle with models that match the empirically observed clustering of defaults during recessions. In contrast, we show that incomplete information combined with debt issuance lowers short-term credit spreads of IG firms. Hence, our findings deepen the credit spread puzzle for IG firms at short maturities.

The rest of the paper is organized as follows. In Section 2, we motivate our analysis with empirical stylized facts for IG companies. Section 3 builds a model of corporate debt issuance and default decisions in the presence of asymmetric information between the manager and creditors. In Section 4, we present the implications of our model for optimal capital structure decisions and derive model-implied credit spreads and default rates. Section 5 concludes. Proofs and further details concerning the empirical analysis are in the Online Appendix.

\section{Stylized facts}

In this section, we discuss four stylized facts about the corporate bond market that provide empirical foundations for our model.

Fact 1: IG companies dominate the bond market. The top panel of Figure 1 documents the evolution in the dollar amount of non-financial IG bonds outstanding and compares it to that of higher- and lower-quality speculative grade bonds (labeled B and C). ${ }^{7}$ As a per-

\footnotetext{
${ }^{6}$ See, for example, Chen, Collin-Dufresne, and Goldstein (2009), Bhamra, Kuehn, and Strebulaev (2010), Chen (2010), Gomes and Schmid (2018), Bai, Goldstein, and Yang (2018).

${ }^{7}$ There is an increase in the size of the market of bonds rated by credit agencies. This is due in part to the growth in bond issuance by companies, but also to an increase in the coverage of bonds by credit agencies, i.e., the proportion of bonds that are not rated has been decreasing over time. In Figures 1 and 2,
} 
centage share, IG bonds comprise the majority of non-financial debt rated by credit agencies (Figure 2, top panel). The proportion is around $80 \%$ at the beginning of the sample period in 1990 and remains steadily high, around 70\%, throughout the rest of the sample period. The middle panels in Figure 1 and 2 show the dollar amount and percentage shares of new bond issues. The IG portion of new issues exhibits more variation than the share in total amount outstanding, but remains high throughout the 1990-2017 sample period. On average, new issues of speculative-grade bonds comprise $30.5 \%$ of the market, an estimate consistent with the figures reported by, e.g., Greenwood and Hanson (2013). ${ }^{8}$ Finally, the bottom panel of Figure 1 contains the dollar amount of bonds issued, net of bonds that have matured or have been recalled. Also in this case, net IG issues are preponderant, especially during economic downturns (Figure 2, bottom panel).

Fact 2: Firms rarely default while holding IG status. Table 1 shows average annualized default rates for companies in the IG, B, and C groups. Panels A and B concentrate on firms classified based on credit ratings over the periods 1985-2014 and 2001-2014 (see Section A in the Online Appendix for more details). It is evident that defaults by IG firms are extremely rare. Panel A shows that on average only $0.11 \%$ of IG companies file for bankruptcy within a year of being assigned an IG classification. Defaults over the first month are even less frequent, with an annualized rate of $0.06 \%$. Since credit ratings can reflect stale information, we also classify firms' creditworthiness based on CDS data (see Section B in the Online Appendix for more details). In Panel $\mathrm{C}$ of Table 1, we show that (annualized) IG default rates are virtually zero at horizons from one to three months, with a $0.01 \%$ point estimate that is statistically insignificant from zero. ${ }^{9}$ It is mostly the lowest-rated firms that file for bankruptcy. At the one-month horizon, the average default rate for $\mathrm{C}$ companies can exceed an annualized rate of $15 \%$ (Table 1, Panel A); beyond the first month, default rates

we exclude bonds that are not rated by credit agencies.

${ }^{8}$ For instance, using the Mergent Fixed Income Security Database (FISD), Greenwood and Hanson (2013) document that on average $32 \%$ of debt issuance in the 1983-2008 period consists of high-yield bonds. Drawing from Moody's Bond Surveys, they report that the dollar fraction of high-yield new issues is $11 \%$ in the $1926-$ 1982 (Table 1, panel C, page 1491).

${ }^{9}$ In the Online Appendix, we document that even the few IG firms that default experience a significant credit deterioration within the year before bankruptcy. Investors could have unwinded their positions in these firms when they lost IG status, thus avoiding exposure to jump-to-default risk. 
for firms in the $\mathrm{C}$ group decline progressively but remain elevated. ${ }^{10}$

Fact 3: Firms go bankrupt gradually, then suddenly. Figure 3 reports the average amount of bonds outstanding for firms that defaulted from 1985 to 2017 as a function of time to default. Companies take advantage of the credit market by steadily issuing bonds along their path to default. From ten years to about a year prior to default, their stock of debt increases by a factor of four. Starting from one year prior to default, the amount of debt levels off and declines slightly immediately before bankruptcy. A possible interpretation of these patterns is that companies rely on the credit market as a means to buffer negative shocks. However, their ability to issue debt is curtailed as they get closer to bankruptcy, suggesting that they eventually face a debt capacity constraint.

Fact 4: Firms gradually transition to fallen angels before defaulting. Figure 4 depicts the average credit rating for firms that defaulted from 1985 to 2017 as a function of time to default. The plot shows that the typical firm experiences a progressive deterioration in its credit status before eventually defaulting. Five years prior to the default event, the typical firm has a BB+ credit rating. Moreover, in unreported results we find that as the time to default increases, the firm's credit rating improves to investment grade. Figure 5 shows that along its path to default, the firm experiences an increase in leverage. Five years prior to default leverage is approximately 45\%, it then increases at an accelerating pace to reach $80 \%$ the year before default. In sum, this evidence supports the interpretation that firms gradually transition to fallen angels, then suddenly default.

In summary, we have presented evidence that IG firms (i) dominate the bond market in terms of debt issuance, (ii) hardly ever default while holding IG status, (iii) accumulate a significant amount of debt up to about a year before default, when their access to the bond market is curtailed, and (iv) typically diffuse into fallen angels before defaulting.

\footnotetext{
${ }^{10}$ It is likely that credit default swaps (CDS) trading declines when the company is close to distress and the contract is in the money. In contrast, credit agencies are likely to update their ratings more frequently when conditions for a company deteriorate. Hence, since CDSs are less traded when default risk is high, it is not surprising that empirical default rates for companies assigned a $\mathrm{C}$ label based on CDS-implied ratings underestimate the default rate obtained when companies are classified based on credit ratings (Table 1, Panel C vs. Panels A and B). This is consistent with the evidence in, e.g., Subrahmanyam, Tang, and Wang (2014).
} 


\section{Model}

To explain the stylized facts of the previous section, we develop a model of corporate debt issuance and default decisions in the presence of asymmetric information. As in Duffie and Lando (2001), we assume that creditors have less information than the firm's managers. However, two main features distinguish our model from Duffie and Lando (2001). First, we allow firms to issue both debt and equity, consistent with the empirical observation that a large fraction of IG firms are net issuers of corporate debt. Second, we model asymmetric information by assuming that creditors can continuously observe the value of the firm's assets with a delay. This feature reflects the fact that it takes time for market participants to acquire the accounting information needed to accurately value a firm's assets, while also limiting the ability of managers from forever hiding information from the public.

\subsection{Setup}

There are two state variables in this economy. The first is $\operatorname{EBIT}\left(X_{t}\right)$, whose risk-neutral dynamics are exogenously specified:

$$
\frac{d X}{X}=\mu d t+\sigma d B^{\mathbb{Q}}
$$

We specify the risk free rate $r$ to be constant and to satisfy the constraint $(r>\mu)$. As such, the present value $\left(V_{t}\right)$ of the claim to EBIT can be determined from the risk-neutral expectation:

$$
V_{t}=\mathbb{E}_{t}^{\mathbb{Q}}\left[\int_{t}^{\infty} d s e^{-r(s-t)} X_{s}\right]=\frac{X_{t}}{r-\mu}
$$

Since the claim to EBIT is proportional to EBIT itself, it inherits the same dynamics:

$$
\frac{d V}{V}=\mu d t+\sigma d B^{\mathbb{Q}}
$$


As required to preclude arbitrage, these dynamics imply that the risk-neutral expected return on the claim to EBIT equals the risk free rate:

$$
\frac{d V+X d t}{V}=r d t+\sigma d B^{\mathbb{Q}}
$$

Due to the linear relation between $X_{t}$ and $V_{t}$ in equation (2), we are free to choose either as the exogenous state variable. We find it more convenient to choose $V_{t}$. While management directly observes $X_{t}$ (and hence also $V_{t}$ ) at time- $t$, creditors observe only lagged EBIT $X_{t-L}$, and thus, only a lagged firm value $V_{t-L}$, where $L$ is a time lag that captures the information asymmetry between management and creditors.

The second state variable is the face value of outstanding debt $F_{t}$, which is characterized by a constant amortization rate $\xi$ and coupon rate $c$. The effective average maturity is $\frac{1}{\xi}$. During the interval $(t, t+d t), \xi F_{t} d t$ units of debt mature. Therefore, over this interval, the sum of coupon and principal payments to debtholders is $(c+\xi) F_{t} d t$. The dynamics for the face value of debt follows:

$$
d F_{t}=\left(-\xi F_{t}+\Gamma_{t}\right) d t
$$

in which $\Gamma_{t}$ captures debt issuance at date- $t$, the form of which will be specified below.

The firm chooses an initial financing mix of debt and equity at time zero. After time zero, we assume that firms can issue additional debt, at least until the time in which they exhaust their "debt issuing capacity," which we refer to as $\tau_{c}$. Given that debt capacity is specified below in terms of lagged firm value, all agents are aware of whether the current time $t$ is greater than or less than $\tau_{c}$. After this time, if the firm is losing money, it is limited to either issue equity to service the debt in place or choose to default, as in Duffie and Lando (2001). There are four relevant time regimes:

1. Regime 1: $t \in\left(0, \tau_{c}\right)$. In this regime, firms have the ability to raise new debt to service debt in place. Because equity holders do not need to infuse money into the firm during this time regime, there is no advantage for them to choose to default. Therefore, this regime is characterized by a zero default intensity. We refer to firms in this regime as "Investment-Grade" firms. 
2. Regime 2: $t=\tau_{c}^{-}$. At this point in time, the firm exhausts its debt capacity. Because the firm can no longer issue debt, if its asset value (which is known only by the manager) falls below the default threshold (the value of which is publicly known), then the firm immediately defaults. Rather than a default intensity, this regime/instant of time is associated with a finite probability of default.

3. Regime 3: $t \in\left(\tau_{c}, \tau_{c}+L\right)$. Firms can no longer issue debt and may default. Absent default, creditors observe lagged firm value $V_{t-L}$ and infer that the firm's assets must have remained above the default threshold over the time interval $\left[\tau_{c}, t\right]$, which has duration $\left(t-\tau_{c}\right)$ less than $L$. This regime is characterized by a time-dependent default intensity.

4. Regime 4: $t \in\left(\tau_{c}+L, \infty\right)$. As in Regime 3, firms can no longer issue debt and may default. Absent default, creditors observe lagged firm value $V_{t-L}$ and infer that the firm's assets must have remained above the default threshold over the time interval $\left[\tau_{c}, t\right]$, which has duration $\left(t-\tau_{c}\right)$ greater than $L$. It is convenient to express this time interval as $\left[\tau_{c}, t-L\right] \cup[t-L, t]$. Below we show that the knowledge of lagged asset value $V_{t-L}$ makes the knowledge that firm value remained above the default threshold during the interval $\left[\tau_{c}, t-L\right]$ redundant. Thus, given $V_{t-L}$, the only additional useful information is that default did not occur over the interval $[t-L, t]$. This information structure leads to a time-independent default intensity.

To solve for the value of debt and equity under the information set of creditors, we first need to derive the optimal default boundary chosen by management (that is, for times after debt capacity has been exhausted) and then solve for the value of the firm's securities backward in time, starting from Regime 4.

Below, it will be convenient to introduce the scaled state variable $v_{t}=V_{t} / F_{t}$, which can be interpreted as a proxy for inverse leverage. ${ }^{11}$ There is a lower boundary $v_{b}$ at which it is optimal for shareholders to default. We define the date of this event as $\tau_{b}$ and thus obtain the relation $v_{b}=V_{\tau_{b}} / F_{\tau_{b}}$. For times $t \geq \tau_{c}$ (i.e., times after debt capacity has been exhausted),

\footnotetext{
${ }^{11}$ Note that $V$ is not the sum of debt and equity values, but rather the claim to EBIT, which includes the claims to taxes, bankruptcy costs, and issuance costs. Still, we find it convenient to refer to $v=\frac{V}{F}$ as inverse leverage.
} 
the firm is restricted from issuing additional debt, implying that $\Gamma_{t}=0$ for these dates. As such, the dynamics for the face value of debt simplify to

$$
d F=-\xi F d t
$$

with solution

$$
F_{t}=F_{\tau_{c}} e^{-\xi\left(t-\tau_{c}\right)} \quad \forall t \in\left(\tau_{c}, \tau_{b}\right)
$$

For times $t \geq \tau_{c}$, an application of Ito's lemma implies that $v_{t}=\frac{V_{t}}{F_{t}}$ evolves via:

$$
\frac{d v_{t}}{v_{t}}=(\mu+\xi) d t+\sigma d B^{\mathbb{Q}}
$$

Assuming a constant tax rate $\theta$, the cash flows to equity, government and debt for times $t \in\left(\tau_{c}, \tau_{b}\right)$ are therefore:

$$
\begin{aligned}
\text { Equity : } & X_{t}-\theta\left(X_{t}-c F_{t}\right)-(c+\xi) F_{t} \\
\text { Government : } & \theta\left(X_{t}-c F_{t}\right) \\
\text { Debt : } & (c+\xi) F_{t} .
\end{aligned}
$$

At default, firm value is split among debtholders, government, and bankruptcy costs as:

$$
\begin{aligned}
& \text { Debt : } \quad(1-\alpha)(1-\theta) V_{\tau_{b}} \\
& \text { Government : } \quad(1-\alpha) \theta V_{\tau_{b}} \\
& \text { Bankruptcy Costs : } \quad \alpha V_{\tau_{b}} \text {. }
\end{aligned}
$$

\subsection{Shareholders' optimal default policy}

In our framework, it is in the shareholders' best interest for management to avoid default prior to the firm's debt capacity being exhausted, i.e., $t<\tau_{c}$. This is because equity holders receive zero payoff in case of bankruptcy and, therefore, it is best for them to maintain solvency as long as no cash injection into the firm is required from them. Since default 
can occur only after debt capacity is exhausted, we determine the optimal default policy by considering equity valuation at times $t>\tau_{c}$.

The equity claim $S\left(V_{t}, F_{t}\right)$ is the solution to:

$$
\begin{aligned}
S\left(V_{t}, F_{t}\right) & =\mathbb{E}_{t}^{\mathbb{Q}}\left[\int_{t}^{\tau_{b}} d s e^{-r(s-t)}\left(X_{s}-\theta\left(X_{s}-c F_{s}\right)-(c+\xi) F_{s}\right)\right] \quad t \in\left(\tau_{c}, \tau_{b}\right) \quad(11) \\
& =\mathbb{E}_{t}^{\mathbb{Q}}\left[\int_{t}^{\tau_{b}} d s e^{-r(s-t)}\left((1-\theta)(r-\mu) V_{s}-F_{s}(c(1-\theta)+\xi)\right)\right] \quad t \in\left(\tau_{c}, \tau_{b}\right),
\end{aligned}
$$

where we have used the identity $X_{s}=(r-\mu) V_{s}$. Because

$e^{-r t} S\left(V_{t}, F_{t}\right)+\int_{0}^{t} d s e^{-r s}\left((1-\theta)(r-\mu) V_{s}-F_{s}(c(1-\theta)+\xi)\right)$ is a $\mathbb{Q}$-martingale, it follows that $S\left(V_{t}, F_{t}\right)$ satisfies the PDE:

$$
0=-r S+\mu V S_{V}+\frac{\sigma^{2}}{2} V^{2} S_{V V}-\xi F S_{F}+(1-\theta)(r-\mu) V_{s}-F_{s}(c(1-\theta)+\xi),
$$

subject to the boundary conditions:

$$
\begin{aligned}
S\left(V=v_{b} F, F\right) & =0 \\
\lim _{(V / F) \rightarrow \infty} S(V, F) & =(1-\theta) V-F\left(\frac{c(1-\theta)+\xi}{r+\xi}\right) .
\end{aligned}
$$

We look for a solution of the form:

$$
S\left(V_{t}, F_{t}\right)=F_{t} s\left(v_{t}=V_{t} / F_{t}\right) .
$$


It follows that

$$
\begin{aligned}
S_{V}\left(V_{t}, F_{t}\right) & =s_{v}\left(v_{t}\right) \\
S_{V V}\left(V_{t}, F_{t}\right) & =\left(\frac{1}{F_{t}}\right) s_{v v}\left(v_{t}\right) \\
S_{F}\left(V_{t}, F_{t}\right) & =s\left(v_{t}\right)-v_{t} s_{v}\left(v_{t}\right) .
\end{aligned}
$$

Plugging these into the PDE in equation (12), we find that our conjectured solution holds if $s\left(v_{t}\right)$ satisfies the ODE:

$$
0=-(r+\xi) s+(\mu+\xi) v s_{v}+\frac{\sigma^{2}}{2} v^{2} s_{v v}+(1-\theta)(r-\mu) v_{t}-(c(1-\theta)+\xi)
$$

The solution to this ODE is:

$$
s(v)=A v^{\phi}+B v^{-\omega}+(1-\theta) v-\left(\frac{c(1-\theta)+\xi}{r+\xi}\right)
$$

in which the parameters $(\phi, \omega)$ are defined by

$$
\begin{aligned}
\phi & =\left(\frac{1}{\sigma^{2}}\right)\left[\left(\left(\sigma^{2} / 2\right)-(\mu+\xi)\right)+\sqrt{\left(\left(\sigma^{2} / 2\right)-(\mu+\xi)\right)^{2}+2 \sigma^{2}(r+\xi)}\right] \\
-\omega & =\left(\frac{1}{\sigma^{2}}\right)\left[\left(\left(\sigma^{2} / 2\right)-(\mu+\xi)\right)-\sqrt{\left(\left(\sigma^{2} / 2\right)-(\mu+\xi)\right)^{2}+2 \sigma^{2}(r+\xi)}\right] .
\end{aligned}
$$

It can be shown that both $\phi$ and $\omega$ are positive.

The values of constants $A$ and $B$ are determined by the boundary conditions:

$$
\begin{aligned}
s\left(v_{b}\right) & =0 \\
\lim _{v \rightarrow \infty} s(v) & =(1-\theta) v-\left(\frac{c(1-\theta)+\xi}{r+\xi}\right) .
\end{aligned}
$$


We find:

$$
s(v)=\left\{(1-\theta)\left(v-v_{b}\left(v / v_{b}\right)^{-\omega}\right)-\left(\frac{c(1-\theta)+\xi}{r+\xi}\right)\left(1-\left(v / v_{b}\right)^{-\omega}\right)\right\} \mathbf{1}_{\left(v>v_{b}\right)} .
$$

So far, the solution has been expressed in terms of an exogenous bankruptcy threshold $v_{b}$. Below, we assume that shareholders will choose $v_{b}$ optimally. This optimal solution can be found using either the smooth pasting condition $d s /\left.d v\right|_{v=v_{b}}=0$, or the first order condition $d s /\left.d v_{b}\right|_{v=v_{b}}=0$. The optimal location for the default boundary is:

$$
v_{b}=\left(\frac{1}{1-\theta}\right)\left(\frac{c(1-\theta)+\xi}{r+\xi}\right)\left(\frac{\omega}{1+\omega}\right) .
$$

For the analysis that follows, it is convenient to define the variable

$$
y_{t}=\log \left(\frac{V_{t}}{v_{b} F_{\tau_{c}} e^{-\xi\left(t-\tau_{c}\right)}}\right) \text {. }
$$

For times $t>\tau_{c}$, debt is amortized at a rate $\xi$ and so, by equation $(7), F_{t}=F_{\tau_{c}} e^{-\xi\left(t-\tau_{c}\right)}$. Using $v_{t} \equiv V_{t} / F_{t}$, definition (22) is then equivalent to $y_{t}=\log \left(v_{t} / v_{b}\right)$, which provides a measure of how far the firm is away from the default boundary. ${ }^{12}$ From equation (3) and Ito's lemma, we find:

$$
d y=m d t+\sigma d B^{\mathbb{Q}},
$$

where we have defined $m=\left(\mu+\xi-\frac{\sigma^{2}}{2}\right)$. We define the random default time $\tau_{b}$ as the first time when firm value drops below the default threshold:

$$
\tau_{b}=\inf \left\{t \geq \tau_{c}: v_{t} \leq v_{b}\right\}=\inf \left\{t \geq \tau_{c}: y_{t} \leq 0\right\} .
$$

\footnotetext{
${ }^{12}$ As we will see below, for times $t<\tau_{c}$, it is more useful to define $y_{t}$ as in equation (22) rather than as $y_{t}=\log \left(v_{t} / v_{b}\right)$, which explains our choice of definition.
} 


\subsection{Debt valuation}

To solve for the bond price, we work backwards in time, starting with the time interval $t \geq \tau_{c}$. We further break this regime into two separate sub-intervals, depending on whether $\tau_{c} \leq t \leq \tau_{c}+L$ (which we refer to as regime 3) or $t \geq \tau_{c}+L$ (which we refer to as regime 4). In the following subsections, we formally characterize the solution for each regime.

\subsubsection{Debt value in Regime 4: $t \geq \tau_{c}+L$}

If default has not yet occurred by time $t \in\left[\tau_{c}+L, \infty\right)$, then creditors, aware that the firm had previously exhausted its debt capacity at time $\tau_{c}$, infer that the value of the firm's assets must have remained above the threshold level $v_{b}$ during the time interval $\left(\tau_{c}, t\right)$ :

$$
\min _{s \in\left[\tau_{c}, t\right]}\left\{v_{s}-v_{b}\right\}>0, \text { or equivalently, } \min _{s \in\left[\tau_{c}, t\right]}\left\{y_{s}\right\}>0
$$

In addition, at time $t$, creditors know the lagged asset value $v_{t-L},{ }^{13}$ or, equivalently, $y_{t-L}$. Because the firm value process is one-factor Markov, it follows that the probability density for $y_{t}$ conditional upon the creditor's information set can be expressed as:

$$
\pi\left(y_{t} \mid \min _{s \in\left[\tau_{c}, t-L\right]}\left\{y_{s}\right\}>0, y_{t-L}, \min _{s \in[t-L, t]}\left\{y_{s}\right\}>0\right)=\pi\left(y_{t} \mid y_{t-L}, \min _{s \in[t-L, t]}\left\{y_{s}\right\}>0\right) .
$$

Equation (26) states that knowing $y_{t-L}$ makes the information that $y_{s}>0$ for all times $s \in\left(\tau_{c},(t-L)\right)$ incrementally useless for determining the conditional probability density for $y_{t}$. As we demonstrate below, this fact makes the transition density independent of time $t$, leading to bond prices that are more tractable in Regime 4 than in Regime 3. For conciseness, we use the notation:

$$
\mathcal{F}_{4, t}=\left\{y_{t-L}, \tau_{b}>t\right\}
$$

\footnotetext{
${ }^{13}$ More accurately, at time $t$, creditors know the time series $\left\{v_{s}\right\}, s \in(-L, t-L)$. However, for our purposes, $v_{t-L}$ serves as a sufficient statistic.
} 
in spite of the fact that $\tau_{b}$ may be less than $t$ (in which case the security is worthless) and that creditors observe $F_{t}$.

The following proposition shows that the information set $\mathcal{F}_{4, t}$ generates a time-invariant setting in which the default intensity depends only on survival up to time $t$, and $y_{t-L} \equiv$ $\log \left(v_{t-L} / v_{b}\right)$.

Proposition 1 For times $t \geq \tau_{c}+L$, the value of debt $D_{4}\left(\mathbf{1}_{\left\{\tau_{b}>t\right\}}, y_{t-L}, F_{t}\right)$ with face value $F_{t}$, coupon $c$, and amortization rate $\xi$, is given by the sum of two components:

$$
D_{4}\left(\mathbf{1}_{\left\{\tau_{b}>t\right\}}, y_{t-L}, F_{t}\right)=D_{4,1}\left(\mathbf{1}_{\left\{\tau_{b}>t\right\}}, y_{t-L}, F_{t}\right)+D_{4,2}\left(\mathbf{1}_{\left\{\tau_{b}>t\right\}}, y_{t-L}, F_{t}\right),
$$

where

$$
\begin{aligned}
& D_{4,1}\left(\mathbf{1}_{\left\{\tau_{b}>t\right\}}, y_{t-L}, F_{t}\right)=(c+\xi) F_{t} \mathbf{1}_{\left\{\tau_{b}>t\right\}} d_{4,1}\left(y_{t-L}\right) \\
& D_{4,2}\left(\mathbf{1}_{\left\{\tau_{b}>t\right\}}, y_{t-L}, F_{t}\right)=(1-\alpha)(1-\theta) v_{b} F_{t} \mathbf{1}_{\left\{\tau_{b}>t\right\}}\left[1-(r+\xi) d_{4,1}\left(y_{t-L}\right)\right],
\end{aligned}
$$

with

$$
d_{4,1}\left(y_{t-L}\right)=\int_{t}^{\infty} d T e^{-(r+\xi)(T-t)} \pi^{\mathbb{Q}}\left(\tau_{b}>T \mid \mathcal{F}_{4, t}\right)
$$

and $\pi^{\mathbb{Q}}\left(\tau_{b}>T \mid \mathcal{F}_{4, t}\right)$ given in equation (D.18) of the Online Appendix.

In Proposition 1, $D_{4,1}\left(\mathbf{1}_{\left\{\tau_{b}>t\right\}}, y_{t-L}, F_{t}\right)$ is the value of a claim to coupons and maturing principal prior to default, while $D_{4,2}\left(\mathbf{1}_{\left\{\tau_{b}>t\right\}}, y_{t-L}, F_{t}\right)$ is the claim to recovery conditional upon default.

The following corollary shows that, in this regime, the default intensity is time-independent and is similar to that derived in Duffie and Lando (2001). 
Corollary 1 For times $t \geq \tau_{c}+L$, the time-t default intensity $\lambda_{4, d}^{\mathbb{Q}}\left(y_{t-L}\right)$ satisfies

$$
\begin{aligned}
\lambda_{4, d}^{\mathbb{Q}}\left(y_{t-L}\right) & =\left.\frac{\sigma^{2}}{2} \frac{\partial}{\partial y_{t}} \pi_{4}^{\mathbb{Q}}\left(y_{t} \mid \tau_{b}>t, y_{t-L}\right)\right|_{y_{t}=0} \\
& =\frac{y_{t-L}}{\sqrt{2 \pi \sigma^{2} L^{3}}}\left(\frac{e^{-\left(\frac{1}{2 \sigma^{2} L}\right)\left(y_{t-L}+m L\right)^{2}}}{N\left(\frac{y_{t-L}+m L}{\sqrt{\sigma^{2} L}}\right)-e^{-\frac{2 y_{t-L} m}{\sigma^{2}}} N\left(\frac{-y_{t-L}+m L}{\sqrt{\sigma^{2} L}}\right)}\right) \mathbf{1}_{\left\{y_{t-L}>0\right\}},
\end{aligned}
$$

where the conditional density $\pi_{4}^{\mathbb{Q}}\left(y_{t} \mid \tau_{b}>t, y_{t-L}\right)$ is given by equation (D.1) of Lemma 1.

It is worth noting that the bond price $D_{4}\left(\mathbf{1}_{\left\{\tau_{b}>t\right\}}, y_{t-L}, F_{t}\right)$ does not satisfy the standard ordinary differential equation (ODE) for pricing contingent claims, that is,

$$
(c+\xi) F_{t}-\left(r+\xi+\lambda_{4, d}^{\mathbb{Q}}\left(y_{t-L}\right)\right) D_{4}+m D_{4, y}+\frac{\sigma^{2}}{2} D_{4, y y}+(1-\alpha)(1-\theta) v_{b} \lambda_{4}^{\mathbb{Q}}\left(y_{t-L}\right) \neq 0,
$$

where we have used the notation $D_{4, y}=\frac{\partial}{\partial y_{t-L}} D_{4}, D_{4, y y}=\frac{\partial^{2}}{\partial y_{t-L}^{2}} D_{4}$. This is because the expected growth rate of $y_{t}$ conditional upon the information set of creditors is larger than the unconditional growth rate $m:^{14}$

$$
\begin{aligned}
\mu_{y}\left(y_{t-L}\right) & \equiv\left(\frac{1}{d t}\right) \mathbb{E}^{\mathbb{Q}}\left[d y_{t-L} \mid y_{t-L}, \tau_{b}>(t-L)\right] \\
& >m .
\end{aligned}
$$

\footnotetext{
${ }^{14}$ To understand this result intuitively, consider a gambler with initial wealth $W_{0}$ who wagers each period (of duration $\Delta t$ ) a bet of size $\$ \sqrt{\Delta t}$ on a fair coin for $N=\left(\frac{T}{\Delta t}\right)$ periods and must stop gambling if they ever become bankrupt. That is, each bet pays off $+\$ \sqrt{\Delta t}(-\$ \sqrt{\Delta t})$ if the coin flip returns "Heads" ("Tails"). If we are told only that the gambler never went bankrupt, then the conditional probability that the first coin flip was "Heads" is higher than $50 \%$. Moreover, this probability increases the lower is $W_{0}$. Indeed, for the special case $W_{0}=\sqrt{\Delta t}$, the conditional probability that the first coin flip was heads equals $100 \%$ (because, had it been tails, the gambler would have gone bankrupt immediately), and the conditional expected change in wealth per period is $\mu_{y}\left(y_{t-L}\right)=\left(\frac{\sqrt{\Delta t}}{\Delta t}\right)=\left(\frac{1}{\sqrt{\Delta t}}\right)$, which explodes in the continuous time limit.
} 
Indeed, we find that

$$
\begin{aligned}
& \lim _{y_{t-L} \rightarrow 0} \mu_{y}\left(y_{t-L}\right)=\infty \\
& \lim _{y_{t-L} \rightarrow 0} D_{4, y_{t-L}}\left(y_{t-L}\right)=0,
\end{aligned}
$$

but that the product $\left(\mu_{y}\left(y_{t-L}\right) D_{4, y_{t-L}}\left(y_{t-L}\right)\right)$ remains finite in the limit.

\subsubsection{Debt value in Regime 3: $\tau_{c} \leq t<\tau_{c}+L$}

We next determine the value of debt for times $t \in\left[\tau_{c}, \tau_{c}+L\right)$, which we refer to as Regime 3 . An important special case to consider is the price of debt at $t=\tau_{c}$, which will be used as an input to determine bond prices at earlier times. In this section, we focus on this case, leaving the more general case of $t \in\left(\tau_{c}, \tau_{c}+L\right)$ to Section $\mathrm{E}$ of the Online Appendix.

Note that during Regime 3, assuming default has not occurred by time $t$, outsiders know only lagged firm value $y_{t-L}$ and that firm value has remained above the default boundary during the time interval $s \in\left[\tau_{c}, t\right]$ :

$$
\mathcal{F}_{3, t}=\left\{y_{t-L}, \min _{s \in\left[\tau_{c}, t\right]}\left\{y_{s}\right\}>0\right\}, \quad \forall t \in\left(\tau_{c},\left(\tau_{c}+L\right)\right) .
$$

In contrast to the information set in Regime 4, for all times $t \in\left[\tau_{c},\left(\tau_{c}+L\right)\right)$, the duration of the time interval $\left[\tau_{c}, t\right]$ in which the creditor knows that the firm value remained above the default boundary is less than $L$. In particular, for the special case $t=\tau_{c}$, creditors know only that firm value is above the default boundary at a single instant, namely, $y_{\tau_{c}}>0$. Because of this feature, as we demonstrate in Section E of the Online Appendix, the price of debt and the default intensity are a function of time $t$ in Regime 3, in contrast to the time-independent values derived for Regime 4 in Proposition 1.

The instant $\tau_{c}$ is the time at which the firm exhausts its debt capacity. We define it as the first time the ratio of lagged firm value $V_{t-L}$ to the face value of debt $F_{t}$ reaches a lower threshold $\underline{\Psi}$, which is contractually specified in the covenants of previous bond issues. 
Formally,

$$
\tau_{c}=\inf \left\{t: \frac{V_{t-L}}{F_{t}}=\underline{\Psi}\right\} .
$$

It therefore follows that $V_{\tau_{c}-L}=\underline{\Psi} F_{\tau_{c}}$. It is straightforward to show that:

$$
y_{\tau_{c}-L}=\ln \left(\underline{\Psi} /\left(v_{b} e^{\xi L}\right)\right)
$$

That is, $y_{\tau_{c}-L}$ is a pre-determined number, not a variable. With these definitions in hand, as well as the simplified notation for the creditors' information set $\mathcal{F}_{3, \tau_{c}}$ in equation (36), we now price the time- $\tau_{c}$ value of debt in Regime 3 .

Proposition 2 The time- $\tau_{c}$ value of debt, $D_{3}\left(\mathbf{1}_{\left\{\tau_{b}>\tau_{c}\right\}}, F_{\tau_{c}}\right)$, with coupon c, and amortization rate $\xi>0$, is the sum of two components:

$$
D_{3}\left(\mathbf{1}_{\left\{\tau_{b}>\tau_{c}\right\}}, F_{\tau_{c}}\right)=D_{3,1}\left(\mathbf{1}_{\left\{\tau_{b}>\tau_{c}\right\}}, F_{\tau_{c}}\right)+D_{3,2}\left(\mathbf{1}_{\left\{\tau_{b}>\tau_{c}\right\}}, F_{\tau_{c}}\right)
$$

where

$$
\begin{aligned}
& D_{3,1}\left(\mathbf{1}_{\left\{\tau_{b}>\tau_{c}\right\}}, F_{\tau_{c}}\right)=(c+\xi) F_{\tau_{c}} \mathbf{1}_{\left\{\tau_{b}>\tau_{c}\right\}} d_{3,1} \\
& D_{3,2}\left(\mathbf{1}_{\left\{\tau_{b}>\tau_{c}\right\}}, F_{\tau_{c}}\right)=(1-\alpha)(1-\theta) v_{b} F_{\tau_{c}} \mathbf{1}_{\left\{\tau_{b}>\tau_{c}\right\}}\left[1-(r+\xi) d_{3,1}\right],
\end{aligned}
$$

with

$$
d_{3,1}=\int_{\tau_{c}}^{\infty} d T e^{-(r+\xi)\left(T-\tau_{c}\right)} \pi^{\mathbb{Q}}\left(\tau_{b}>T \mid \mathcal{F}_{3, \tau_{c}}\right)
$$

and $\pi^{\mathbb{Q}}\left(\tau_{b}>T \mid \mathcal{F}_{\tau_{c}}\right)$, given in equation (D.33) of the Online Appendix.

In Proposition 2, the term $D_{3,1}\left(\mathbf{1}_{\left\{\tau_{b}>\tau_{c}\right\}}, F_{\tau_{c}}\right)$ is the time- $\tau_{c}$ present value of a coupon and principal payments stream, $(c+\xi) F_{T} d T$, for times $T \in\left(\tau_{c}, \tau_{b}\right)$. The term $D_{3,2}\left(\mathbf{1}_{\left\{\tau_{b}>\tau_{c}\right\}}, F_{\tau_{c}}\right)$ is the time- $\tau_{c}$ present value of the claim to recovery $(1-\alpha)(1-\theta) v_{b} F_{\tau_{b}}$ if default occurs during the interval $(T, T+d T)$, for times $T \in\left(\tau_{c}, \infty\right)$. Note that, given $d_{3,1}$ is independent 
of $F_{\tau_{c}}$, it follows that each component of equation (39) is linear in $F_{\tau_{c}}$, and hence so is the debt value $D_{3}\left(\mathbf{1}_{\left\{\tau_{b}>\tau_{c}\right\}}, F_{\tau_{c}}\right)$.

In what follows, it is convenient to normalize the bond price by $F_{\tau_{c}}$ :

$$
\left(\frac{D_{3}\left(\mathbf{1}_{\left\{\tau_{b}>\tau_{c}\right\}}, F_{\tau_{c}}\right)}{F_{\tau_{c}}}\right)=\mathbf{1}_{\left\{\tau_{b}>\tau_{c}\right\}}\left[(c+\xi) d_{3,1}+(1-\alpha)(1-\theta) v_{b}\left(1-(r+\xi) d_{3,1}\right)\right]
$$

We emphasize that the normalized bond price given in equation (43) is a constant determined by the parameters of the model, rather than a random variable.

\subsubsection{Debt value in Regime 2: $t=\tau_{c}^{-}$}

Because firm value dynamics follow a diffusion process, the time $\tau_{c}$ at which debt capacity is exhausted is predictable by both creditors and the manager in that, moments prior to $\tau_{c}$, the probability that debt capacity will be exhausted in the next instant approaches one. Therefore, for the special case $t=\tau_{c}^{-}$, we define

$$
\mathcal{F}_{2, \tau_{c}^{-}}=\left\{F_{\tau_{c}}, y_{\tau_{c}-L}=\log \left(\underline{\Psi} e^{-\xi L} / v_{b}\right)\right\}
$$

It follows from the evolution of $y_{t}$ in equation (23) that the probability density of $y_{\tau_{c}}$ conditional on the lagged value $y_{\tau_{c}-L}=\log \left(\bar{\Psi} e^{-\xi L} / v_{b}\right)$ is normally distributed, with mean $\left(\ln \left(\underline{\Psi} e^{-\xi L} / v_{b}\right)+m L\right)$ and variance $\sigma^{2} L$. Hence:

$$
\pi^{\mathbb{Q}}\left(y_{\tau_{c}} \mid \mathcal{F}_{2, \tau_{c}^{-}}\right)=\frac{1}{\sqrt{2 \pi \sigma^{2} L}} e^{-\left(\frac{1}{2 \sigma^{2} L}\right)\left[y_{\tau_{c}}-\left(\ln \left(\underline{\Psi} e^{-\xi L} / v_{b}\right)+m L\right)\right]^{2}}
$$


Therefore, the probability that default occurs at time $\tau_{c}$ equals the probability that $\left(y_{\tau_{c}}<0\right)$, or

$$
\begin{aligned}
\pi_{2}^{\mathbb{Q}}\left(\tau_{b}=\tau_{c} \mid \mathcal{F}_{2, \tau_{c}^{-}}\right) & =\int_{-\infty}^{0} \pi\left(y_{\tau_{c}} \mid y_{\tau_{c}-L}\right) d y_{\tau_{c}} \\
& =N\left(\frac{-\ln \left(\underline{\Psi} e^{-\xi L} / v_{b}\right)-m L}{\sqrt{\sigma^{2} L}}\right)
\end{aligned}
$$

and thus the probability of survival is:

$$
\pi_{2}^{\mathbb{Q}}\left(\tau_{b}>\tau_{c} \mid \mathcal{F}_{2, \tau_{c}^{-}}\right)=N\left(\frac{\ln \left(\underline{\Psi} e^{-\xi L} / v_{b}\right)+m L}{\sqrt{\sigma^{2} L}}\right)
$$

The next proposition characterizes the bond price in Regime 2.

Proposition 3 The time- $\tau_{c}^{-}$value of debt, $D_{2}\left(F_{\tau_{c}}\right)$, with face value $F_{\tau_{c}}$, coupon $c$, and amortization rate $\xi>0$, is given by

$$
\begin{aligned}
& D_{2}\left(F_{\tau_{c}}\right)=N\left(\frac{\log \left(\underline{\Psi} e^{-\xi L} / v_{b}\right)+m L}{\sqrt{\sigma^{2} L}}\right) D_{3}\left(\mathbf{1}_{\left\{\tau_{b}>\tau_{c}\right\}}, F_{\tau_{c}}\right) \\
& \quad+(1-\alpha)(1-\theta) \underline{\Psi} F_{\tau_{c}} e^{\left(m-\xi+\frac{\sigma^{2}}{2}\right) L} N\left(\frac{-\log \left(\underline{\Psi} e^{-\xi L} / v_{b}\right)-\left(m+\sigma^{2}\right) L}{\sqrt{\sigma^{2} L}}\right),
\end{aligned}
$$

where the debt value $D_{3}\left(\mathbf{1}_{\left\{\tau_{b}>\tau_{c}\right\}}, F_{\tau_{c}}\right)$ is given in Proposition 2.

In Proposition 3, the value of the debt claim at time $\tau_{c}^{-}$is the sum of two terms: (i) the value of debt $D_{3}\left(\mathbf{1}_{\left\{\tau_{b}>\tau_{c}\right\}}, F_{\tau_{c}}\right)$ multiplied by the probability that default does not occur at $\tau_{c}$ and (ii) the expected recovery if default occurs at $\tau_{c}$.

Below, it will be convenient for us to identify the ratio of the value of debt scaled by the 
outstanding face value:

$$
\begin{aligned}
\frac{D_{2}\left(F_{\tau_{c}}\right)}{F_{\tau_{c}}}= & N\left(\frac{\log \left(\underline{\Psi} e^{-\xi L} / v_{b}\right)+m L}{\sqrt{\sigma^{2} L}}\right) \frac{D_{3}\left(\mathbf{1}_{\left\{\tau_{b}>\tau_{c}\right\}}, F_{\tau_{c}}\right)}{F_{\tau_{c}}} \\
& +(1-\alpha)(1-\theta) \underline{\Psi} e^{\left(m-\xi+\frac{\sigma^{2}}{2}\right) L} N\left(\frac{-\log \left(\underline{\Psi} e^{-\xi L} / v_{b}\right)-\left(m+\sigma^{2}\right) L}{\sqrt{\sigma^{2} L}}\right),
\end{aligned}
$$

where the ratio $\left(\frac{D_{3}\left(\mathbf{1}_{\left\{\tau_{b}>\tau_{c}\right\}}, F_{\tau_{c}}\right)}{F_{\tau_{c}}}\right)$ is given in equation (43). As in that case, the ratio $\left(\frac{D_{2}\left(F_{\tau_{c}}\right)}{F_{\tau_{c}}}\right)$ in equation (49) is a constant determined by the parameters of the model, rather than a random variable.

\subsubsection{Debt value in Regime 1: $0 \leq t<\tau_{c}$}

For all times $\left(t<\tau_{c}\right)$, creditors know (i) the face value of debt outstanding $F_{t}$, and (ii) lagged firm value $V_{t-L}$, that is,

$$
\mathcal{F}_{1, t}=\left\{V_{t-L} ; F_{t}\right\}, \quad t<\tau_{c},
$$

Note that, because $\left(t<\tau_{c}\right)$, it necessarily follows that $\left(V_{t-L}-\underline{\Psi} F_{t}\right)>0$.

At time $t=0$, the firm issues debt with initial face value $F_{0}$ and with a maturity structure such that a fraction $\xi d t$ of outstanding principal matures during each interval $d t$. In the absence of any additional debt issuances, the level of outstanding principal at date- $t$ would be $F_{t}=F_{0} e^{-\xi t}$. However, similar to DeMarzo and He (2018), we assume that the firm can issue new pari-passu debt in order to both service existing debt and to augment dividend payments to shareholders. We assume that the firm continues to issue debt until it exhausts its debt capacity, which we referred to above as time $\tau_{c}$. Because shareholders are not required to infuse additional funds into the firm (i.e., no equity issuances) for times $t<\tau_{c}$, it is optimal for them to avoid default during this regime, implying that the default intensity is zero for these times. After exhausting debt capacity, we assume that covenants restrict any future debt issuances. That is, for times $t>\tau_{c}$, the firm has to either issue new equity to service debt in place or default, as in Duffie and Lando (2001).

The dynamics $d F_{t}$ for the face value of debt are determined endogenously by identifying how much future cash flow must be promised to new bondholders in order to entice them 
to purchase the new debt issuance. During the interval $(t, t+d t)$, the firm owes debtholders principal and interest payments of $(c+\xi) F_{t} d t$. However, due to the tax deductability of interest payments, the amount that needs to be raised to service existing debt is only $(c(1-\theta)+\xi) F_{t} d t$. Following DeMarzo and He (2018), whose model predicts that firms will issue debt more aggressively when leverage levels are low, we assume that at date- $t$, the firm chooses to raise more debt than what is needed to service existing debt. Specifically, for a given parameter value $\beta \geq 0$, we set debt issuance equal to ${ }^{15}$

$$
\text { debt issuance }=\left[(c(1-\theta)+\xi) F_{t}+\beta\left(V_{t-L}-\underline{\Psi} F_{t}\right)\right] d t \text {. }
$$

Combining these debt issuance cash flows with cash flows to equity in the absence of debt issuance (i.e., equation (9)), we find that dividends paid out to shareholders at date-t equal:

$$
\text { dividends }=\left[(1-\theta) X_{t}+\beta\left(V_{t-L}-\underline{\Psi} F_{t}\right)\right] d t
$$

Because EBIT $X_{t}$ is guaranteed to be positive, and given that, by construction, the term $\left(V_{t-L}-\underline{\Psi} F_{t}\right)$ is positive within Regime 1, it follows that dividends are positive for all times during Regime 1, implying that management, acting in the best interest of shareholders, would never default prior to their debt capacity being exhausted.

In order to raise this money, the firm issues additional debt, which we assume is paripassu. As the debt issuance policy is known, in order to preclude arbitrage, the price of debt per unit of face value, $\left(\frac{D_{1}\left(V_{t-L}, F_{t}\right)}{F_{t}}\right)$ must remain constant prior to and after the debt issuance. The fraction of debt owned by the new owners, determined at time $t$, is

$$
\pi_{\text {new }}=\left(\frac{F_{t+d t}-F_{t} e^{-\xi d t}}{F_{t+d t}}\right) .
$$

\footnotetext{
${ }^{15}$ Below, we define $\Psi_{t} \equiv V_{t-L} / F_{t}$, which can be interpreted as a proxy for lagged inverse leverage. By definition of being in Regime-1, we have the restriction $\Psi_{t} \geq \underline{\Psi}$. Note that the amount of debt issued above what is required to service existing debt, $\beta\left(V_{t-L}-\underline{\Psi} F_{t}\right)=\beta V_{t-L}\left(1-\left(\underline{\Psi} / \Psi_{t}\right)\right)$ is positive for all times $t<\tau_{c}$, and is increasing in inverse leverage $\Psi_{t}$. The implication is that, consistent with DeMarzo and He (2018), debt issuance is more aggressive when the firms leverage ratio is low. Incidentally, setting $\beta=0$ does not qualitatively affect any of our results.
} 
The intuition for this equation is as follows: The firm enters time $t$ with face value $F_{t}$. If there were no additional debt issuance, the firm would leave with $F_{t} e^{-\xi d t}=(1-\xi d t) F_{t}$ in face value of debt, because an amount $\xi F_{t} d t$ matured. This implies that the fraction of debt owned by previous owners is

$$
\pi_{\text {old }}=\left(\frac{F_{t} e^{-\xi d t}}{F_{t+d t}}\right)
$$

It follows that the dynamics $d F_{t}$ can be determined by equating the value of the new debt claim to the amount new creditors pay for this claim:

$$
\left[((1-\theta) c+\xi) F_{t}+\beta\left(V_{t-L}-\underline{\Psi} F_{t}\right)\right] d t=\left(\frac{D_{1}\left(V_{t-L}, F_{t}\right)}{F_{t}}\right)\left[F_{t+d t}-F_{t} e^{-\xi d t}\right] .
$$

In the continuous-time limit, this implies that the dynamics for the face value of debt is locally deterministic, and equal to:

$$
d F_{t}=\left[-\xi F_{t}+\left(\frac{F_{t}}{D_{1}\left(V_{t-L}, F_{t}\right)}\right)\left[((1-\theta) c+\xi) F_{t}+\beta\left(V_{t-L}-\underline{\Psi} F_{t}\right)\right]\right] d t
$$

Note that this equation specifies the face value of debt dynamics in terms of the yet-to-beidentified value of outstanding debt $D_{1}\left(V_{t-L}, F_{t}\right)$. We identify the value of debt as a solution to the following expectation:

$$
D_{1}\left(V_{t-L}, F_{t}\right)=(c+\xi) F_{t} d t+e^{-r d t} \mathbb{E}^{\mathbb{Q}}\left[\left(\frac{F_{t} e^{-\xi d t}}{F_{t+d t}}\right) D_{1}\left(V_{t-L+d t}, F_{t+d t}\right)\right] .
$$

Intuitively, this states that the debt claim at date- $t$ is the sum of cash flows received this period from coupon and maturing debt, plus the risk-neutral expected value of the future claim, scaled by the fraction of the future claim owned by the date- $t$ bondholders. Using Itô's 
lemma, we can express this expectation in terms of the partial differential equation (PDE):

$$
\begin{aligned}
0= & \theta c F_{t}-r D+\beta\left(V_{t-L}-\underline{\Psi} F_{t}\right)\left[\left(\frac{F_{t}}{D}\right) D_{F}-1\right]+\mu V_{t-L} D_{V} \\
& +\frac{\sigma^{2}}{2} V_{t-L}^{2} D_{V V}-\xi F_{t} D_{F}+\left(\frac{F_{t}^{2}}{D}\right) D_{F}(c(1-\theta)+\xi) .
\end{aligned}
$$

The following proposition shows that the PDE (58) and the boundary conditions satisfy a certain scaling condition that allows us to rewrite the price of the bond in Regime 1 as the solution to an ordinary differential equation (ODE).

Proposition 4 The bond price $D_{1}\left(V_{t-L}, F_{t}\right)$ is homogeneous of degree one in its arguments and thus can be expressed as:

$$
D_{1}\left(V_{t-L}, F_{t}\right)=F_{t} d\left(\Psi_{t}\right), \quad \Psi_{t} \equiv \frac{V_{t-L}}{F_{t}}
$$

where $d\left(\Psi_{t}\right)$ satisfies the following ODE:

$$
\begin{aligned}
0= & -(r+\xi) d+(c+\xi)+\frac{\sigma^{2}}{2} \Psi^{2} d_{\Psi \Psi}+ \\
& \Psi d_{\Psi}\left[(\mu+\xi)-\left(\frac{1}{d}\right)(\beta(\Psi-\underline{\Psi})+(1-\theta) c+\xi)\right],
\end{aligned}
$$

subject to the boundary conditions:

$$
\begin{aligned}
d\left(\Psi_{t}=\underline{\Psi}\right) & =\left(\frac{D_{2}\left(F_{\tau_{c}}\right)}{F_{\tau_{c}}}\right) \\
\lim _{\Psi_{t} \rightarrow \infty} d_{\Psi}\left(\Psi_{t}\right) & =0 .
\end{aligned}
$$

The boundary condition (61) is a value-matching condition that precludes arbitrage opportunities at date $\tau_{c}$, that is, when $\Psi_{t}=\underline{\Psi}$. The boundary condition (62) states that the 
debt price approaches a constant as (lagged) firm leverage approaches zero (i.e., as lagged inverse leverage approaches infinity). ${ }^{16}$

\subsection{Creditors' valuation of equity}

It is convenient to define $\widehat{V}_{t}=V_{t-L}$ in order to emphasize that, at date $t$, creditors know only $\widehat{V}_{t}$. Furthermore, we define $\widehat{S}_{t}=\widehat{S}\left(\widehat{V}_{t}, F_{t}\right)$ to be the equity value conditional on the creditors' information set, and $S_{t}=S\left(V_{t}, F_{t}\right)$ to be the equity value conditional on the manager's information set.

Recall that, from definition (22), for $t \geq \tau_{c}, y_{t}=\log \left(V_{t} /\left(v_{b} F_{t}\right)\right)$. For this time interval, with a slight abuse of notation, we find it convenient to express the value of equity as $S\left(y_{t}, F_{t}\right)$ rather than $S\left(V_{t}, F_{t}\right)$. Specifically, from equation (20), we have;

$$
S\left(y_{t}, F_{t}\right)=F_{t} \mathbf{1}_{\left(y_{t}>0\right)}\left\{(1-\theta) v_{b}\left(e^{y_{t}}-e^{-\omega y_{t}}\right)-\left(\frac{c(1-\theta)+\xi}{r+\xi}\right)\left(1-e^{-\omega y_{t}}\right)\right\} \cdot t \geq \tau_{c} .
$$

The following proposition characterizes the equity value $\widehat{S}\left(y_{t-L}, F_{t}\right)$ conditional upon the creditors' information set.

Proposition 5 For times $t \geq \tau_{c}$, creditors' valuation of equity is given by

$$
\widehat{S}\left(y_{t-L}, F_{t}\right)= \begin{cases}\int_{0}^{\infty} \pi_{3}^{\mathbb{Q}}\left(y_{t} \mid \tau_{b}>t, y_{t-L}\right) S\left(y_{t}, F_{t}\right) d y_{t} & \text { if } \tau_{c} \leq t<\tau_{c}+L \\ \int_{0}^{\infty} \pi_{4}^{\mathbb{Q}}\left(y_{t} \mid \tau_{b}>t, y_{t-L}\right) S\left(y_{t}, F_{t}\right) d y_{t} & \text { if } t \geq \tau_{c}+L\end{cases}
$$

\footnotetext{
${ }^{16}$ For the case $\beta=0$, debt becomes risk free as $\Psi_{t} \rightarrow \infty$, because in this limit it takes infinitely long for the firm to reach $\tau_{c}$. Guessing that $d(\Psi)$ approaches a constant as $\Psi_{t} \rightarrow \infty$, and plugging in this guess into equation (60), we find that the bond price satisfies the risk-free valuation $\lim _{\Psi_{t} \rightarrow \infty} d\left(\Psi_{t}\right)=\frac{c+\xi}{r+\xi}$. For $\beta>0$, however, debt is not risk free as $\Psi_{t} \rightarrow \infty$. Indeed, as $\beta$ increases, the expected time for $\tau_{c}$ (and in turn, the expected time to default) decreases. Under this scenario, one can investigate bond prices for large values of $\Psi_{t}$ via the Taylor series expansion $d\left(\Psi_{t}\right)=\sum_{j=0}^{\infty} d_{j} \Psi_{t}^{-j}$ (where the $\left\{d_{j}\right\}$ are constants). As $\lim _{\Psi_{t} \rightarrow \infty} d\left(\Psi_{t}\right)=d_{0}$, the debt price is asymptotically constant, and therefore satisfies equation (62). Thus the boundary condition (62) holds even when $\beta$ is positive.
} 
where $\pi_{3}^{\mathbb{Q}}\left(y_{t} \mid \tau_{b}>t, y_{t-L}\right)$ is given by equation (D.4) in Lemma $2, \pi_{4}^{\mathbb{Q}}\left(y_{t} \mid \tau_{b}>t, y_{t-L}\right)$ is given in equation (D.1) in Lemma 1 , and $S\left(y_{t}, F_{t}\right)$ is given by equation (63).

For times $t<\tau_{c}$, creditors' valuation of equity is given by

$$
\widehat{S}\left(\widehat{V}_{t}, F_{t}\right)=\mathbb{E}_{t}^{\mathbb{Q}}\left[\int_{t}^{\tau_{c}} d T e^{-r(T-t)}\left[(1-\theta)(r-\mu) \widehat{V}_{T+L}+\beta\left(\widehat{V}_{T}-\underline{\Psi} F_{T}\right)\right]+e^{-r\left(\tau_{c}-t\right)} \widehat{S}_{\tau_{c}} \mid \mathcal{F}_{t}\right]
$$

where

$$
\begin{aligned}
\widehat{S}_{\tau_{c}} & =(1-\theta) \underline{\Psi} F_{\tau_{c}} e^{L\left(m-\xi+\left(\sigma^{2} / 2\right)\right)} N\left[\frac{y_{\tau_{c}-L}+m L+\sigma^{2} L}{\sqrt{\sigma^{2} L}}\right] \\
& -\left(\frac{c(1-\theta)+\xi}{r+\xi}\right) F_{\tau_{c}} N\left[\frac{y_{\tau_{c}-L}+m L}{\sqrt{\sigma^{2} L}}\right] \\
& +\left[\left(\frac{c(1-\theta)+\xi}{r+\xi}\right)-(1-\theta) v_{b}\right] F_{\tau_{c}} e^{-\omega y_{\tau_{c}-L}} e^{L\left(\left(\omega^{2} \sigma^{2} / 2\right)-\omega m\right)} N\left[\frac{y_{\tau_{c}-L}+m L-\omega \sigma^{2} L}{\sqrt{\sigma^{2} L}}\right],
\end{aligned}
$$

with $y_{\tau_{c}-L}=\log \left(\underline{\Psi} e^{-\xi L} / v_{b}\right)$.

With the value of $\widehat{S}_{\tau_{c}}$ obtained in equation (66), we can determine the outsiders' valuation of equity $S_{t}$ for $t<\tau_{c}$ by solving the expectation in equation (65). Because $e^{-r t} \widehat{S}\left(\widehat{V}_{t}, F_{t}\right)+$ $\mathbb{E}_{t}^{\mathbb{Q}}\left[\int_{0}^{t} d T e^{-r T}\left[(1-\theta)(r-\mu) \widehat{V}_{T+L}+\beta\left(\widehat{V}_{T}-\underline{\Psi} F_{T}\right)\right]\right]$ is a $\mathbb{Q}$-martingale, the expectation in equation (65) reduces to the following PDE:

$$
\begin{aligned}
0= & -r \widehat{S}+\mu \widehat{V}_{\widehat{S}}+\frac{\sigma^{2}}{2} \widehat{V}^{2} \widehat{S}_{\widehat{V} \widehat{V}}+(1-\theta)(r-\mu) \widehat{V} e^{\mu L}+\beta(\widehat{V}-\underline{\Psi} F) \\
& +\widehat{S}_{F}\left[-\xi F+\left(\frac{F}{D_{1}(\widehat{V}, F)}\right)[((1-\theta) c+\xi) F+\beta(\widehat{V}-\underline{\Psi} F)]\right] .
\end{aligned}
$$

The following proposition shows that the PDE (67) and the boundary conditions satisfy a certain scaling condition that allows us to rewrite the price of equity in the creditors' 
information set as the solution of an ODE.

Proposition 6 The equity price $\widehat{S}\left(V_{t-L}, F_{t}\right)$ is homogeneous of degree one in its arguments, and thus can be expressed as:

$$
\widehat{S}\left(\widehat{V}_{t}, F_{t}\right)=F_{t} \widehat{s}\left(\Psi=\widehat{V}_{t} / F_{t}\right)
$$

where $\widehat{s}(\Psi)$ satisfies the ODE:

$$
\begin{aligned}
0= & -r \widehat{s}+\mu \Psi \widehat{s}_{\Psi}+\frac{\sigma^{2}}{2} \Psi^{2} \widehat{s}_{\Psi \Psi}+(1-\theta)(r-\mu) \Psi e^{\mu L}+\beta(\Psi-\underline{\Psi} F) \\
& +\left(\widehat{s}(\Psi)-\Psi \widehat{s}_{\Psi}(\Psi)\right)\left[-\xi+\left(\frac{1}{d(\Psi)}\right)[((1-\theta) c+\xi)+\beta(\Psi-\underline{\Psi})]\right]
\end{aligned}
$$

subject to the boundary conditions:

$$
\begin{aligned}
\widehat{s}(\Psi=\underline{\Psi}) & =\frac{\widehat{S}_{\tau_{c}}}{F_{\tau_{c}}} \\
\lim _{\Psi \rightarrow \infty} \widehat{s}_{\Psi \Psi}(\Psi) & =0 .
\end{aligned}
$$

The boundary condition (70) guarantees continuity of the equity price at time $\tau_{c}$, that is, when $\Psi_{t}=\underline{\Psi}$. The boundary condition $(71)$ is a standard "no bubble" condition. ${ }^{17}$

\subsection{Optimal capital structure and debt dynamics}

In this section, we solve for the firm's optimal capital structure at time $t=0$. For tractability, we assume that the manager does not have an informational advantage at this time and that, like the creditors, she observes only the lagged asset value $\widehat{V}_{0}=V_{-L}$. Because the firm begins with no debt (i.e., $F_{0^{-}}=0$ ), it follows that shareholders will receive as dividend the present value of debt $D_{1}\left(\widehat{V}_{0}, F_{0}\right)$. Therefore, the objective of management is to choose $F_{0}$ in order to

\footnotetext{
${ }^{17}$ One can express the scaled equity function as a Taylor series expansion $\widehat{s}\left(\Psi_{t}\right)=\sum_{j=-1}^{\infty} s_{j} \Psi_{t}^{-j}$ (where the $\left\{s_{j}\right\}$ are constants). This functional form clearly satisfies the boundary condition (71).
} 
maximize:

$$
\max _{F_{0}}\left[\widehat{S}\left(\widehat{V}_{0}, F_{0}\right)+D_{1}\left(\widehat{V}_{0}, F_{0}\right)\right]=\max _{F_{0}}\left[F_{0} \widehat{s}\left(\Psi_{0}\right)+F_{0} d\left(\Psi_{0}\right)\right]
$$

Because $\widehat{V}_{0}$ is an exogenous constant, we can divide equation (72) by $\widehat{V}_{0}$, implying that equation (72) is equivalent to:

$$
\max _{\Psi_{0}}\left[\left(\frac{1}{\Psi_{0}}\right) \widehat{s}\left(\Psi_{0}\right)+\left(\frac{1}{\Psi_{0}}\right) d\left(\Psi_{0}\right)\right]
$$

After choosing its initial capital structure, the firm continuously issues debt at a rate $d F_{t}$ given by equation (56), until it exhausts its debt capacity. Applying Itô's lemma to $\Psi_{t} \equiv\left(\widehat{V}_{t} / F_{t}\right)$ we obtain the following dynamics for $\Psi_{t}$ :

$$
\frac{d \Psi_{t}}{\Psi_{t}}=\left[\mu+\xi-\left(\frac{1}{d(\Psi)}\right)[((1-\theta) c+\xi)+\beta(\Psi-\underline{\Psi})]\right] d t+\sigma d B^{\mathbb{Q}} \quad t \in\left(0, \tau_{c}\right)
$$

By construction, at the random time $\tau_{c}, \Psi_{\tau_{c}}=\underline{\Psi}$, where $\underline{\Psi}$ is an exogenous parameter representing the firm's debt capacity. ${ }^{18}$

\footnotetext{
${ }^{18}$ It is worth noting that our framework does not permit firms to create a Ponzi scheme in which it can forever issue debt to service debt in place, even for the case in which $\underline{\Psi}=0$. That is, leverage can reach infinity, or equivalently, inverse leverage can reach zero, in finite time. To see this, note that $\left(\frac{1}{d(\Psi)}\right)=$ $\left(\frac{F}{D_{1}}\right)=\left(\frac{1}{\Psi}\right)\left(\frac{\widehat{V}}{D_{1}}\right)$. As the recovery rate is finite in our model, thus so is $\left(\frac{1}{\text { recov }}\right)=\left(\frac{\widehat{V}}{D_{1}}\right)$. Therefore $\lim _{\Psi \rightarrow 0}\left(\frac{\Psi}{d(\Psi)}\right)=\left(\frac{1}{\text { recov }}\right)$. Therefore, when $\underline{\Psi}=0$, the dynamics of $\Psi$ as $\Psi \rightarrow 0$ is

$$
\lim _{\Psi \rightarrow 0}: \quad d \Psi \approx-\left(\frac{1}{\text { recov }}\right)((1-\theta) c+\xi) d t+\sigma \Psi d B^{\mathbb{Q}}
$$

which can clearly reach $\Psi_{t}=0$ in finite time.
} 


\section{Results}

There are two defining features of our model that, taken together, set it apart from the previous literature. First, we allow for informational asymmetry between the firm's manager and creditors. Second, the firm is able to issue debt until it reaches its debt capacity. It is useful to organize the discussion of our model's implications along these two elements, so as to more easily draw a comparison with the previous literature.

The key model coefficients associated with information asymmetry and debt issuance are the information lag parameter $L$ and the debt capacity parameter $\underline{\Psi}$. In the baseline case, we assume that it takes creditors six months to learn the true value of the firm's assets. Hence, they observe firm value $V_{t}$ with a delay $L=0.5$. Furthermore, we use $\underline{\Psi}=1.60$; this value generates a market leverage at time $\tau_{c}$ of approximately $75 \%$, in line with leverage values of firms that recently transitioned to "fallen angel" status.

Other special cases are also relevant. For instance, when $\left(L=0, \underline{\Psi}=\widehat{V}_{0} / F_{0}\right)$, the manager and creditors share the same information set, and the firm is permitted to issue debt only at time $t=0$. This case is similar to the Leland (1994) setting. Another special case is $\left(L>0, \underline{\Psi}=\widehat{V}_{0} / F_{0}\right)$. This case is closely related to the economy of Duffie and Lando (2001), in which a better-informed manager chooses the optimal mix of debt and equity at time zero, but is prevented from issuing debt in the future. Finally, the case in which $\left(L=0, \underline{\Psi}>\widehat{V}_{0} / F_{0}\right)$ falls within the literature on optimal capital structure dynamics with complete information (e.g., Goldstein, Ju, and Leland (2001), Hennessy and Whited (2007), DeMarzo and He (2018)).

Table 2 reports the rest of the model coefficients for the baseline calibration. We set the annual risk-free rate to $3.0 \%$, a value consistent with a $1 \%$ real rate and $2 \%$ expected inflation. We choose a $3.5 \%$ coupon rate, so that bonds are priced at par when they are issued by a firm that selects its time-0 capital structure optimally. The drift and volatility of the EBIT dynamics in equation (1) are set to $\mu=0$ and $\sigma=25 \%$, respectively. In the model, the capital structure choice is driven by the trade-off between debt tax shield and bankruptcy cost. In this respect, we assume that corporate profits are taxed at a $\theta=25 \%$ rate, while the loss given default parameter is set to $\alpha=40 \%$. As in DeMarzo and He (2018), we assume an amortization rate $\xi=10 \%$, corresponding to an expected debt maturity of $1 / \xi=10$ years. Also as in DeMarzo and He (2018), we assume that the firm issues debt 
more aggressively when leverage is low, which we capture by setting $\beta=0.01 \%$.

\subsection{Optimal initial capital structure}

Figure 6 shows the optimal firm capital structure at time $t=0$ as a function of the information lag $L$. The blue line, labeled "BGG," portrays the solution for our model, computed as in Section 3.5. The red line shows similar results for a firm that is restricted to issuing equity only at time $t=0$, i.e., $\underline{\Psi}=\widehat{V}_{0} / F_{0} \cdot{ }^{19}$ We label this case "Duffie-Lando."

In our baseline calibration $(L=0.5)$, the optimal initial leverage is $25.1 \%$, compared with $48.4 \%$ in the Duffie-Lando case. In our model, the firm continues to borrow after time $t=0$ to service debt in place, and its leverage increases to $75.8 \%$ by the time the credit constraint binds at time $\tau_{c}$. Hence, the ability to issue debt guarantees that default cannot occur in the "short term" (i.e., prior to $\tau_{c}$ ), in contrast to a firm that is restricted from issuing debt after date-0 (as in Duffie and Lando (2001)). However, these future debt issuances significantly increase the probability of default at longer maturities. This in turn makes it optimal for the firm to choose a lower initial leverage in our framework compared with that of Duffie and Lando (2001).

Furthermore, Figure 6 shows that as the information asymmetry between the manager and creditors increases, the firm issues less debt initially. For instance, when creditors observe the value of the assets with a one-year delay, optimal initial leverage decreases to $22 \%$ in our model; a similar drop occurs in the Duffie-Lando case, in which optimal initial leverage is $45.3 \%$. At the other extreme, when $L \rightarrow 0$, both manager and creditors observe the true value of the assets. In this case, the Duffie-Lando case collapses into the Leland model, with initial optimal leverage peaking at $51.7 \%$. In our model, the ability to issue additional debt in the future increases the riskiness of the initial debt in place, which in turn causes the optimal initial leverage to be lower $(28.9 \%)$.

Next, we illustrate the sensitivity of the firm's optimal initial capital structure to the credit constraint coefficient $\underline{\Psi}$. Figure 7 shows both the optimal leverage at time $t=0$ (the red stars) and the time- $\tau_{c}$ leverage (the blue triangles) as a function of $\underline{\Psi}$. At time- 0 , the op-

\footnotetext{
${ }^{19}$ In our model, we treat $\underline{\Psi}$ as an exogenous credit constraint that binds at a random time $\tau_{c}$ (equation (37)). From time $\tau_{c}$ onward, our economy is similar to that of Duffie and Lando (2001). Therefore, in the DuffieLando capital structure illustration, we assume that the firm is put in place at time $\tau_{c}$ and we treat $\underline{\Psi}$ as a choice variable selected by the manager to maximize the initial firm value.
} 
timal leverage ratio is hump-shaped in $\underline{\Psi}$. When $\underline{\Psi}$ is small, the manager issues a substantial amount of debt before exhausting debt capacity, and the firm reaches time $\tau_{c}$ with leverage ratios in excess of $90 \%$. Original creditors anticipate a high default probability shortly after $\tau_{c}$, resulting in a high time-0 cost of debt financing. Thus, the manager will choose a low initial leverage ratio. As $\underline{\Psi}$ increases, creditors know that the manager will exhaust debt capacity at lower levels of leverage and that the firm faces a lower default probability at "intermediate" maturities. Lower default rates increase the value of the original debt issuance and, in turn, the optimal initial leverage.

As $\underline{\Psi}$ increases further, the debt capacity constraint puts an upper bound on the initial leverage. In particular, as $\underline{\Psi} \rightarrow \infty$, the time-0 and time- $\tau_{c}$ leverage converge at a speed that depends on the amortization parameter $\xi$. When $\xi>0$, the firm is under strain to repay its debt after it reaches $\tau_{c}$ and thus faces a higher default probability. Hence, it is optimal for the manager to choose a lower initial leverage. To confirm this intuition, Figure 8 shows that, when $\xi=0$, the initial and time- $\tau_{c}$ leverage coincide for values of $\underline{\Psi}$ as low as 2.5 , while in the baseline case of $\xi=0.1$, the initial leverage converges to the time- $\tau_{c}$ leverage for values of $\underline{\Psi}$ in excess of 50 (Figure 7 ).

Figure 9 shows the effect of the amortization coefficient $\xi$ on the optimal time-0 leverage and debt-capacity leverage at $t=\tau_{c}$. There are two effects driving the time- $\tau_{c}$ leverage. A higher amortization rate (i) increases debt value because the firm repays debtholders faster; and (ii) lowers debt value because the perpetual coupon stream thins out as the firm repays the principal. In our baseline calibration, the first effect dominates and the time- $\tau_{c}$ leverage increases with $\xi$. At time $t=0$, the pattern in the time- 0 optimal leverage mirrors that of the time- $\tau_{c}$ leverage. When the time- $\tau_{c}$ leverage increases, the time- 0 creditors anticipate a higher probability of default. This perception decreases the value of time- 0 debt, leading the manager to choose a lower initial leverage.

Finally, Figure 10 shows firm leverage as a function of the EBIT volatility coefficient $\sigma$. As the riskiness of cash flows increases, the firm faces a higher debt financing cost and, as a result, it chooses a more conservative time- 0 mix of debt and equity and reaches $\tau_{c}$ with a lower leverage. 


\subsection{Term structure of credit spreads}

We use the debt pricing formulas, derived in Section 3, to simulate model-implied default times and then compute the term-structure of defaultable bond spreads as in Section 2.4, page 647, of Duffie and Lando (2001). Specifically, in each simulated path for asset values, we price a defaultable zero coupon bond with maturity $T$ whose payoff at maturity is either $\$ 1$, if there is no default, or a recovery value of $\$(1-\alpha)$ if default occurs at any time $\tau_{b} \leq T$.

Figure 11 shows the model-implied term structure of credit spreads as a function of the information lag $L$. For all value of $L$, we fix $\Psi_{0}$ at the optimal time- 0 value. ${ }^{20}$ As the information lag $L$ increases, debt becomes riskier and credit spreads go up. However, in all cases short-maturity credit spreads are nearly zero. This is because in our model IG companies are not subject to (instantaneous) jump-to-default risk; hence, they command no (instantaneous) jump-to-default premium.

Figure 12 documents the sensitivity of credit spreads to changes in $\underline{\Psi}$. As $\underline{\Psi}$ decreases, firms arrive at $\tau_{c}$ with a larger stock of debt. Hence, creditors expect the firm to reach its default boundary sooner than in the baseline case and therefore price debt lower. Even in this case, however, the impact of a lower $\underline{\Psi}$ is mostly visible in longer-dated spreads. In contrast, short-maturity debt largely remains safe, as the IG company can avoid default at short horizons by accessing its available debt capacity. A similar pattern is evident in Figure 13: As asset volatility increases, debt becomes riskier and spreads go up. However, the increase is mostly visible at longer maturities, while short-term IG spreads stay low.

Figure 14 shows the effect of an increase in the amortization rate $\xi$. The main point of the plot is to demonstrate that even when the firm issues short-maturity debt, short-term IG spreads remain small. For example, spreads with tenor up to two years are virtually zero for all values of $\xi$. The reason is that, in our model, as long as the firm has access to the credit market, it can raise as much funds as necessary to service debt in place. This is in stark contrast with other models of debt issuance that allow for positive amortization, e.g., Leland and Toft (1996). In their model, the manager issues new debt with face value equal to that of the amortized bonds. Since debt is issued at market price, the dollar amount raised might be insufficient to fully cover the cost of repaying the amortized debt. In such a case, the manager would have to issue additional equity to keep the firm operating, possibly

\footnotetext{
${ }^{20}$ For ease of comparison, we use the same value of $\Psi_{0}$ across Figures 11 to 14 .
} 
leading to a strategic default. In contrast, in our model, the manager issues enough debt to service debt in place. This is consistent with IG companies' ability to tap the credit market. Hence, as long as the firm has not exhausted its debt capacity, the firm will not jump to default and short-term credit spreads are not affected.

For maturities larger than two years, spreads are positive, albeit small, regardless of the amortization rate $\xi$. Figure 14 shows that the sensitivity of these spreads to $\xi$ depends on maturity. Specifically, for tenors between approximately two to 30 years, the dependence of spreads on $\xi$ is non-monotonic. At these intermediate horizons, firms have reached their time- $\tau_{c}$ debt capacity and are forced to issue equity to service debt in place. From this point onward, a higher amortization rate $\xi$ increases the financial burden on the firm, resulting in higher default probabilities and credit spreads. For tenors longer than 30 years, spreads fall as $\xi$ increases. By this time, firms have repaid most of their debt that is sinking at a faster rate $\xi$. Hence, at long maturities default probabilities and credit spreads fall with $\xi$.

In contrast to the previous illustrations that focused on IG firms, Figure 15 shows spreads for a fallen-angel company that has reached a leverage of $85 \%$. In the complete information case $(L \approx 0)$, spreads are small and close to zero at short maturities. As the degree of asymmetric information between managers and creditors increases, spreads rise considerably. For instance, an information lag of $L=1$ year produces spreads of 250 basis points at the one-month horizon. This happens because after the firm reaches its debt capacity at time $\tau_{c}$, it behaves similarly to a firm described by the Duffie-Lando economy. In particular, as leverage increases, jumps to default are possible and are priced in the firm's debt.

\subsection{Default rates}

Table 3 shows model-implied expected default rates for firms in different credit-rating groups. We assume an annual $5 \%$ risk premium to express the asset value process in equation (3) under the physical probability measure. We then simulate a sample of 10,000 firms, and track

each of them until its eventual default. For each firm and at each point of its simulated life span, we record the time to the company's default and use the firm's leverage as a proxy for credit worthiness. In particular, we assign firms with leverage no higher than $60 \%$ to the IG group. Companies with leverage between $60 \%$ and $70 \%$ are in the $\mathrm{B}$ group, while the rest are given a $\mathrm{C}$ label. We then compute the proportion of the firms in a rating group that 
default at various time horizons and report the annualized default rate in the table.

Model-implied default rates are close to the empirical estimates in Table 1. Just as in the data, IG companies hardly ever go bankrupt; at short horizons, default rates are virtually zero and they increase progressively over time. Failures remain infrequent among B firms, while firms in the $\mathrm{C}$ category behave in a way that is consistent with the possibility of jumps to defaults. At the one-month horizon, the annualized default rate is approximately $11 \%$, a number that closely matches the empirical default rates for high-yield bonds. Beyond the first month, default rates decline progressively, though they remain elevated, as in the data.

\section{Conclusion}

In their seminal paper, Duffie and Lando (2001) demonstrate that if managers observe a sufficiently bad private signal, then it will be in the best interests of shareholders to declare default, rather than have shareholders service existing debt. Based on the creditors' information set, such a default would be unanticipated and thus would be described as a "jump to default." Duffie and Lando (2001) conclude that the asymmetric information channel provides an economic justification for the so-called reduced-form models of default.

In this paper, we argue that the conclusions of Duffie and Lando (2001) are based upon the assumption that firms are unable to issue new debt in order to service existing debt. While such an assumption may be an appropriate description for highly leveraged firms (which we refer to as "high-yield" firms, or "fallen angels"), in general, moderately-leveraged firms (which we refer to as "investment-grade" (IG) firms) have the ability to access debt markets. To account for this reality, we generalize the framework of Duffie and Lando (2001) by allowing investment-grade firms to raise debt in order to service existing debt. Under this more realistic assumption, a manager of an IG firm will maximize shareholder value by concealing any bad private signal and servicing existing debt via additional borrowing.

This strategy permits IG firms to avoid jumping to default, at least until their debt capacity has been exhausted and the firm has been downgraded to "fallen angel" status. Creditors are aware of the manager's informational advantage and price it rationally into the firm's claims. Since IG firms do not face jump-to-default risk, their bond yields do not command a jump-to-default premium. A jump-to-default due to asymmetric information is possible in our model only after firms become "fallen angels" and exhaust their ability to borrow. 
An implication of our model is that the relatively large spreads on short-maturity IG debt over risk-free securities cannot be explained by jump-to-default premia due to asymmetric information. Therefore, other channels such as asymmetric taxes, market imperfections (e.g., illiquidity), or jumps due to public information, are needed to explain these large spreads. In this respect, our paper deepens the credit-spread puzzle.

While our framework allows for an important generalization over that of Duffie and Lando (2001), certain restrictive and counterfactual assumptions are made to maintain tractability. For instance, in our model, it is assumed that firms continue to borrow until debt capacity has been fully utilized. In both theory and practice, however, if the manager receives a sufficiently strong positive private signal, it would be in the the best interest of shareholders for the firm to issue equity rather than debt. Such an equity issuance would provide a signal regarding the firm's true value and therefore, would create a filtering problem even more complex than the one we solve in this paper. As a second example of an unrealistic restriction, we assume that once a firm becomes a fallen angel, it is never able to access debt markets again, even if the firm eventually regains its IG status. We emphasize however, that accounting for either of these restrictions will not impact our main conclusion, namely, that the asymmetric information channel will not generate the possibility of a jump-to-default for any firm that has the ability to raise debt to service existing debt. 
Table 1: Empirical Default Rates. Each month, we classify firms as investment grade (IG), higher-quality speculative grade (B), and lower-quality speculative-grade firms (C). In Panels A and B, the classification is based on credit ratings issued by the three main rating agencies (Moody's, Standard and Poor's, and Fitch). In Panel C, the classification is implied by the price of CDS contracts written on debt issued by the firms. Panel A shows average annualized default rates from 1985 to 2014 for firms in each rating category that have defaulted in the next 12 months; Panels B and C show default rates for the 20012014 period. Heteroskedasticity- and autocorrelation-robust (Newey-West) standard errors are in parentheses.

Annualized Default Rates

\begin{tabular}{lccccccc}
\multirow{2}{*}{ Rating } & \multicolumn{7}{c}{ Annualized Default Rates } \\
\cline { 2 - 7 } & $0-1 \mathrm{M}$ & $1-2 \mathrm{M}$ & $2-3 \mathrm{M}$ & $3-6 \mathrm{M}$ & $6-9 \mathrm{M}$ & $9-12 \mathrm{M}$ & $0-12 \mathrm{M}$ \\
\hline \multirow{6}{*}{ IG } & 0.06 & 0.07 & 0.07 & 0.08 & 0.11 & 0.15 & 0.10 \\
& $(0.02)$ & $(0.03)$ & $(0.03)$ & $(0.02)$ & $(0.03)$ & $(0.04)$ & $(0.02)$ \\
B & 0.20 & 0.34 & 0.48 & 0.63 & 0.84 & 1.02 & 0.71 \\
& $(0.05)$ & $(0.08)$ & $(0.10)$ & $(0.13)$ & $(0.16)$ & $(0.20)$ & $(0.13)$ \\
C & 14.46 & 13.66 & 12.54 & 11.10 & 9.14 & 7.47 & 10.31 \\
& $(1.41)$ & $(1.45)$ & $(1.21)$ & $(1.08)$ & $(0.92)$ & $(0.75)$ & $(0.94)$ \\
\hline
\end{tabular}

Panel B: Classification based on credit ratings, 2001-2014

\begin{tabular}{lccccccc} 
IG & 0.07 & 0.09 & 0.09 & 0.09 & 0.12 & 0.17 & 0.11 \\
& $(0.03)$ & $(0.04)$ & $(0.04)$ & $(0.03)$ & $(0.04)$ & $(0.05)$ & $(0.03)$ \\
$\mathrm{B}$ & 0.21 & 0.37 & 0.50 & 0.58 & 0.75 & 0.84 & 0.63 \\
& $(0.07)$ & $(0.10)$ & $(0.13)$ & $(0.15)$ & $(0.18)$ & $(0.21)$ & $(0.15)$ \\
$\mathrm{C}$ & 12.94 & 12.12 & 11.03 & 9.74 & 7.76 & 6.18 & 8.93 \\
& $(1.64)$ & $(1.65)$ & $(1.34)$ & $(1.22)$ & $(0.93)$ & $(0.73)$ & $(0.98)$ \\
\hline
\end{tabular}

Panel C: Classification based on CDS-implied ratings, 2001-2014

\begin{tabular}{lccccccc} 
IG & 0.01 & 0.01 & 0.01 & 0.04 & 0.04 & 0.05 & 0.03 \\
& $(0.01)$ & $(0.01)$ & $(0.01)$ & $(0.01)$ & $(0.02)$ & $(0.02)$ & $(0.01)$ \\
$\mathrm{B}$ & 0.29 & 0.35 & 0.34 & 0.42 & 0.51 & 0.51 & 0.44 \\
& $(0.11)$ & $(0.12)$ & $(0.13)$ & $(0.15)$ & $(0.19)$ & $(0.20)$ & $(0.14)$ \\
$\mathrm{C}$ & 3.30 & 3.12 & 3.12 & 3.05 & 2.94 & 2.81 & 3.00 \\
& $(0.91)$ & $(0.95)$ & $(0.82)$ & $(0.80)$ & $(0.73)$ & $(0.61)$ & $(0.60)$ \\
\hline
\end{tabular}


Table 2: Baseline Model Coefficients. Below are the values of the model coefficients in the baseline calibration.

\begin{tabular}{lcc} 
Parameter & Symbol & Value \\
\hline Coupon rate & $c$ & $3.5 \%$ \\
Annual risk-free rate & $r$ & $3.0 \%$ \\
Annual asset volatility & $\sigma$ & $25 \%$ \\
Corporate tax rate & $\theta$ & $25 \%$ \\
Loss given default & $\alpha$ & $40 \%$ \\
Maximum debt capacity & $\underline{\Psi}$ & 1.60 \\
Creditors' information delay (in years) & $L$ & 0.5 \\
Amortization rate & $\xi$ & $10 \%$ \\
Discretionary debt issuance intensity & $\beta$ & $0.01 \%$ \\
\hline
\end{tabular}

Table 3: Average Model-Implied Default Rates. We simulate a history of 10,000 firms from our model and track them from inception through their default time. For each firm and at any point in time of the simulations, we record the time to default and classify the observation as investment grade (IG) if the firm's leverage is below $60 \%$. We classify firms with leverage between $60 \%$ and $70 \%$ as higher-quality speculative grade (B). Lower-quality speculative-grade firms (C) have leverage in excess of $70 \%$. The table shows average default rates across firms in the simulated sample.

Average annualized default rates

\begin{tabular}{lccccccc} 
& $0-1 \mathrm{M}$ & $1-2 \mathrm{M}$ & $2-3 \mathrm{M}$ & $3-6 \mathrm{M}$ & $6-9 \mathrm{M}$ & $9-12 \mathrm{M}$ & $0-12 \mathrm{M}$ \\
\hline $\mathrm{IG}$ & 0.00 & 0.00 & 0.00 & 0.00 & 0.00 & 0.00 & 0.00 \\
$\mathrm{~B}$ & 0.28 & 0.65 & 1.04 & 1.58 & 2.12 & 2.47 & 1.71 \\
$\mathrm{C}$ & 11.06 & 10.66 & 10.19 & 9.18 & 7.81 & 6.63 & 8.57 \\
\hline
\end{tabular}




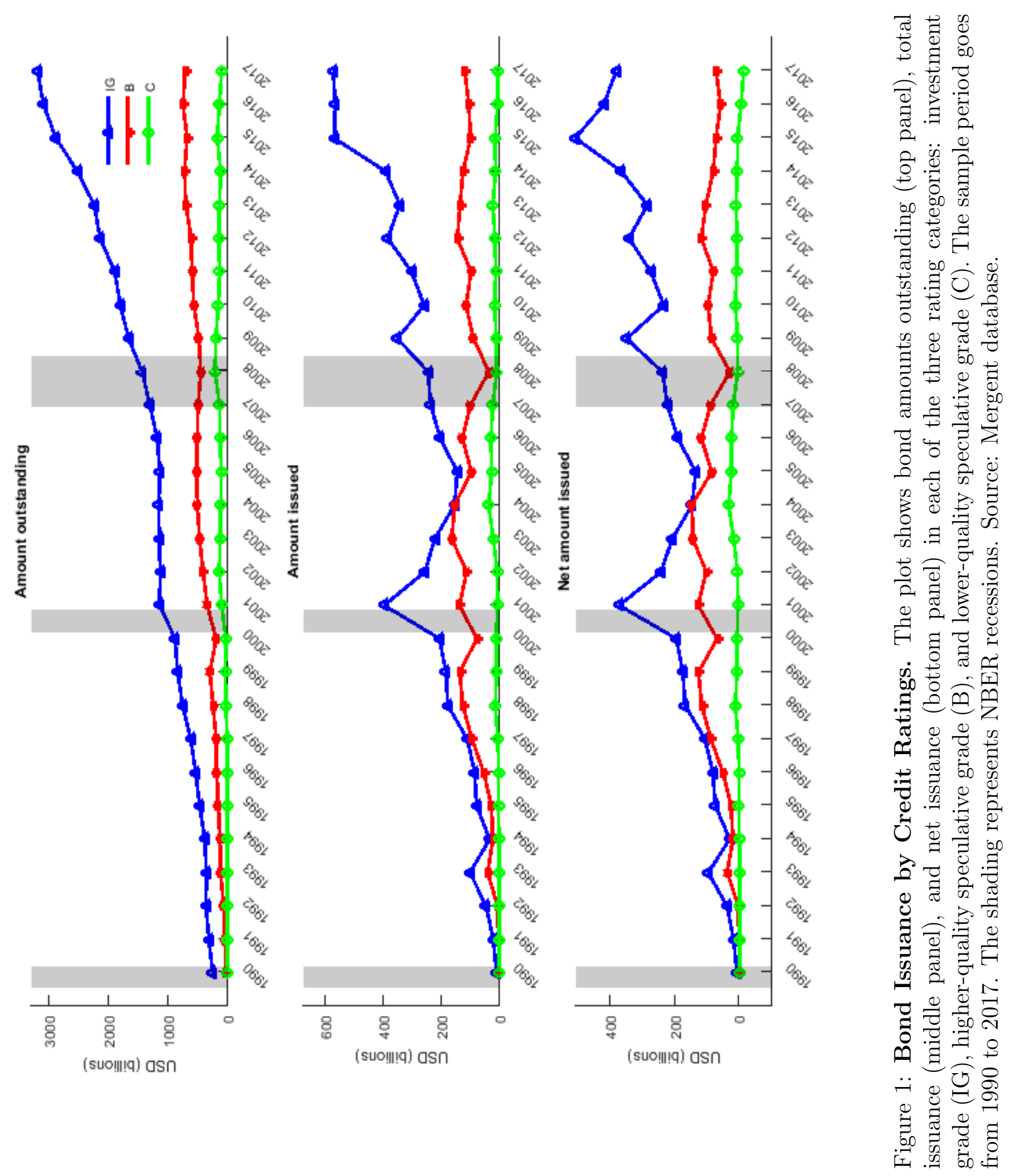



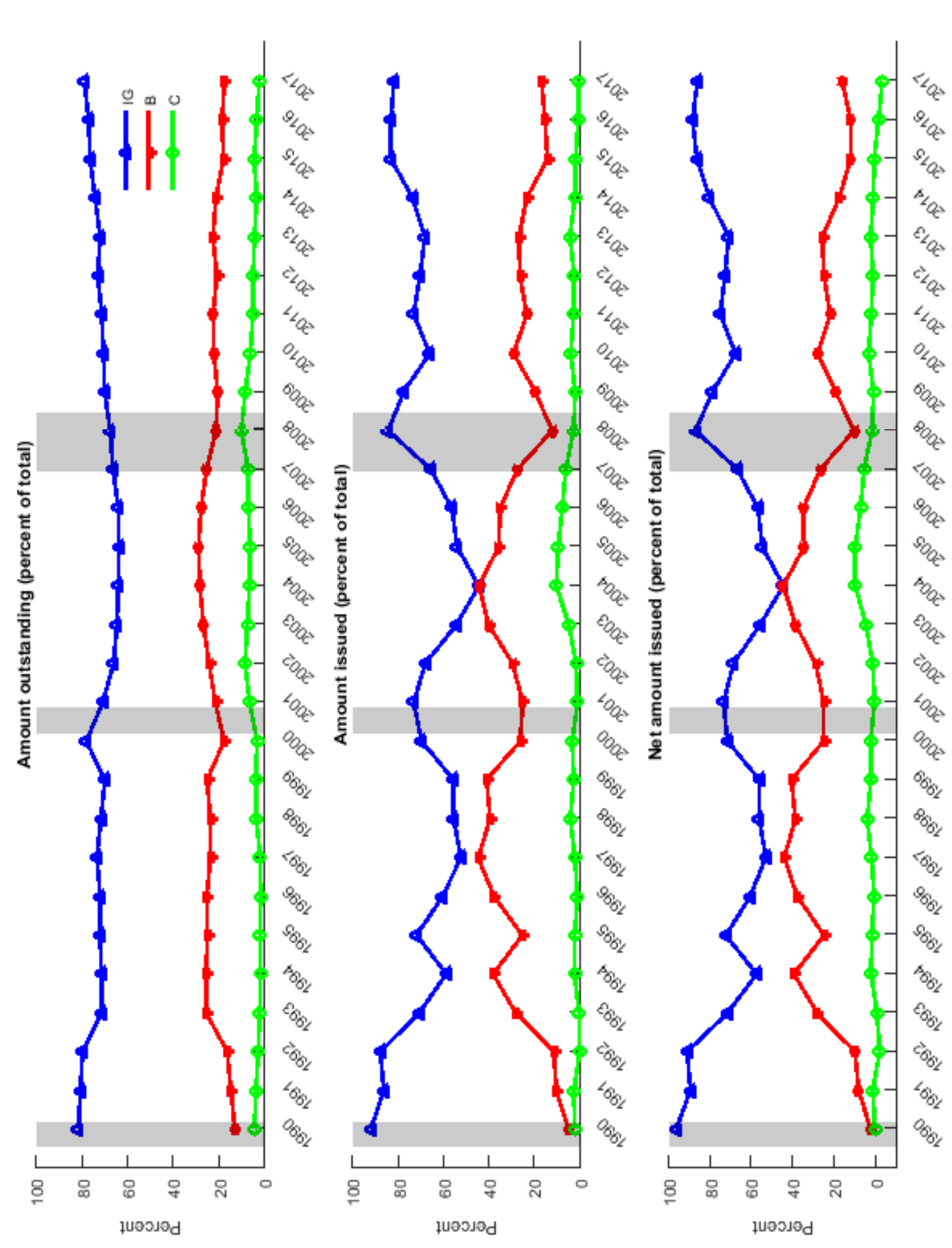

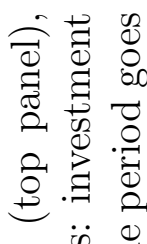

品氨

: 80

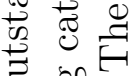

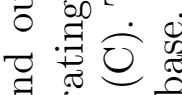

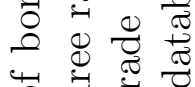

पै 35

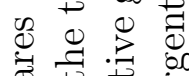

क

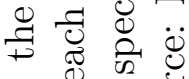

目总

元

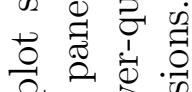

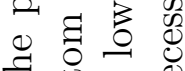

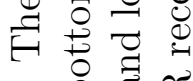

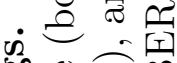

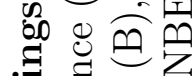

武

क 50

记苛.

记

च

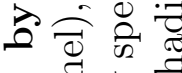

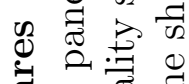

कै

ช

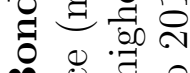

0 :

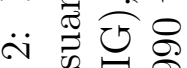

o. 요의

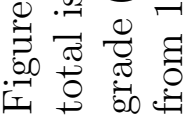




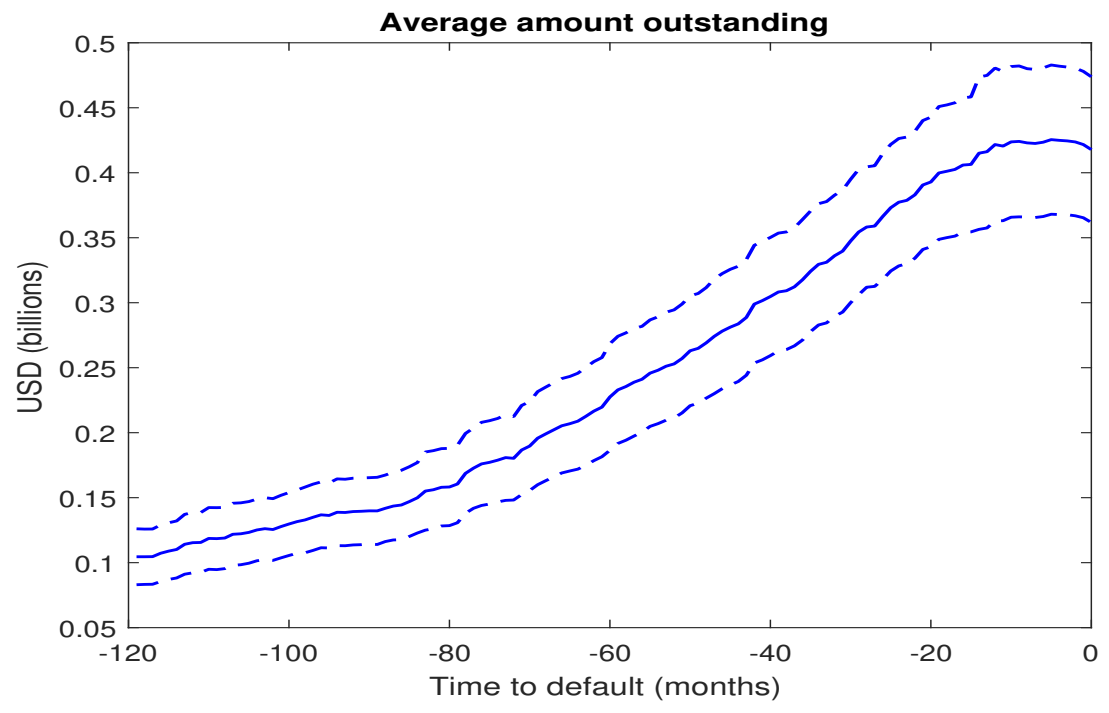

Figure 3: Average Amount of Bonds Outstanding along the Default Path. The plot shows the average amount of bonds outstanding for firms that defaulted from 1985 to 2017 as a function of time to default. The dashed lines show the $90 \%$ confidence bands. Source: Mergent database. 


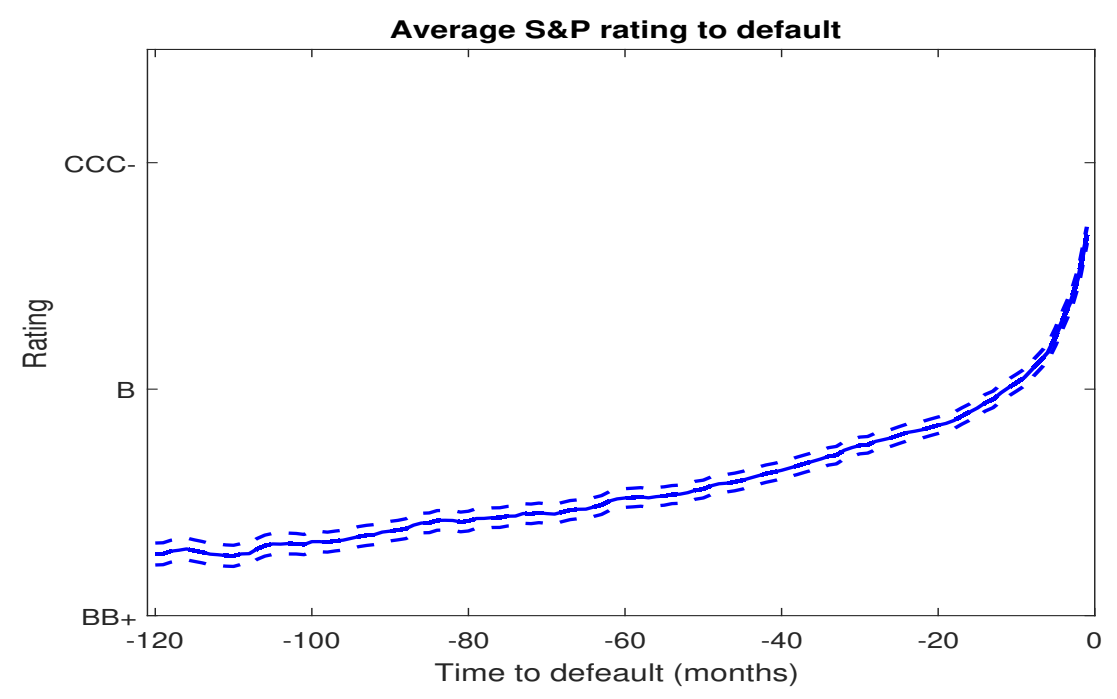

Figure 4: Average S\&P Rating along the Default Path. The plot shows the average credit rating for firms that defaulted from 1985 to 2017 as a function of time to default. The dashed lines show the $90 \%$ confidence bands. Source: S\&P Credit Ratings from Capital IQ.

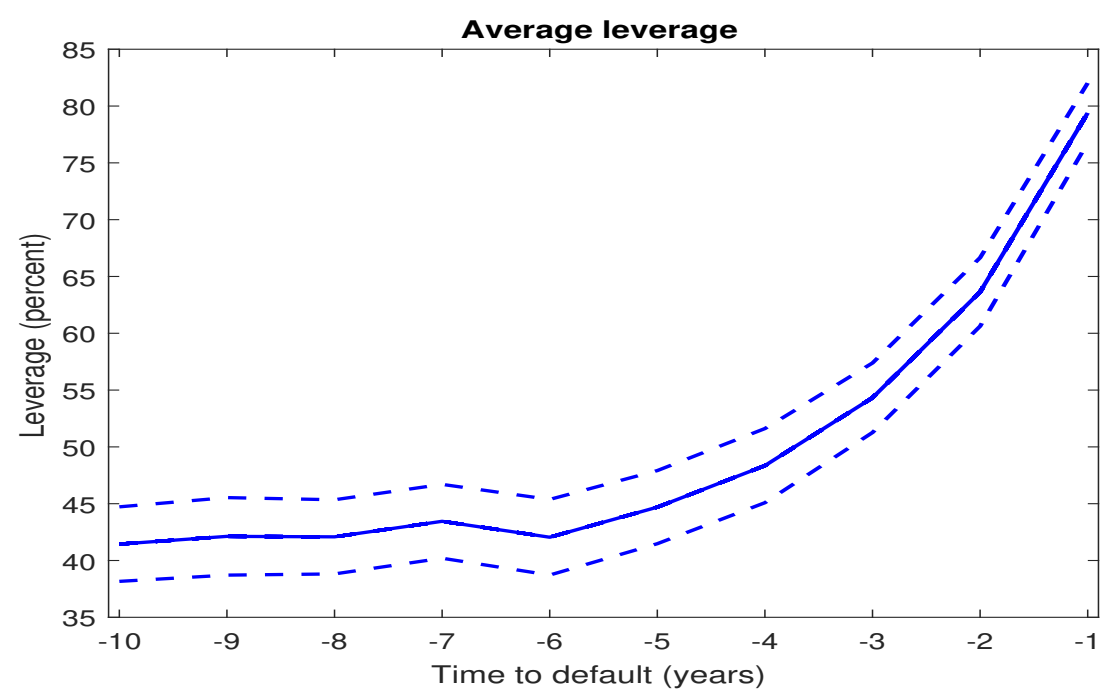

Figure 5: Average Firm Leverage along the Default Path. The plot shows the average leverage for firms that defaulted from 1985 to 2017 as a function of time to default. Each year, we compute the average value of the firm total outstanding equity using CRSP data, and the total book value of debt from Compustat; leverage is the ratio of debt book value over total firm value, given by the sum of the equity and debt values. The dashed lines show the $90 \%$ confidence bands. Sources: S\&P Credit Ratings from Capital IQ, Compustat, and $\mathrm{CRSP}^{\circledR}$, Center for Research in Security Prices, Booth School of Business, The University of Chicago. Used with permission. All rights reserved. crsp.uchicago.edu. 


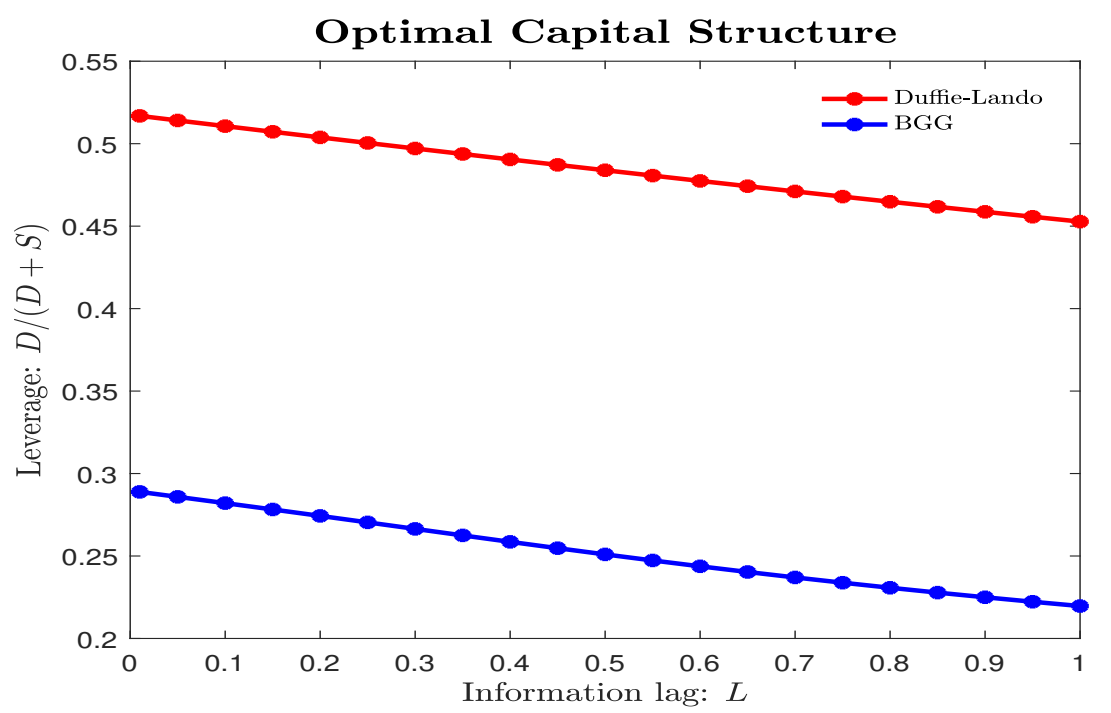

Figure 6: Optimal Capital Structure. The plots show the optimal time-0 capital structure as a function of the information lag $L$ between creditors and the manager, where $L$ ranges from 0 to 1 year, $0 \leq L \leq 1$. The 'BBG' line denotes our baseline model in which the manager can issue debt till borrowing capacity is reached; the 'Duffie-Lando' line corresponds to a firm that can only issue equity to service debt in place. The other parameter values are in Table 2.

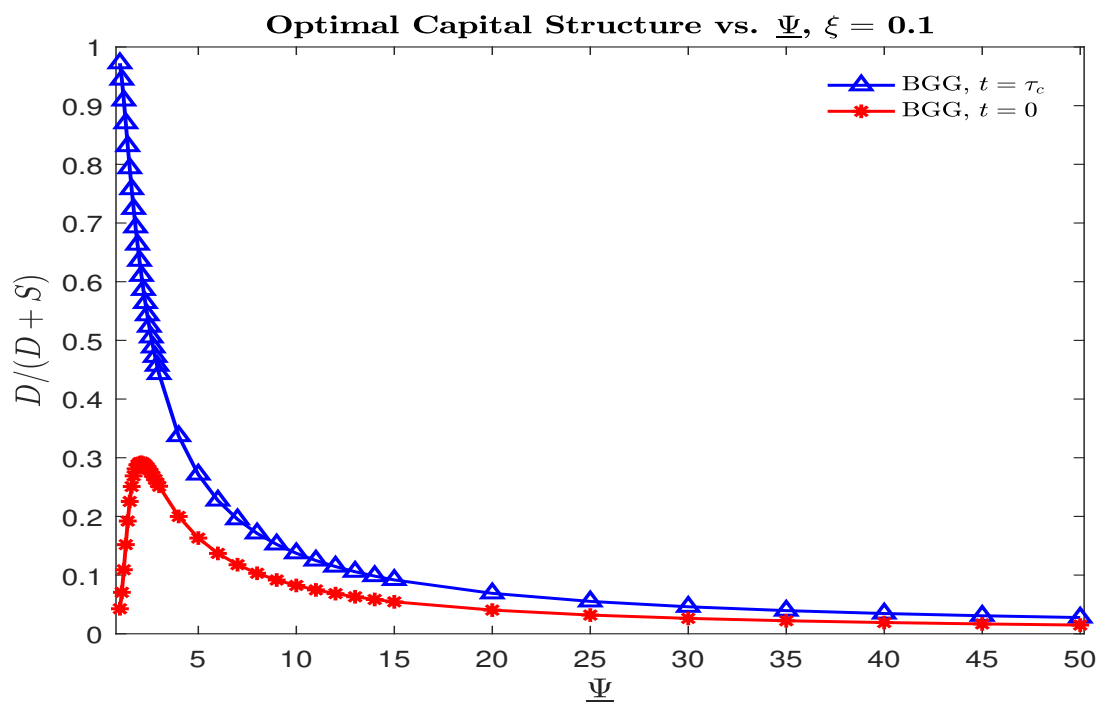

Figure 7: Optimal Capital Structure and Credit Constraints, $\xi=0.1$. The plot shows the optimal leverage at time $t=0$ (the red stars) and the time- $\tau_{c}$ leverage (the blue triangles) as a function of the credit constraint parameter $\underline{\Psi}$. The other parameter values are in Table 2. 


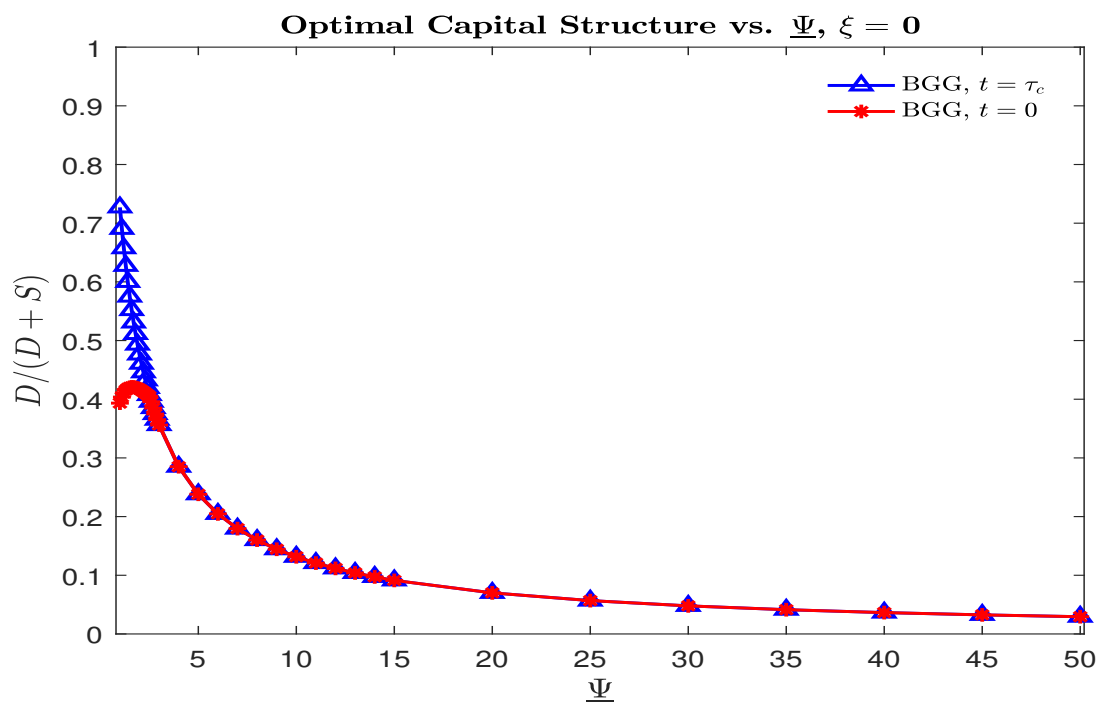

Figure 8: Optimal Capital Structure and Credit Constraints, $\xi=0$. The plot shows the optimal leverage at time $t=0$ (the red stars) and the time- $\tau_{c}$ leverage (the blue triangles) as a function of the credit constraint parameter $\underline{\Psi}$. The other parameter values are in Table 2 .

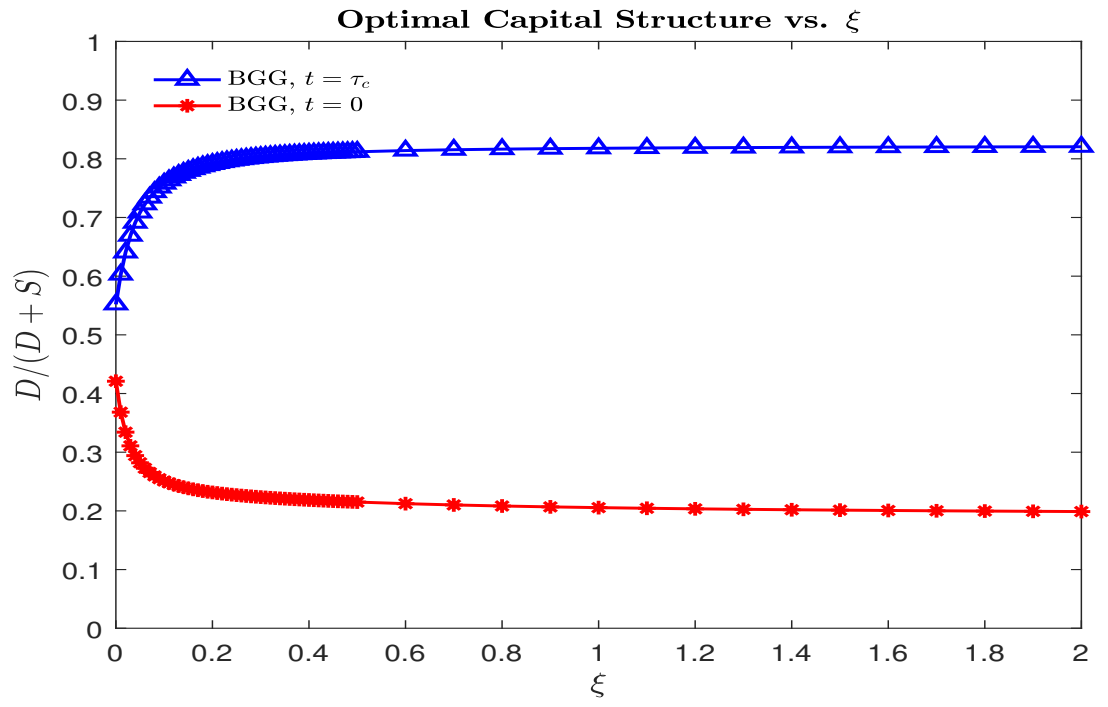

Figure 9: Optimal Capital Structure and the Amortization Rate $\xi$. The plot shows the optimal leverage at time $t=0$ (the red stars) and the time- $\tau_{c}$ leverage (the blue triangles) as a function of the amortization rate $\xi$. The other parameter values are in Table 2. 


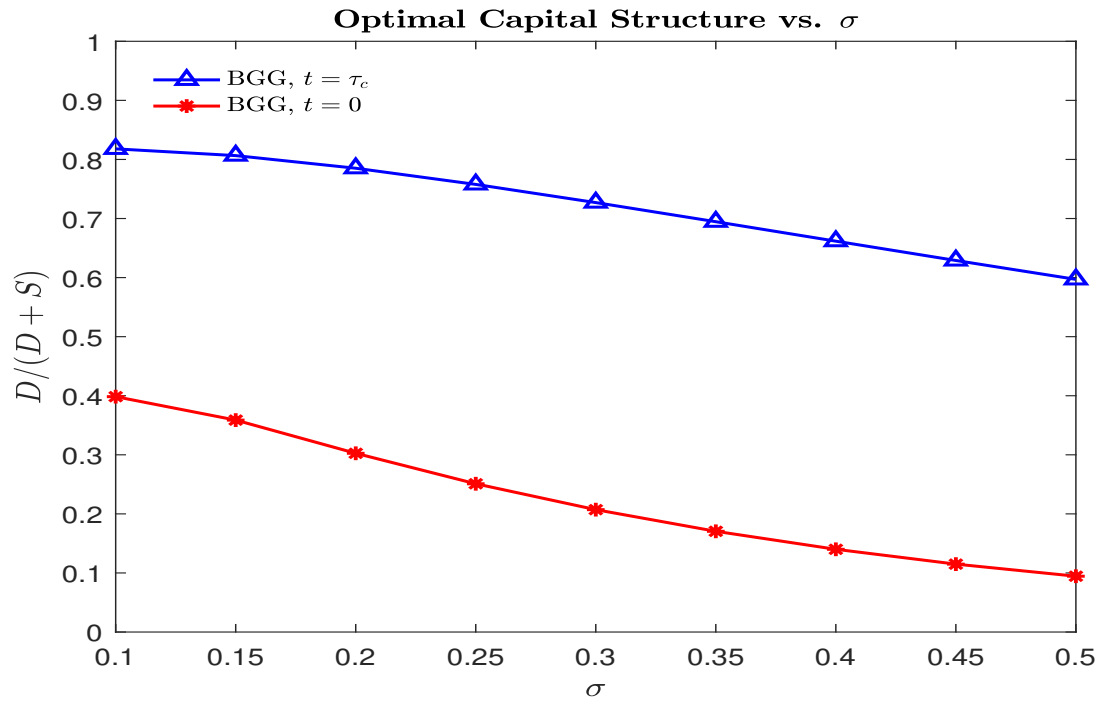

Figure 10: Optimal Capital Structure and Volatility. The plot shows the optimal leverage at time $t=0$ (the red stars) and the time- $\tau_{c}$ leverage (the blue triangles) as a function of the EBIT volatility coefficient $\sigma$. The other parameter values are in Table 2 .

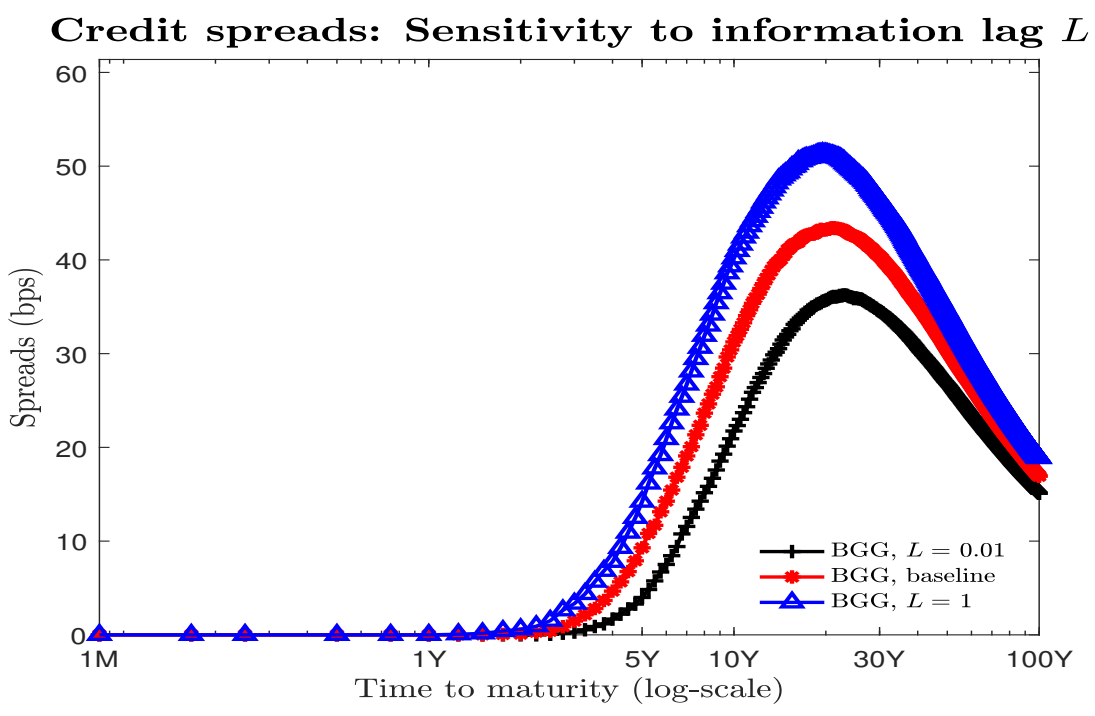

Figure 11: Credit Spreads and Information Asymmetry. The plot illustrates the sensitivity of the credit spreads curve to the information gap parameter $L$. In all cases, $\Psi_{0}$ is fixed at the optimal time- 0 value that corresponds to a $25.1 \%$ leverage in the baseline case. The other parameter values are in Table 2. 


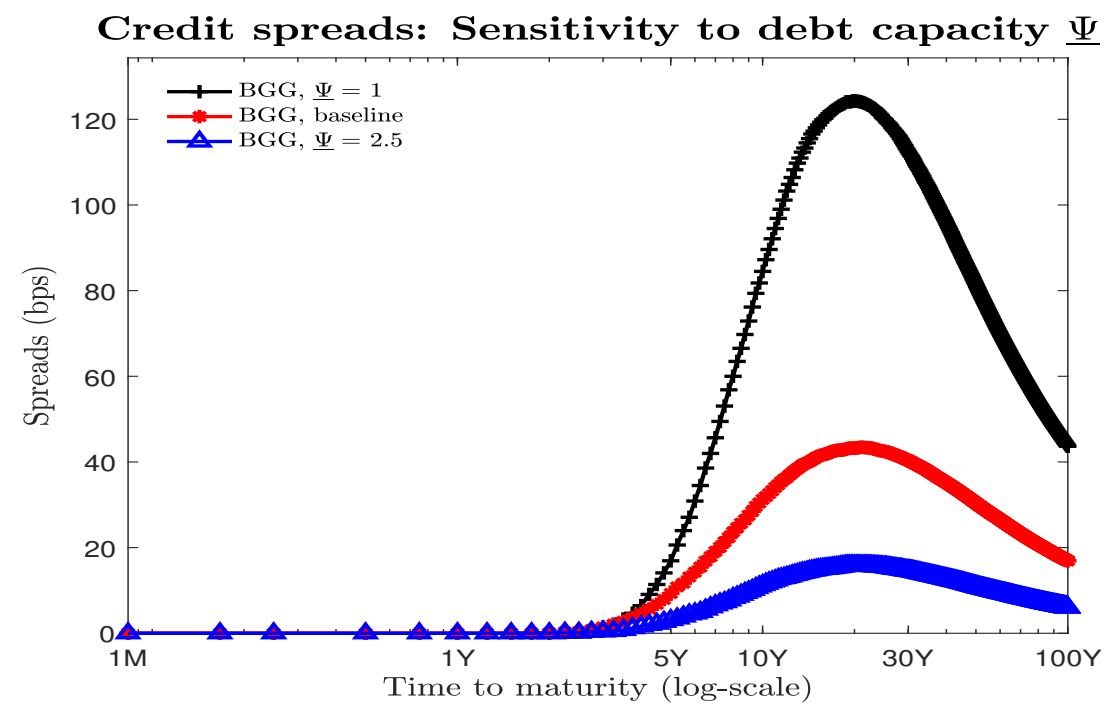

Figure 12: Credit Spreads and Credit Constraints. The plot illustrates the sensitivity of the credit spreads curve to the credit constraint parameter $\underline{\Psi}$. In all cases, $\Psi_{0}$ is fixed at the optimal time- 0 value that corresponds to a $25.1 \%$ leverage in the baseline case. The other parameter values are in Table 2.

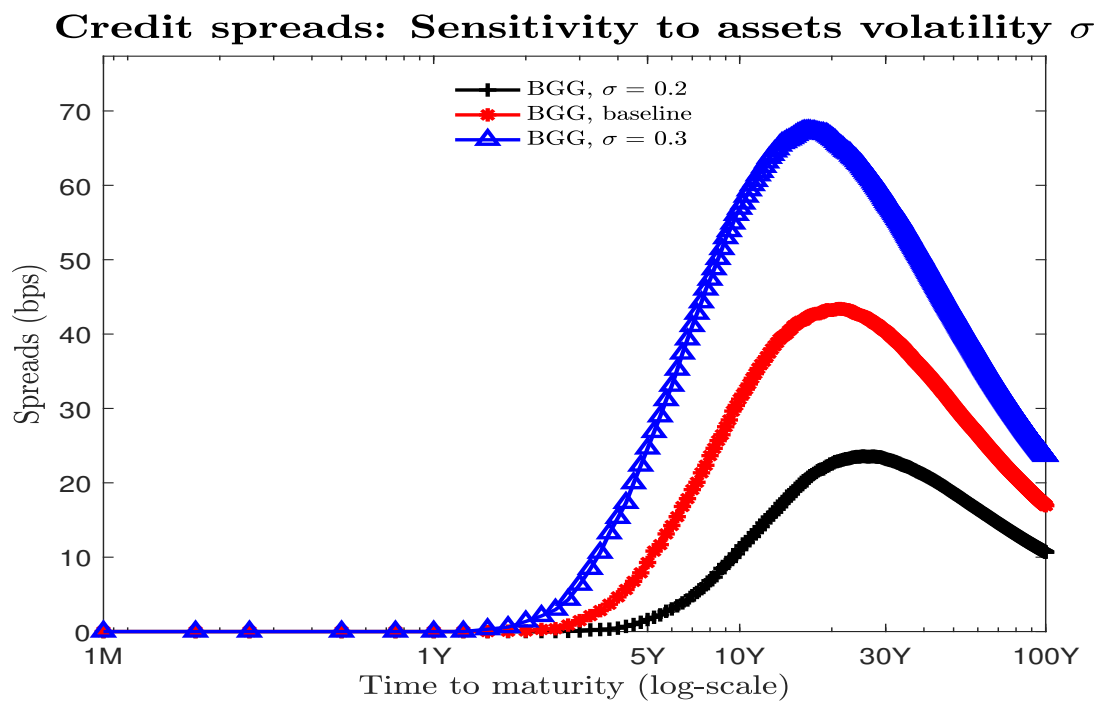

Figure 13: Credit Spreads and EBIT Volatility. The plot illustrates the sensitivity of the credit spreads curve to the EBIT volatility parameter $\sigma$. In all cases, $\Psi_{0}$ is fixed at the optimal time- 0 value that corresponds to a $25.1 \%$ leverage in the baseline case. The other parameter values are in Table 2. 


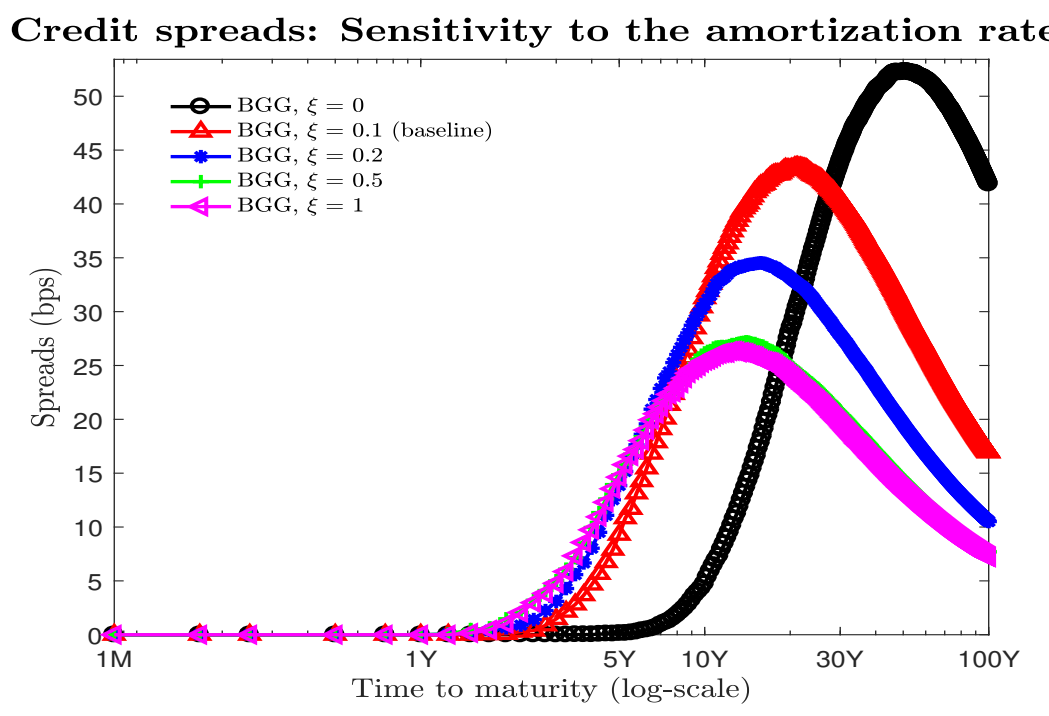

Figure 14: Credit Spreads and the Amortization Rate $\xi$. The plots illustrate the sensitivity of the credit spreads curve to the amortization rate $\xi$. In all cases, $\Psi_{0}$ is fixed at the optimal time-0 value that corresponds to a $25.1 \%$ leverage in the baseline case. The other parameter values are in Table 2.

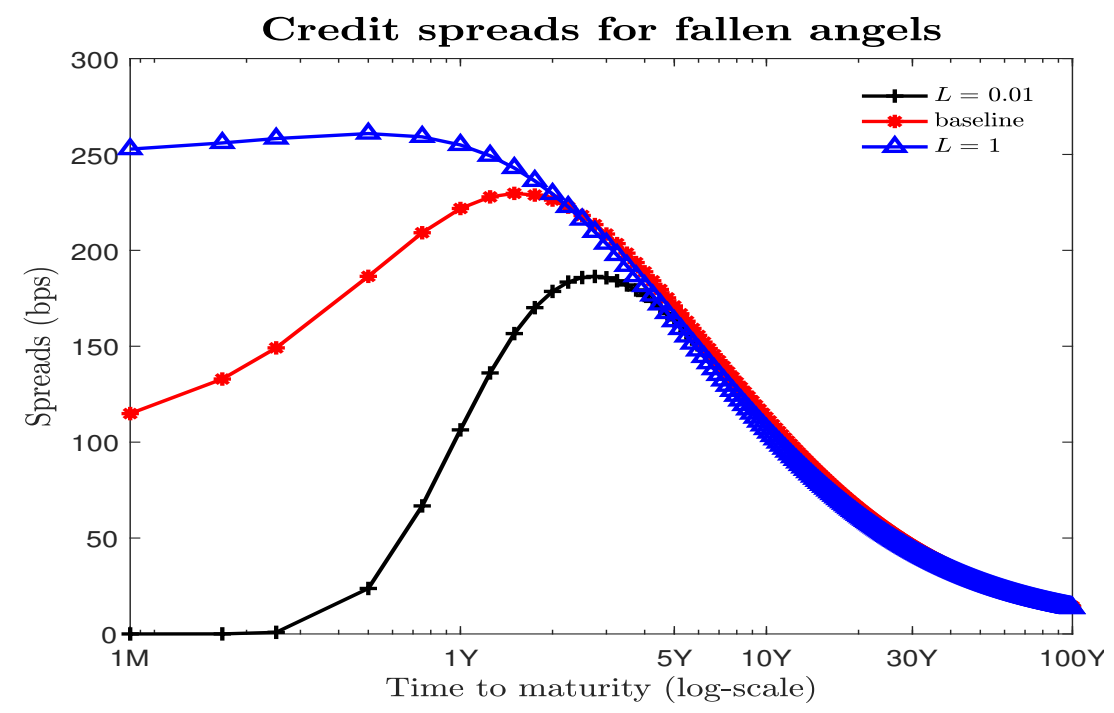

Figure 15: Credit Spreads for Fallen Angels. The plots shows credit spreads for a company that has reached an $85 \%$ leverage in the baseline case. The three lines contrast the complete information case $(L \approx 0)$ to the cases in which the information lags between creditors and the manager are $L=0.5$ and $L=1$ years. The other parameter values are in Table 2 . 


\section{References}

Abel, A. B., 2016, "Investment with Leverage," Working Paper, Wharton School of the University of Pennsylvania.

Abel, A. B., 2017, "Optimal debt and profitability in the tradeoff theory," Journal of Finance, forthcoming.

Acharya, V. V., D. Gale, and T. Yorulmazer, 2011, "Rollover Risk and Market Freezes," Journal of Finance, 66, 1177-1209.

Admati, A. R., P. M. DeMarzo, M. F. Hellwig, and P. C. Pfleiderer, 2017, "The leverage ratchet effect," Stanford University Working Paper No. 3029.

Bai, J., P. Collin-Dufresne, R. Goldstein, and J. Helwege, 2015, "On Bounding Credit-Event Risk Premia," Review of Financial Studies, 28(9), 2608-2642.

Bai, J., R. S. Goldstein, and F. Yang, 2018, "Is the Credit Spread Puzzle a Myth?," Georgetown McDonough School of Business Research Paper.

Bhamra, H., L.-A. Kuehn, and I. A. Strebulaev, 2010, "The Aggregate Dynamics of Capital Structure and Macroeconomic Risk," Review of Financial Studies, 23 (12), 4187-4241.

Black, F., and J. C. Cox, 1976, "Valuing corporate securities: Some effects of bond indenture provisions," The Journal of Finance, 31(2), 351-367.

Carré, S., 2016, "Disclosures, Rollover Risk, and Debt Runs," Working Paper, Ecole Polytechnique Fédérale de Lausanne.

Chen, H., 2010, "Macroeconomic Conditions and the Puzzles of Credit Spreads and Capital Structure," Journal of Finance, 65, 2171-2212.

Chen, L., P. Collin-Dufresne, and R. Goldstein, 2009, "On the Relation Between the Credit Spread Puzzle and the Equity Premium Puzzle," Review of Financial Studies, 22, 33673409.

Chen, L., D. Lesmond, and J. Wei, 2007, "Corporate Yield Spreads and Bond Liquidity," Journal of Finance, 62, 119-149. 
Chernov, M., L. Schmid, and A. Schneider, 2017, "A Macrofinance View of US Sovereign CDS Premiums," Working Paper, UCLA.

Clark, T., and M. Weinstein, 1983, "The Behavior of the Common Stock of Bankrupt Firms," Journal of Finance, 38, 489-504.

Culp, C. L., Y. Nozawa, and P. Veronesi, 2018, "Option-based credit spreads," American Economic Review, 108(2), 454-88.

Dang, T. V., G. Gorton, and B. Holmström, 2015, "Ignorance, Debt and Financial Crises," Working Paper, Yale University.

Dangl, T., and J. Zechner, 2004, "Credit risk and dynamic capital structure choice," Journal of Financial Intermediation, 13(2), 183-204.

— , 2016, "Debt maturity and the dynamics of leverage," CFS Working Paper.

DeMarzo, P., and Z. He, 2018, "Leverage Dynamics without Commitment," Working Paper, Stanford University and University of Chicago.

Diamond, D. W., and P. H. Dybvig, 1983, "Bank runs, deposit insurance, and liquidity," Journal of Political Economy, 91, 401-419.

Driessen, J., 2005, "Is Default Event Risk Priced in Corporate Bonds?," Review of Financial Studies, 18, 165-195.

Duffie, D., and D. Lando, 2001, "Term structures of credit spreads with incomplete accounting information," Econometrica, 69(3), 633-664.

Duffie, D., and K. Singleton, 1997, "An Econometric Model of the Term Structure of Interest Rate Swap Yields," Journal of Finance, 52(4), 1287-1322.

Elton, E. J., M. J. Gruber, D. Agrawal, and C. Mann, 2001, "Explaining the Rate Spread on Corporate Bonds," Journal of Finance, 56, 247-277.

Feldhütter, P., and S. M. Schaefer, 2018, "The myth of the credit spread puzzle," The Review of Financial Studies, 31(8), 2897-2942.

Fischer, E. O., R. Heinkel, and J. Zechner, 1989, "Dynamic capital structure choice: Theory and tests," The Journal of Finance, 44(1), 19-40. 
Giesecke, K., 2006, "Default and information," Journal of economic dynamics and control, 30(11), 2281-2303.

Goldstein, R., N. Ju, and H. Leland, 2001, "An EBITBased Model of Dynamic Capital Structure," The Journal of Business, 74(4), 483-512.

Gomes, J. F., and L. Schmid, 2018, "Equilibrium Asset Pricing with Leverage and Default," Journal of Finance, forthcoming.

Gorbenko, A. S., and I. A. Strebulaev, 2010, "Temporary versus Permanent Shocks: Explaining Corporate Financial Policies," Review of Financial Studies, 23, 2591-2647.

Greenwood, R., and S. G. Hanson, 2013, "Issuer quality and corporate bond returns," The Review of Financial Studies, 26(6), 1483-1525.

Harrison, J., 1985, Brownian Motion and Stochastic Flow Systems. John Wiley and Sons, New York, NY.

He, Z., and W. Xiong, 2012, "Dynamic Debt Runs," Review of Financial Studies, 25, 17991843.

Hennessy, C. A., and T. M. Whited, 2007, "How Costly Is External Financing? Evidence from a Structural Estimation," The Journal of Finance, 62(4), 1705-1745.

Jarrow, R., D. Lando, and S. Turnbull, 1997, "A Markov Model for the Term Structure of Credit Spreads," Review of Financial Studies, 10, 481-523.

Jarrow, R., and P. Protter, 2004, "Structural versus reduced form models: a new information based perspective," Journal of Investment management, 2(2), 1-10.

Lang, L., and R. Stulz, 1992, "Contagion and competitive intra-industry effects of bankruptcy announcements: An empirical analysis," Journal of Financial Economics, $32,45-60$.

Leland, H. E., 1994, "Corporate debt value, bond covenants, and optimal capital structure," The Journal of Finance, 49(4), 1213-1252.

Leland, H. E., and K. B. Toft, 1996, "Optimal capital structure, endogenous bankruptcy, and the term structure of credit spreads," The Journal of Finance, 51(3), 987-1019. 
Longstaff, F., S. Mithal, and E. Neis, 2005, "Corporate Yield Spreads: Default Risk or Liquidity? New Evidence from the Credit Default Swap Market," Journal of Finance, 60, 2213-2253.

Merton, R. C., 1974, "On the Pricing of Corporate Debt: The Risk Structure of Interest Rates," Journal of Finance, 29, 449-470.

Schroth, E., G. A. Suarez, and L. A. Taylor, 2014, "Dynamic debt runs and financial fragility: Evidence from the 2007 ABCP crisis," Journal of Financial Economics, 112, 164-189.

Shin, H. S., 2003, "Disclosures and Asset Returns," Econometrica, 71, 105-133.

Strebulaev, S. D. I., and X. Zhao, 2012, "A market-based study of the cost of default," Review of Financial Studies, 25, 3573-3609.

Subrahmanyam, M. G., D. Y. Tang, and S. Q. Wang, 2014, "Does the tail wag the dog?: The effect of credit default swaps on credit risk," The Review of Financial Studies, 27(10), 2927-2960.

Warner, J., 1977, "Bankruptcy costs: Some evidence," Journal of Finance, 32, 337-347.

Zhou, C., 2001, "The term structure of credit spreads with jump risk," Journal of Banking and Finance, 25, 2015-2040. 


\section{Asymmetric Information, Dynamic Debt Issuance, and the Term Structure of Credit Spreads Online Appendix}

Luca Benzoni, Lorenzo Garlappi, and Robert S. Goldstein 
This Online Apendix contains addional analysis to accompany the manuscript. Sections A, B, and C provide further empirical details regarding the stylized facts in Section 2 of the paper. Section D contains proofs and Section E derives the bond price in Regime 3 for times $t \in\left(\tau_{c}, \tau_{c}+L\right)$.

\section{A Classifying firms based on bond ratings}

We collect the entire history of credit ratings given by the three main U.S. rating agencies (Moody's Investor Services, Standard \& Poor's Ratings Services, and Fitch Ratings) from the Mergent database. While Mergent contains ratings going back to the early part of the $20^{\text {th }}$ century, ratings are limited to a very small number of debt issues through the mid 1980s. Hence, here we focus on the sample period from 1985 to 2014.

Mergent provides ratings specific to particular bond issues, rather than an overall company rating. Hence, for a given issuer, each month we collect all ratings awarded on that month to any of its outstanding bonds and use that information to classify the company. ${ }^{1}$ We divide individual bond ratings in three categories: investment grade (IG), higher-quality speculative grade (B), and lower-quality speculative grade ( $\mathrm{C}$ and lower), where the last two categories, $\mathrm{B}$ and $\mathrm{C}$, together comprise the universe of speculative grade ratings. We then assign the company to one of the three categories when the majority of the company's bond ratings are in that category. When no fresh ratings are given by any agency to the outstanding bonds of that company, we classify the firm based on ratings collected in the previous month. If no new ratings were issued the previous month, we go further back, up to 12 months. In case no new ratings are available in the entire 12 month period, we do not classify the firm. This approach mitigates the problem of classifying companies based on stale ratings.

Figure A.1 shows the percentage of firms in each of the three rating categories: investment grade (the IG category), higher-quality speculative grade (the B category), and lower-quality speculative grade (the $\mathrm{C}$ category). The figure reflects the changing nature of debt markets and the evolution of the rating agencies' services. Prior to the 1980s, rating agencies were mostly focusing on blue chip industrial firms. This is consistent with a preponderance of IG

\footnotetext{
${ }^{1}$ We exclude ratings on government agencies' bonds (e.g., U.S. Treasury, U.S. and foreign agencies, municipalities).
} 
ratings in the early part of the sample period. Over time, financial disintermediation and capital markets development allowed a broader variety of firms to raise funds in the bond market. Along the way, rating agencies expanded their coverage of lower-quality issues. These changes are reflected in an increased proportion of speculative-grade firms. Higherquality speculative issues display an increasing trend through the 1990s. The proportion of lower-quality ratings remains mostly stable over the sample period, but increases during recessions; for instance, the percentage of firms in the C category peaks in 1991, 2001, and 2009.

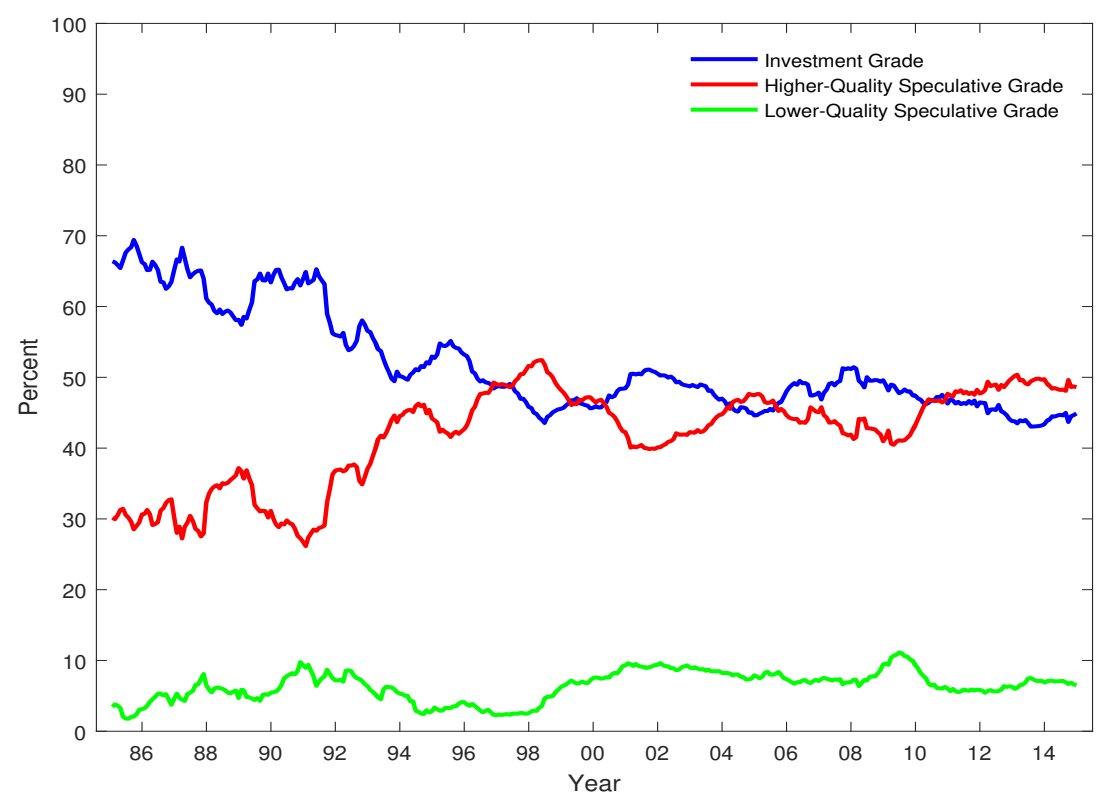

Figure A.1: Percentage of Firms by Credit Ratings. The plots show the percentage of firms in each of the three rating categories: investment grade (IG), higher-quality speculative grade (B), and lower-quality speculative grade (C). The sample period goes from 1985 to 2014. Source: Mergent database.

To document default rates among rated firms, we obtain the entire history of bankruptcy filings starting from 1985 (also available through the Mergent database). Each month, after we classify firms in the three rating categories, we identify those that filed for bankruptcy over the next 12 months. We record the number of months that have elapsed between the month of the classification and the bankruptcy time. Then we count bankruptcies that occurred within the first, second, and third month of the classification (0-1, 1-2, and 2-3 months), the second, third, and fourth quarters (3-6, 6-9, and 10-12 months), and the entire year (0-12 
months). For ease of comparison across periods of different length, we annualize all count variables. ${ }^{2}$ The results are in Table Table 1 of the paper; we discuss them in Section 2 of the paper.

\section{B Classifying firms based on CDS premia}

In the previous section, we have classified firms based on credit ratings that are up to 12 months old. Such ratings might not fully reflect the information available to market participants at the time of the classification. Hence, here we consider an alternative classification of firms into the same three rating categories that is based on CDS data.

CDS contracts provide insurance in case of credit events that affect the value of a reference entity (such as the bond issued by a company that files for bankruptcy). Therefore, CDS premia reflect market participants' assessment of default risk for the company that issues the reference bond. The CDS market is generally liquid. Thus, CDS contract are a useful source of real-time information about a company's credit worthiness.

To translate CDS premia into a proxy for a company's credit rating, we compare the cost of insuring bonds issued by that company with that of insuring portfolios of investment-grade and high-yield bonds (the CDX-IG and CDX-HY indices constructed by Markit Financial Information Services). Each month from 2001 to 2014 we aggregate daily five-year CDS premia from the Markit database into an average monthly CDS premium. ${ }^{3}$ Similarly, we compute monthly averages of daily five-year CDX-IG and CDX-HY premia. If the CDS premia on a firm's bonds do not exceed the CDX-IG index by more than 100 basis points (bps), then we classify that firm as investment grade (the IG category). We use the 100 bps threshold to avoid excluding creditworthy companies whose CDS premia lie slightly above the CDX-IG level, i.e., the average IG premium. In unreported results, we find the analysis to be robust to the choice of the threshold value. In contrast, when CDS premia on a firm's bonds exceed the CDX-HY premium we classify that firm as lower-quality speculative grade (the $\mathrm{C}$ category). Finally, if CDS premia lie in between the IG and $\mathrm{C}$ thresholds, then we classify the company as higher-quality speculative grade (the B category).

\footnotetext{
${ }^{2}$ We multiply the count variables for the $0-1,1-2$, and $2-3$ periods by 12 , and those for the quarterly periods by 4 .

${ }^{3}$ Prior to analysis, we exclude CDS contracts written on bonds issued by Government and sovereign entities.
} 
Figure B.2 shows the proportion of firms in each category based on CDS-implied ratings. The trading of CDS contracts on IG companies is predominant throughout the sample period, especially in the early 2000s when the CDS market was in its infancy and trading concentrated in high-quality big names. ${ }^{4}$ Over time, the proportion of CDS contracts on IG firms fluctuates around a downward trend, with drops in 2001-2002 and 2008-2009 at the depth of two recessions, and peaks during the subsequent recovery periods.

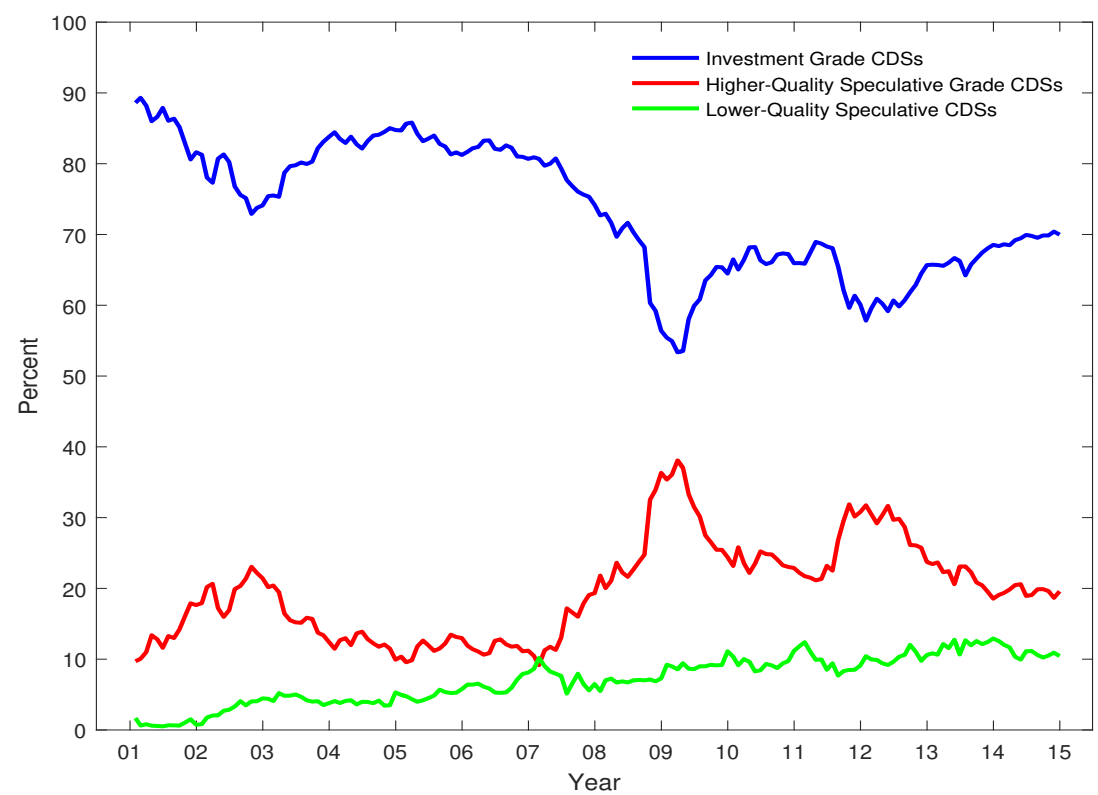

Figure B.2: Percentage of Firms by CDS-Implied Ratings The plots show the percentage of firms in each of the three rating categories (IG, B, and C) based on ratings implied by CDS data. The sample period goes from 2001 to 2014. Source: Markit databases.

The proportion of CDS contracts on higher-quality speculative-grade firms generally increases throughout the sample. Further, CDS trading in the B category exhibits peaks during recessions and declines in the expansions that follow, a pattern that is the direct opposite of the fluctuations in the proportion of IG CDS contracts. This is consistent with both (1) a reshuffling in CDS trading across rating categories over the business cycle and (2) an increase in CDS premia for IG firms during recessions combined with a decline in CDS premia of B firms during expansions that shift firms from one rating category to the other.

\footnotetext{
${ }^{4}$ This is consistent with, e.g., Subrahmanyam, Tang, and Wang (2014).
} 
Finally, Figure B.2 shows that little high-yield trading takes place in the early years of the CDS market. That changes over time, with a proportion of CDS contracts on low-grade speculative firms steadily increasing over the sample period.

Similar to Section A, each month we identify firms that filed for bankruptcy within the following 12 months. We then compute the average annualized default rates within the first, second, and third month of the classification (0-1, 1-2, and 2-3 months), the second, third, and fourth quarters (3-6, 6-9, and 10-12 months), and the entire year (0-12 months). The results are in Table 1, Panel $\mathrm{C}$ in the paper; heteroskedasticity- and autocorrelation-robust (Newey-West) standard errors are in parentheses. The main point of the table is to show that at horizons from one to three months, IG default rates are virtually zero: the point estimate for the annualized default rate is $0.01 \%$ and statistically insignificant.

When we restrict our attention to firms that held IG status for at least one of the 12 months preceding the default event, we find that the great majority of these companies exhibit a considerable run-up in credit spreads for many months before they default. This provides investors with a signal that the credit worthiness of such companies has deteriorated below IG well before their bankruptcy. Figure B.3 shows the difference between the average CDS premium on those firms and the CDX-IG index. This spread is very small 12 months prior to bankruptcy and then increases in the ensuing months as the firms drop out of the IG group and approach bankruptcy. This evidence suggests that an investment policy that (1) holds bonds issued by firms in the IG category, and (2) unwinds these positions when the firm loses IG status, faces virtually zero default risk. Hence, the jump-to-default premium for this portfolio should be negligible.

\section{Robustness Checks}

In the paper, we classify firms in the IG, B, and $\mathrm{C}$ rating categories over the period 19852014 using the Mergent dataset. We then compute empirical default rates for companies that have experienced bankruptcy within a year of the classification. Here we check the robustness of our findings using data from the Moody's Default and Recovery Database (DRD). There are two advantages to this dataset. First, the database spans a longer sample period starting from 1920. Second, Moody's reports a default flag that captures not only bankruptcies but also other credit events such as missed payments beyond the grace period 


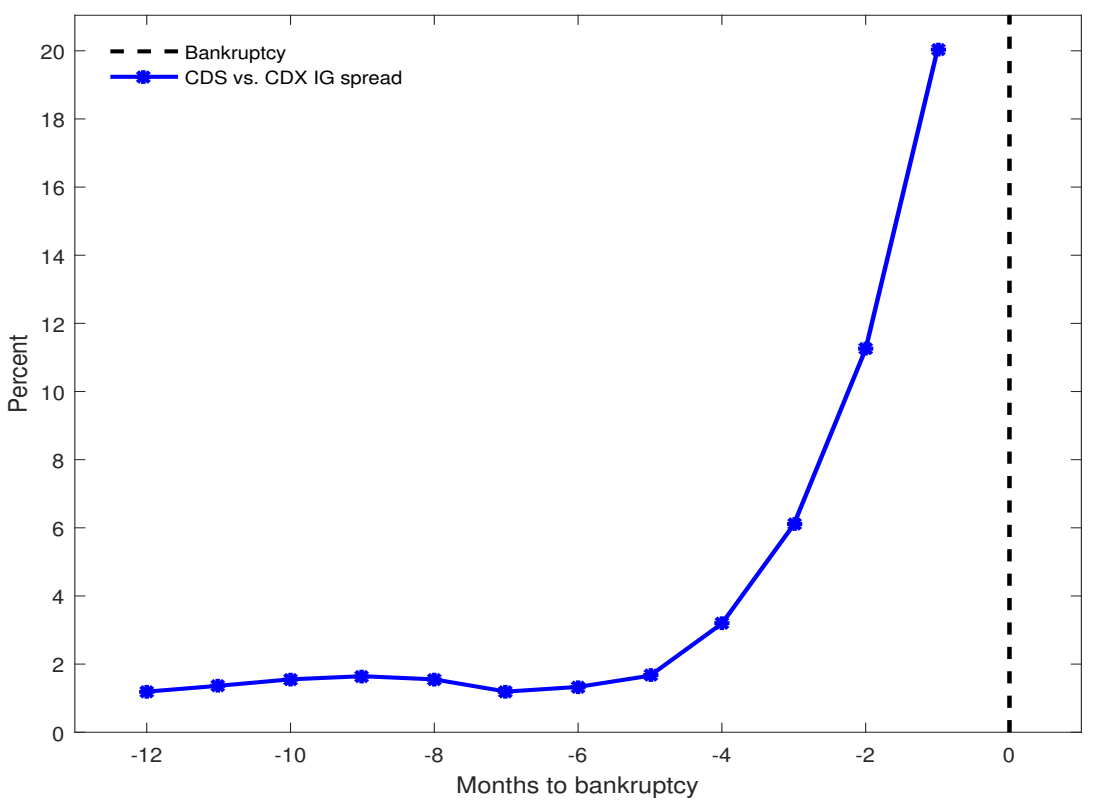

Figure B.3: Average CDS Premium on Investment Grade Firms up to Bankruptcy. Among the firms that went bankrupt from 2001 to 2014, we classify as investment grade those that had CDS contracts trading at a premium no higher than 100 basis points of the CDX Investment Grade Index for at least one of the 12 months preceding the bankruptcy time. The plot shows the average CDS premium, in excess of the CDX Investment Grade Index, on those investment grade firms in the 12 months leading up to their bankruptcy.

and debt restructuring that reduces the value of the bondholder claim.

While the Moody's data go as far back as 1920, we find many early ratings to be stale. In unreported results, we find that, for most IG defaults that occurred over 1920-1940, Moody's did not update the IG rating past the default event. Hence, we only use data starting from 1940 .

First, we document the average rating of firms that experienced a delinquency, i.e., they were issued a D rating, along their path to default. Figure C.4 shows results for the 19402017 (top panel) and the 1985-2017 (bottom panel) sample periods over the ten-year window leading to the default event. The results are nearly indistinguishable across the two periods and consistent with the evidence in Figure 4 in the paper: ten years prior to delinquency, the typical firm starts out with a $\mathrm{BB}+$ rating, which progressively deteriorates as the firm approaches its default time. ${ }^{5}$

\footnotetext{
${ }^{5}$ For ease of comparison with the results in Figure 4 in the paper, we map the letter designations for
} 
Next, we compute empirical default rates using Moody's DRD data, similar to the analysis in Section 2 of the paper where we relied instead on individual bond ratings from the Mergent database. The results for the 1940-2014 sample period are in Panel B of Table C.1. They are similar to those reported in the paper over the shorter 1985-2014 window based on the stricter bankruptcy classification flag. For completeness, panels C and D show results for the 1985-2014 and 2001-2014 windows, which show results consistent with those in the main text for the same two periods.

Moody's ratings into those of Standard \& Poor's. 

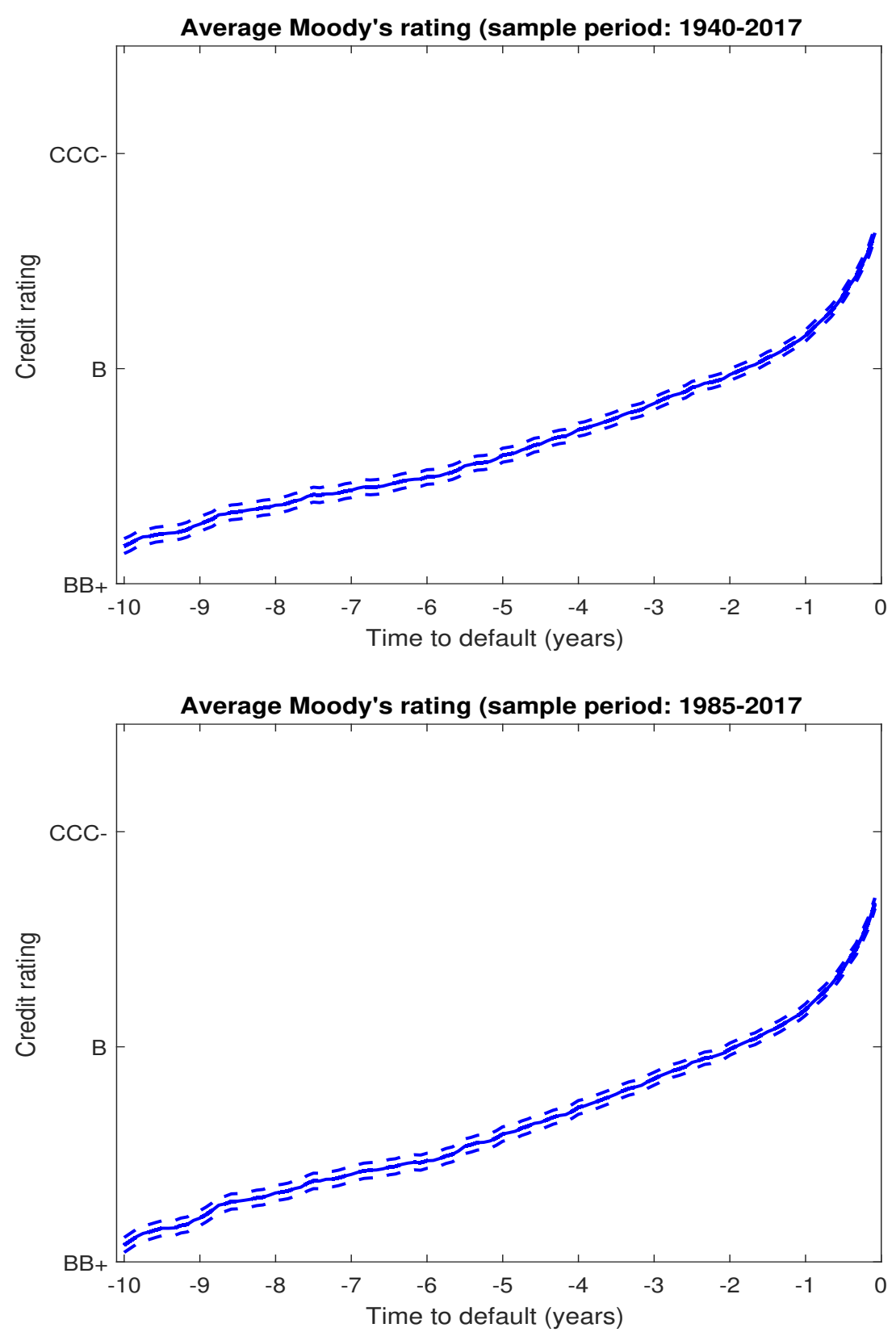

Figure C.4: Average Moody's Rating along the Default Path. The plots show the average credit rating for defaulted firms as a function of time to default. The dashed lines denote the 90\% confidence bands. Sample periods: 1940-2017 (top panel) and 1985-2017 (bottom panel). Source: Moody's Investment Services Default and Recovery Database. 
Table C.1: Empirical Defaults Rates. Each month, we classify firms as investment grade (IG), higher-quality speculative grade (B), and lower-quality speculative-grade firms (C) based on ratings issued by Moody's Investors' Services. The panels show average annualized default rates computed over various periods for firms in each rating category that have defaulted in the next 12 months. Heteroskedasticity- and autocorrelation-robust (NeweyWest) standard errors are in parentheses. Source: Moody's Default and Recovery Database.

Annualized Default Rates

\begin{tabular}{lccccccc} 
Rating & \multicolumn{7}{c}{ Panel A: $1920-2014$} \\
\cline { 2 - 8 } & $0-1 \mathrm{M}$ & $1-2 \mathrm{M}$ & $2-3 \mathrm{M}$ & $3-6 \mathrm{M}$ & $6-9 \mathrm{M}$ & $9-12 \mathrm{M}$ & $0-12 \mathrm{M}$ \\
\hline \multirow{7}{*}{ IG } & 0.09 & 0.10 & 0.11 & 0.13 & 0.16 & 0.18 & 0.14 \\
& $(0.02)$ & $(0.02)$ & $(0.02)$ & $(0.02)$ & $(0.03)$ & $(0.03)$ & $(0.02)$ \\
B & 1.56 & 1.78 & 1.91 & 2.11 & 2.35 & 2.51 & 2.18 \\
& $(0.24)$ & $(0.25)$ & $(0.26)$ & $(0.28)$ & $(0.30)$ & $(0.32)$ & $(0.27)$ \\
C & 8.39 & 7.58 & 7.11 & 6.47 & 5.58 & 4.85 & 6.15 \\
& $(1.22)$ & $(1.11)$ & $(1.04)$ & $(0.89)$ & $(0.73)$ & $(0.62)$ & $(0.79)$ \\
\hline \multirow{7}{*}{ IG } & 0.03 & 0.04 & 0.04 & 0.07 & 0.08 & 0.10 & 0.07 \\
& $(0.01)$ & $(0.01)$ & $(0.01)$ & $(0.02)$ & $(0.02)$ & $(0.02)$ & $(0.02)$ \\
B & 1.16 & 1.45 & 1.61 & 1.88 & 2.20 & 2.41 & 1.97 \\
& $(0.20)$ & $(0.23)$ & $(0.25)$ & $(0.29)$ & $(0.33)$ & $(0.36)$ & $(0.29)$ \\
C & 10.33 & 9.25 & 8.66 & 7.81 & 6.60 & 5.73 & 7.39 \\
& $(1.62)$ & $(1.47)$ & $(1.37)$ & $(1.17)$ & $(0.94)$ & $(0.80)$ & $(1.02)$ \\
\hline
\end{tabular}


Table C.1, continued

\begin{tabular}{lccccccc}
\hline \multirow{7}{*}{ Rating } & \multicolumn{7}{c}{ Annualized Default Rates } \\
\cline { 2 - 8 } & $0-1 \mathrm{M}$ & $1-2 \mathrm{M}$ & $2-3 \mathrm{M}$ & $3-6 \mathrm{M}$ & $6-9 \mathrm{M}$ & $9-12 \mathrm{M}$ & $0-12 \mathrm{M}$ \\
\hline \multirow{7}{*}{ IG } & 0.03 & 0.04 & 0.05 & 0.08 & 0.11 & 0.13 & 0.09 \\
& $(0.02)$ & $(0.02)$ & $(0.02)$ & $(0.02)$ & $(0.03)$ & $(0.03)$ & $(0.02)$ \\
B & 1.30 & 1.68 & 1.90 & 2.24 & 2.65 & 2.92 & 2.36 \\
& $(0.23)$ & $(0.27)$ & $(0.29)$ & $(0.33)$ & $(0.38)$ & $(0.42)$ & $(0.33)$ \\
C & 14.36 & 12.85 & 12.00 & 10.76 & 9.11 & 7.88 & 10.20 \\
& $(1.83)$ & $(1.66)$ & $(1.55)$ & $(1.29)$ & $(0.99)$ & $(0.84)$ & $(1.05)$ \\
\hline \multirow{7}{*}{ IG } & 0.05 & 0.06 & 0.07 & 0.11 & 0.14 & 0.16 & 0.11 \\
& $(0.03)$ & $(0.03)$ & $(0.03)$ & $(0.03)$ & $(0.04)$ & $(0.04)$ & $(0.03)$ \\
B & 0.53 & 0.90 & 1.07 & 1.32 & 1.72 & 1.98 & 1.46 \\
& $(0.15)$ & $(0.23)$ & $(0.27)$ & $(0.33)$ & $(0.45)$ & $(0.50)$ & $(0.35)$ \\
C & 14.33 & 13.10 & 12.46 & 11.36 & 9.65 & 8.43 & 10.68 \\
& $(2.26)$ & $(2.04)$ & $(1.91)$ & $(1.58)$ & $(1.17)$ & $(0.99)$ & $(1.26)$ \\
\hline
\end{tabular}




\section{Proofs}

Lemma 1 The density $\pi_{4}^{\mathbb{Q}}\left(y_{t} \mid y_{t-L}, \tau_{b}>t\right), t \geq \tau_{c}+L$ is given by

$$
\pi_{4}^{\mathbb{Q}}\left(y_{t} \mid y_{t-L}, \tau_{b}>t\right)=\frac{\pi^{\mathbb{Q}}\left(y_{t}, \tau_{b}>t \mid y_{t-L}, \tau_{b}>(t-L)\right)}{\pi^{\mathbb{Q}}\left(\tau_{b}>t \mid y_{t-L}, \tau_{b}>(t-L)\right)},
$$

where the numerator and denominator are

$$
\begin{aligned}
& \pi^{\mathbb{Q}}\left(y_{t}, \tau_{b}>t \mid y_{t-L}, \tau_{b}>(t-L)\right)= \\
& \mathbf{1}_{\left\{y_{t}>0\right\}} \mathbf{1}_{\left\{y_{t-L}>0\right\}}\left[\frac{1}{\sqrt{2 \pi \sigma^{2} L}} \exp \left\{\left(\frac{-1}{2 \sigma^{2} L}\right)\left[y_{t}-y_{t-L}-m L\right]^{2}\right\}\right. \\
& \left.-e^{-\frac{2 y(t-L)^{m}}{\sigma^{2}}} \frac{1}{\sqrt{2 \pi \sigma^{2} L}} \exp \left\{\left(\frac{-1}{2 \sigma^{2} L}\right)\left[y_{t}+y_{t-L}-m L\right]^{2}\right\}\right] \\
& \pi^{\mathbb{Q}}\left(\tau_{b}>t \mid y_{t-L}, \tau_{b}>(t-L)\right)=\left[N\left(\frac{y_{t-L}+m L}{\sqrt{\sigma^{2} L}}\right)-\right. \\
& \left.e^{-\frac{2 y_{t-L} m}{\sigma^{2}}} N\left(\frac{-y_{t-L}+m L}{\sqrt{\sigma^{2} L}}\right)\right] \mathbf{1}_{\left\{y_{t-L}>0\right\}},
\end{aligned}
$$

and $N(\cdot)$ denotes the cumulative standard normal distribution.

Proof. From Proposition 8.1, p. 11 in Harrison (1985) the density $\pi^{\mathbb{Q}}\left(y_{t}, \tau_{b}>t \mid y_{t-L}, \tau_{b}>\right.$ $(t-L))$ in the numerator of (D.1) is characterized by the "free solution" minus an "image solution" whose initial location $-y_{t-L}$ is the same distance from the default boundary as is the actual initial location, that is, $y_{t-L}$. Hence, the numerator of (D.1) is given by

$$
\begin{aligned}
\pi^{\mathbb{Q}}\left(y_{t}, \tau_{b}>t \mid y_{t-L}, \tau_{b}>(t-L)\right) & = \\
\mathbf{1}_{\left\{y_{t}>0\right\}} & \mathbf{1}_{\left\{y_{t-L}>0\right\}} \times\left[\frac{1}{\sqrt{2 \pi \sigma^{2} L}} \exp \left\{\left(\frac{-1}{2 \sigma^{2} L}\right)\left[y_{t}-y_{t-L}-m L\right]^{2}\right\}\right. \\
-e^{-\frac{2 y_{(t-L)} m}{\sigma^{2}}} & \left.\frac{1}{\sqrt{2 \pi \sigma^{2} L}} \exp \left\{\left(\frac{-1}{2 \sigma^{2} L}\right)\left[y_{t}+y_{t-L}-m L\right]^{2}\right\}\right]
\end{aligned}
$$


By integrating over $y_{t}$ we obtain the denominator of (D.1), that is,

$$
\begin{aligned}
\pi^{\mathbb{Q}}\left(\tau_{b}>t \mid y_{t-L}, \tau_{b}>(t-L)\right)= & \\
& {\left[N\left(\frac{y_{t-L}+m L}{\sqrt{\sigma^{2} L}}\right)-e^{-\frac{2 y_{t-L} m}{\sigma^{2}}} N\left(\frac{-y_{t-L}+m L}{\sqrt{\sigma^{2} L}}\right)\right] \mathbf{1}_{\left\{y_{t-L}>0\right\}}, }
\end{aligned}
$$

where $N(\cdot)$ denotes the cumulative standard normal density.

Lemma 2 The density $\pi_{3}^{\mathbb{Q}}\left(y_{t} \mid \tau_{b}>t, y_{t-L}\right), t \in\left(\tau_{c}, \tau_{c}+L\right)$ is given by

$$
\pi_{3}^{\mathbb{Q}}\left(y_{t} \mid \tau_{b}>t, y_{t-L}\right)=\frac{\pi_{3}^{\mathbb{Q}}\left(y_{t}, \tau_{b}>t \mid y_{t-L}\right)}{\pi_{3}^{\mathbb{Q}}\left(\tau_{b}>t \mid y_{t-L}\right)}
$$

where the numerator and denominator are

$$
\begin{aligned}
& \pi_{3}^{\mathbb{Q}}\left(y_{t}, \tau_{b}>t \mid y_{t-L}\right)=\mathbf{1}_{\left\{y_{t}>0\right\}} \int_{0}^{\infty} \frac{d y_{\tau_{c}}}{\sqrt{2 \pi \sigma^{2}\left(t-\tau_{c}\right)}} \\
& \times\left[e^{-\left(\frac{1}{2 \sigma^{2}\left(t-\tau_{c}\right)}\right)\left[y_{t}-y_{\tau_{c}}-m\left(t-\tau_{c}\right)\right]^{2}}-e^{-\frac{2 y_{\tau_{c}} m}{\sigma^{2}}} e^{-\left(\frac{1}{2 \sigma^{2}\left(t-\tau_{c}\right)}\right)\left[y_{t}+y_{\tau_{c}}-m\left(t-\tau_{c}\right)\right]^{2}}\right] \\
& \times \frac{1}{\sqrt{2 \pi \sigma^{2}\left(\tau_{c}-(t-L)\right)}} e^{-\left(\frac{1}{2 \sigma^{2}\left(\tau_{c}-(t-L)\right)}\right)\left[y_{\tau_{c}}-y_{t-L}-m\left(\tau_{c}-(t-L)\right)\right]^{2}}, \\
& \pi_{3}^{\mathbb{Q}}\left(\tau_{b}>t \mid y_{t-L}\right)= \\
& \int_{0}^{\infty} \frac{d y_{\tau_{c}}}{\sqrt{2 \pi \sigma^{2}\left(\tau_{c}-(t-L)\right)}} e^{-\left(\frac{1}{2 \sigma^{2}\left(\tau_{c}-(t-L)\right)}\right)\left[y_{\tau_{c}}-y_{t-L}-m\left(\tau_{c}-(t-L)\right)\right]^{2}} \\
& \times\left\{N\left[\frac{y_{\tau_{c}}+m\left(t-\tau_{c}\right)}{\sqrt{\sigma^{2}\left(t-\tau_{c}\right)}}\right]-e^{-\frac{2 y_{\tau_{c}} m}{\sigma^{2}}} N\left[\frac{-y_{\tau_{c}}+m\left(t-\tau_{c}\right)}{\sqrt{\sigma^{2}\left(t-\tau_{c}\right)}}\right]\right\} .
\end{aligned}
$$




\section{Proof.}

$$
\begin{aligned}
\pi_{3}^{\mathbb{Q}}\left(y_{t}, \tau_{b}>t \mid y_{t-L}\right) & =\int_{0}^{\infty} d y_{\tau_{c}} \pi\left(y_{\tau_{c}}, y_{t}, \tau_{b}>t \mid y_{t-L}\right) \\
= & \int_{0}^{\infty} d y_{\tau_{c}} \pi\left(y_{t}, \tau_{b}>t \mid y_{\tau_{c}}\right) \pi\left(y_{\tau_{c}} \mid y_{t-L}\right) \\
= & 1_{\left\{y_{t}>0\right\}} \int_{0}^{\infty} \frac{d y_{\tau_{c}}}{\sqrt{2 \pi \sigma^{2}\left(t-\tau_{c}\right)}} \\
& \times\left[e^{-\left(\frac{1}{2 \sigma^{2}\left(t-\tau_{c}\right)}\right)\left[y_{t}-y_{\tau_{c}}-m\left(t-\tau_{c}\right)\right]^{2}}-e^{-\frac{2 y \tau_{c} m}{\sigma^{2}}} e^{-\left(\frac{1}{2 \sigma^{2}\left(t-\tau_{c}\right)}\right)\left[y_{t}+y_{\tau_{c}}-m\left(t-\tau_{c}\right)\right]^{2}}\right] \\
& \times \frac{1}{\sqrt{2 \pi \sigma^{2}\left(\tau_{c}-(t-L)\right)}} e^{-\left(\frac{1}{2 \sigma^{2}\left(\tau_{c}-(t-L)\right)}\right)\left[y_{\tau_{c}}-y_{t-L}-m\left(\tau_{c}-(t-L)\right)\right]^{2}},
\end{aligned}
$$

where the lower integration limit is zero because $\tau_{b}$ cannot be greater than $t$ if $y_{\tau_{c}}<0$. Also, the second line holds because, when conditioning on both $\left(y_{\tau_{c}}, y_{t-L}\right), y_{\tau_{c}}$ is a sufficient statistic.

By integrating the joint density (D.7) over $y_{t} \in(0, \infty)$, we find

$$
\begin{aligned}
\pi_{3}^{\mathbb{Q}}\left(\tau_{b}>t \mid y_{t-L}\right)= & \int_{0}^{\infty} \frac{d y_{\tau_{c}}}{\sqrt{2 \pi \sigma^{2}\left(\tau_{c}-(t-L)\right)}} e^{-\left(\frac{1}{2 \sigma^{2}\left(\tau_{c}-(t-L)\right)}\right)\left[y_{\tau_{c}}-y_{t-L}-m\left(\tau_{c}-(t-L)\right)\right]^{2}} \\
& \times\left\{N\left[\frac{y_{\tau_{c}}+m\left(t-\tau_{c}\right)}{\sqrt{\sigma^{2}\left(t-\tau_{c}\right)}}\right]-e^{-\frac{2 y \tau_{c} m}{\sigma^{2}}} N\left[\frac{-y_{\tau_{c}}+m\left(t-\tau_{c}\right)}{\sqrt{\sigma^{2}\left(t-\tau_{c}\right)}}\right]\right\}
\end{aligned}
$$




\section{Proof of Proposition 1}

The value of a claim to coupons and maturing principal prior to default is given by

$$
\begin{aligned}
D_{4,1}\left(\mathbf{1}_{\left\{\tau_{b}>t\right\}}, y_{t-L}, F_{t}\right) & =\mathbb{E}_{t}^{\mathbb{Q}}\left[\int_{t}^{\infty} d T e^{-r(T-t)}(c+\xi) F_{T} \mathbf{1}_{\left\{\tau_{b}>T\right\}}\right] \\
& =\mathbf{1}_{\left(\tau_{b}>t\right)}(c+\xi) F_{t} d_{4,1}\left(y_{t-L}\right),
\end{aligned}
$$

with

$$
d_{4,1}\left(y_{t-L}\right)=\int_{t}^{\infty} d T e^{-(r+\xi)(T-t)} \pi^{\mathbb{Q}}\left(\tau_{b}>T \mid \mathcal{F}_{4, t}\right) .
$$

and $\mathcal{F}_{4, t}$ denoting the information set in Regime 4, assuming default has not yet occurred, that is,

$$
\mathcal{F}_{4, t}=\left\{y_{t-L}, \tau_{b}>t\right\}, \quad t \geq \tau_{c}+L .
$$

In terms of the Dirac delta function $\delta(\cdot)$, the value of debt's claim to recovery conditional upon default is given by

$$
\begin{aligned}
D_{4,2}\left(\mathbf{1}_{\left\{\tau_{b}>t\right\}}, y_{t-L}, F_{t}\right) & =\mathbb{E}_{t}^{\mathbb{Q}}\left[\int_{t}^{\infty} d T e^{-r(T-t)}(1-\alpha)(1-\theta) V_{\tau_{b}} \delta\left(\tau_{b}-T\right)\right] \\
& =(1-\alpha)(1-\theta) v_{b} F_{t} d_{4,2}\left(y_{t-L}\right),
\end{aligned}
$$

with

$$
\begin{aligned}
d_{4,2}\left(y_{t-L}\right) & =\int_{t}^{\infty} d T e^{-(r+\xi)(T-t)} \pi^{\mathbb{Q}}\left(\tau_{b}=T \mid \mathcal{F}_{4, t}\right) \\
& =\left[1-(r+\xi) d_{4,1}\left(y_{t-L}\right)\right] .
\end{aligned}
$$

Equation (D.13) follows from integration-by-parts, and the fact that: $\pi^{\mathbb{Q}}\left(\tau_{b}=T \mid \mathcal{F}_{4, t}\right)=$ $-\frac{\partial}{\partial T} \pi^{\mathbb{Q}}\left(\tau_{b}>T \mid \mathcal{F}_{4, t}\right)$. As shown in equations (D.10) and (D.13), to price the bond, we need the conditional probability $\pi^{\mathbb{Q}}\left(\tau_{b}>T \mid \mathcal{F}_{4, t}\right)$. To derive it, it is useful to start with the 
identity:

$$
\pi^{\mathbb{Q}}\left(y_{T}, \tau_{b}>T, y_{t} \mid y_{t-L}, \tau_{b}>t\right)=\pi^{\mathbb{Q}}\left(y_{T}, \tau_{b}>T \mid y_{t}, \tau_{b}>t\right) \pi_{4}^{\mathbb{Q}}\left(y_{t} \mid y_{t-L}, \tau_{b}>t\right)
$$

where $\pi_{4}^{\mathbb{Q}}\left(y_{t} \mid y_{t-L}, \tau_{b}>t\right)$ is given in Lemma 1 . This relation holds because conditioning upon both $\left(y_{t}, y_{t-L}\right)$ is equivalent to conditioning only upon $y_{t}$ due to $y$-dynamics being Markov. The two terms on the RHS are:

$$
\begin{aligned}
\pi^{\mathbb{Q}}\left(y_{T}, \tau_{b}>T \mid y_{t}, \tau_{b}>t\right) & =\left(\frac{\mathbf{1}_{\left(y_{T}>0\right)} \mathbf{1}_{\left(y_{t}>0\right)}}{\sqrt{2 \pi \sigma^{2}(T-t)}}\right)\left[e^{-\frac{\left[y_{T}-y_{t}-m(T-t)\right]^{2}}{2 \sigma^{2}(T-t)}}-e^{-\frac{2 m y_{t}}{\sigma^{2}}} e^{\frac{-\left[y_{T}+y_{t}-m(T-t)\right]^{2}}{2 \sigma^{2}(T-t)}}\right] \\
\pi_{4}^{\mathbb{Q}}\left(y_{t} \mid y_{t-L}, \tau_{b}>t\right) & =\frac{\pi^{\mathbb{Q}}\left(y_{t}, \tau_{b}>t \mid y_{t-L}, \tau_{b}>(t-L)\right)}{\pi^{\mathbb{Q}}\left(\tau_{b}>t \mid y_{t-L}, \tau_{b}>(t-L)\right)}, \quad \text { (D.15) }
\end{aligned}
$$

where the numerator and denominator are

$$
\begin{aligned}
& \left.\pi^{\mathbb{Q}}\left(y_{t}, \tau_{b}>t \mid y_{t-L}, \tau_{b}>(t-L)\right)\right)= \\
& =\frac{\mathbf{1}_{\left\{y_{t}>0\right\}} \mathbf{1}_{\left\{y_{t-L}>0\right\}}}{\sqrt{2 \pi \sigma^{2} L}}\left[e^{-\frac{\left[y_{t}-y_{t-L}-m L\right.}{2 \sigma^{2} L}}-e^{-\frac{2 y_{(t-L)} m}{\sigma^{2}}} e^{-\frac{\left[y_{t}+y_{t-L}-m L\right.}{2 \sigma^{2} L}}\right] \\
& \left.\pi^{\mathbb{Q}}\left(\tau_{b}>t \mid y_{t-L}, \tau_{b}>(t-L)\right)\right)= \\
& =\left[N\left(\frac{y_{t-L}+m L}{\sqrt{\sigma^{2} L}}\right)-e^{-\frac{2 y_{t-L} m}{\sigma^{2}}} N\left(\frac{-y_{t-L}+m L}{\sqrt{\sigma^{2} L}}\right)\right] \mathbf{1}_{\left\{y_{t-L}>0\right\}},
\end{aligned}
$$

and $N(\cdot)$ denotes the cumulative standard normal distribution. Integrating equation (D.14) 
over $y_{T}$, we find

$$
\begin{aligned}
\pi^{\mathbb{Q}} & \left(y_{t}, \tau_{b}>T \mid y_{t-L}, \tau_{b}>t\right) \equiv \int_{-\infty}^{\infty} d y_{T} \pi^{\mathbb{Q}}\left(y_{T}, \tau_{b}>T, y_{t} \mid y_{t-L}, \tau_{b}>t\right) \\
& =\left[\int_{-\infty}^{\infty} d y_{T} \pi^{\mathbb{Q}}\left(y_{T}, \tau_{b}>T \mid y_{t}, \tau_{b}>t\right)\right] \pi_{4}^{\mathbb{Q}}\left(y_{t} \mid y_{t-L}, \tau_{b}>t\right) \\
& =\mathbf{1}_{\left(y_{t}>0\right)}\left[N\left(\frac{y_{t}+m(T-t)}{\sqrt{\sigma^{2}(T-t)}}\right)-e^{-\frac{2 y_{t} m}{\sigma^{2}}} N\left(\frac{-y_{t}+m(T-t)}{\sqrt{\sigma^{2}(T-t)}}\right)\right] \pi_{4}^{\mathbb{Q}}\left(y_{t} \mid y_{t-L}, \tau_{b}>t\right) .
\end{aligned}
$$

Finally, by integrating equation (D.17) over $y_{t}$, we obtain our desired result:

$$
\begin{aligned}
\pi^{\mathbb{Q}}\left(\tau_{b}>T \mid \mathcal{F}_{4, t}\right) & \equiv \int_{-\infty}^{\infty} d y_{t} \pi^{\mathbb{Q}}\left(y_{t}, \tau_{b}>T \mid \mathcal{F}_{4, t}\right) \\
& =\int_{0}^{\infty} d y_{t}\left[N\left(\frac{y_{t}+m(T-t)}{\sqrt{\sigma^{2}(T-t)}}\right)-e^{-\frac{2 y_{t} m}{\sigma^{2}}} N\left(\frac{-y_{t}+m(T-t)}{\sqrt{\sigma^{2}(T-t)}}\right)\right] \pi_{4}^{\mathbb{Q}}\left(y_{t} \mid \mathcal{F}_{4, t}\right)
\end{aligned}
$$

where $\mathcal{F}_{4, t}$ is the information set defined in (D.11) and $\pi_{4}^{\mathbb{Q}}\left(y_{t} \mid \mathcal{F}_{4, t}\right)$ is given in equation (D.15).

\section{Proof of Corollary 1}

We define the risk-neutral default intensity as

$$
\begin{aligned}
& \lambda_{4, d}^{\mathbb{Q}}\left(\mathbf{1}_{\left\{\tau_{b}>t\right\}}, y_{t-L}\right)=\mathbf{1}_{\left\{\tau_{b}>t\right\}} \lim _{d t \rightarrow 0}\left(\frac{1}{d t}\right) \pi^{\mathbb{Q}}\left(\tau_{b}<(t+d t) \mid \tau_{b}>t, y_{t-L}\right) \\
& \quad=\mathbf{1}_{\left\{\tau_{b}>t\right\}} \lim _{d t \rightarrow 0}\left(\frac{1}{d t}\right) \int_{0}^{\infty} d y_{t} \pi^{\mathbb{Q}}\left(\tau_{b}<(t+d t), y_{t} \mid \tau_{b}>t, y_{t-L}\right) \\
& \quad=\mathbf{1}_{\left\{\tau_{b}>t\right\}} \lim _{d t \rightarrow 0}\left(\frac{1}{d t}\right) \int_{0}^{\infty} d y_{t} \pi^{\mathbb{Q}}\left(\tau_{b}<(t+d t) \mid \tau_{b}>t, y_{t}\right) \pi^{\mathbb{Q}}\left(y_{t} \mid \tau_{b}>t, y_{t-L}\right) .
\end{aligned}
$$


Note that only values of $y_{t}=\alpha \sigma \sqrt{d t}$ contribute to the determination of the default intensity. To see why this is the case, recall that, from a binomial model, $d y= \pm \sigma \sqrt{d t}$. Therefore, only if $y_{t}$ is a few standard deviations away from the boundary at time- $t$ is it possible for default to occur by $(t+d t)$. Changing the integration variables $y_{t}=\alpha \sigma \sqrt{d t}, d y_{t}=d \alpha \sigma \sqrt{d t}$, we find

$$
\begin{aligned}
\pi^{\mathbb{Q}}\left(\tau_{b}<(t+d t) \mid\right. & \left.\tau_{b}>t, y_{t}=\alpha \sigma \sqrt{d t}\right)= \\
& =\left[1-\pi^{\mathbb{Q}}\left(\tau_{b}>(t+d t) \mid \tau_{b}>t, y_{t}=\alpha \sigma \sqrt{d t}\right)\right] \\
& =\left[1-\left\{N\left(\frac{\alpha \sigma \sqrt{d t}+m d t}{\sqrt{\sigma^{2} d t}}\right)-e^{-\frac{2 \alpha \sigma \sqrt{d t} m}{\sigma^{2}}} N\left(\frac{-\alpha \sigma \sqrt{d t}+m d t}{\sqrt{\sigma^{2} d t}}\right)\right\}\right] \\
& =\left[1-\left\{N\left(\alpha+\frac{m}{\sigma} \sqrt{d t}\right)-e^{-\frac{2 \alpha \sigma \sqrt{d t} m}{\sigma^{2}}} N\left(-\alpha+\frac{m}{\sigma} \sqrt{d t}\right)\right\}\right] \\
& \stackrel{d t \rightarrow 0}{=} 1-\{N(\alpha)-N(-\alpha)\} \\
& =2 N(-\alpha) .
\end{aligned}
$$

It might be surprising that this result is not of order $\mathcal{O}(d t)$, but this is because we are conditioning upon values of $y_{t}=\alpha \sigma \sqrt{d t}$ that are "very close" to the default boundary. From equation (D.1), we have

$$
\pi_{4}\left(y_{t}=\alpha \sigma \sqrt{d t} \mid \tau_{b}>t, y_{t-L}\right)=\frac{\pi\left(y_{t}=\alpha \sigma \sqrt{d t}, \tau_{b}>t \mid y_{t-L}, \tau_{b}>(t-L)\right)}{\pi\left(\tau_{b}>t \mid y_{t-L}, \tau_{b}>(t-L)\right)},
$$


Taylor expanding with respect to $y_{t}=\alpha \sigma \sqrt{d t}$, and using the fact that the density goes zero at $y_{t}=0$, we get

$$
\begin{aligned}
\pi\left(y_{t}\right. & \left.=\alpha \sigma \sqrt{d t} \mid \tau_{b}>t, y_{t-L}\right)= \\
& =\frac{\pi\left(y_{t}=0, \tau_{b}>t \mid y_{t-L}, \tau_{b}>(t-L)\right)+\alpha \sigma \sqrt{d t} \pi_{y}\left(y_{t}=0, \tau_{b}>t \mid y_{t-L}, \tau_{b}>(t-L)\right)}{\pi\left(\tau_{b}>t \mid y_{t-L}, \tau_{b}>(t-L)\right)} \\
& =\frac{\alpha \sigma \sqrt{d t} \pi_{y}\left(y_{t}=0, \tau_{b}>t \mid y_{t-L}, \tau_{b}>(t-L)\right)}{\pi\left(\tau_{b}>t \mid y_{t-L}, \tau_{b}>(t-L)\right)}
\end{aligned}
$$

Combining these results, we find:

$$
\begin{aligned}
\lambda_{4, d}^{\mathbb{Q}}\left(\mathbf{1}_{\left\{\tau_{b}>t\right\}}, y_{t-L}\right)= \\
\quad=\lim _{d t \rightarrow 0}\left(\frac{1}{d t}\right) \int_{0}^{\infty} \sigma \sqrt{d t} d \alpha 2 N(-\alpha) \frac{\alpha \sigma \sqrt{d t} \pi_{y}\left(y_{t}=0, \tau_{b}>t \mid y_{t-L}, \tau_{b}>(t-L)\right)}{\pi\left(\tau_{b}>t \mid y_{t-L}, \tau_{b}>(t-L)\right)} \\
\quad=\left(\frac{2 \sigma^{2} \pi_{y}\left(y_{t}=0, \tau_{b}>t \mid y_{t-L}, \tau_{b}>(t-L)\right)}{\pi\left(\tau_{b}>t \mid y_{t-L}, \tau_{b}>(t-L)\right)}\right) \int_{0}^{\infty} d \alpha \alpha N(-\alpha)
\end{aligned}
$$

Using integration by parts, can show that

$$
\int_{0}^{\infty} d \alpha \alpha N(-\alpha)=\frac{1}{4} .
$$

Hence,

$$
\begin{aligned}
\lambda_{4, d}^{\mathbb{Q}}\left(\mathbf{1}_{\left\{\tau_{b}>t\right\}}, y_{t-L}\right) & =\left.\left(\frac{\sigma^{2}}{2}\right) \frac{\partial}{\partial y_{t}}\left(\frac{\pi\left(y_{t}, \tau_{b}>t \mid y_{t-L}, \tau_{b}>(t-L)\right)}{\pi\left(\tau_{b}>t \mid y_{t-L}, \tau_{b}>(t-L)\right)}\right)\right|_{y_{t}=0} \\
& =\left.\left(\frac{\sigma^{2}}{2}\right) \frac{\partial}{\partial y_{t}} \pi_{4}\left(y_{t} \mid y_{t-L}, \tau_{b}>t\right)\right|_{y_{t}=0},
\end{aligned}
$$


which agrees with Duffie and Lando (2001). Expression (32) for the default intensity follows by differentiation of the above expression.

\section{Proof of Proposition 2}

The time- $\tau_{c}$ value of a claim to coupon and principal payments $(c+\xi) F_{T} d T$ made during the interval $d T$ for times $T \in\left(\tau_{c}, \tau_{b}\right)$ is given by

$$
\begin{aligned}
D_{3,1}\left(\mathbf{1}_{\left\{\tau_{b}>\tau_{c}\right\}}, F_{\tau_{c}}\right) & =\mathrm{E}_{\tau_{c}}\left[\int_{\tau_{c}}^{\infty} d T e^{-r(T-t)}(c+\xi) F_{T} \mathbf{1}_{\left\{\tau_{b}>T\right\}}\right] \\
& =(c+\xi) F_{\tau_{c}} \mathbf{1}_{\left\{\tau_{b}>\tau_{c}\right\}} d_{3,1}
\end{aligned}
$$

with

$$
d_{3,1}=\int_{\tau_{c}}^{\infty} d T e^{-(r+\xi)\left(T-\tau_{c}\right)} \pi^{\mathbb{Q}}\left(\tau_{b}>T \mid \mathcal{F}_{3, \tau_{c}}\right)
$$

and $\mathcal{F}_{3, \tau_{c}}$ denoting the information set at time $\tau_{c}$ assuming default has not yet occurred, that is,

$$
\mathcal{F}_{3, \tau_{c}}=\left\{y_{\tau_{c}-L}, \tau_{b}>\tau_{c}\right\}=\left\{y_{\tau_{c}-L}, y_{\tau_{c}}>0\right\} .
$$

The time- $\tau_{c}$ value of a claim to recovery $(1-\alpha)(1-\theta) V_{\tau_{b}}$ which pays out at the random time $\tau_{b} \in\left(\tau_{c}, \infty\right)$ is given by

$$
\begin{aligned}
D_{3,2}\left(\mathbf{1}_{\left\{\tau_{b}>\tau_{c}\right\}}, F_{\tau_{c}}\right) & =\mathrm{E}_{\tau_{c}}\left[\int_{\tau_{c}}^{\infty} d T e^{-r(T-t)}(1-\alpha)(1-\theta) v_{b} F_{T} \delta \tau_{b}=T\right] \\
& =(1-\alpha)(1-\theta) v_{b} F_{\tau_{c}} \mathbf{1}_{\left\{\tau_{b}>\tau_{c}\right\}} d_{3,2}
\end{aligned}
$$


with

$$
\begin{aligned}
d_{3,2} & =\int_{\tau_{c}}^{\infty} d T e^{-(r+\xi)\left(T-\tau_{c}\right)} \pi^{\mathbb{Q}}\left(\tau_{b}=T \mid \mathcal{F}_{3, \tau_{c}}\right) \\
& =\left[1-(r+\xi) d_{3,1}\right] .
\end{aligned}
$$

Equation (D.30) follows from integration-by-parts, and the fact that: $\pi^{\mathbb{Q}}\left(\tau_{b}=T \mid \mathcal{F}_{3, \tau_{c}}\right)=$ $-\frac{\partial}{\partial T} \pi^{\mathbb{Q}}\left(\tau_{b}>T \mid \mathcal{F}_{3, \tau_{c}}\right)$. As shown in equations (D.27) and (D.30), to price the bond in this regime, we need the conditional probability $\pi^{\mathbb{Q}}\left(\tau_{b}>T \mid \mathcal{F}_{3, \tau_{c}}\right)$. To derive it, it is useful to start with the identity:

$$
\begin{aligned}
\pi^{\mathbb{Q}}\left(y_{\tau_{c}}, y_{\tau_{c}}>0 \mid y_{\tau_{c}-L}\right) & =\pi_{3}^{\mathbb{Q}}\left(y_{\tau_{c}} \mid y_{\tau_{c}}>0, y_{\tau_{c}-L}\right) \pi^{\mathbb{Q}}\left(y_{\tau_{c}}>0 \mid y_{\tau_{c}-L}\right) \\
& =\pi^{\mathbb{Q}}\left(y_{\tau_{c}}>0 \mid y_{\tau_{c}}, y_{\tau_{c}-L}\right) \pi^{\mathbb{Q}}\left(y_{\tau_{c}} \mid y_{\tau_{c}-L}\right) .
\end{aligned}
$$

Combining the two previous equations, we find

$$
\begin{gathered}
\pi_{3}^{\mathbb{Q}}\left(y_{\tau_{c}} \mid y_{\tau_{c}}>0, y_{\tau_{c}-L}\right)=\frac{\pi\left(y_{\tau_{c}}>0 \mid y_{\tau_{c}}, y_{\tau_{c}-L}\right) \pi\left(y_{\tau_{c}} \mid y_{\tau_{c}-L}\right)}{\pi\left(y_{\tau_{c}}>0 \mid y_{\tau_{c}-L}\right)} \\
=\left(\frac{\left.1_{\left\{y_{\tau_{c}}>0\right\}}\right)}{N\left(\frac{y_{\tau_{c}-L}+m L}{\sqrt{\sigma^{2} L}}\right)} \frac{1}{\sqrt{2 \pi \sigma^{2} L}} \exp \left[-\left(\frac{1}{2 \sigma^{2} L}\right)\left(y_{\tau_{c}}-y_{\tau_{c}-L}-m L\right)^{2}\right] .\right.
\end{gathered}
$$

To determine the value of $D_{3,1}\left(\mathbf{1}_{\left(\tau_{b}>\tau_{c}\right)}, F_{\tau_{c}}\right)$ in equation (D.27), we need to identify the probability $\pi^{\mathbb{Q}}\left(\tau_{b}>T \mid y_{\tau_{c}}>0, y_{\tau_{c}-L}\right)$. Noting that the condition $\left(y_{\tau_{c}}>0\right)$ is equivalent to 
$\left(\tau_{b}>\tau_{c}\right)$, we accomplish this by integrating over $y_{\tau_{c}}$ as follows:

$$
\begin{aligned}
\pi^{\mathbb{Q}}\left(\tau_{b}>T \mid y_{\tau_{c}}>0, y_{\tau_{c}-L}\right)=\int_{-\infty}^{\infty} d y_{\tau_{c}} \pi^{\mathbb{Q}}\left(\tau_{b}>T, y_{\tau_{c}} \mid y_{\tau_{c}}>0, y_{\tau_{c}-L}\right) \\
=\int_{-\infty}^{\infty} d y_{\tau_{c}} \pi^{\mathbb{Q}}\left(\tau_{b}>T \mid y_{\tau_{c}}, \tau_{b}>\tau_{c}\right) \pi_{3}^{\mathbb{Q}}\left(y_{\tau_{c}} \mid y_{\tau_{c}}>0, y_{\tau_{c}-L}\right) \\
=\int_{0}^{\infty} d y_{\tau_{c}} \pi_{3}^{\mathbb{Q}}\left(y_{\tau_{c}} \mid y_{\tau_{c}}>0, y_{\tau_{c}-L}\right) \\
\quad \times\left[N\left(\frac{y_{\tau_{c}}+m\left(T-\tau_{c}\right)}{\sqrt{\sigma^{2}\left(T-\tau_{c}\right)}}\right)-e^{-\frac{2 y_{\tau_{c}} m}{\sigma^{2}}} N\left(\frac{-y_{\tau_{c}}+m\left(T-\tau_{c}\right)}{\sqrt{\sigma^{2}\left(T-\tau_{c}\right)}}\right)\right]
\end{aligned}
$$

where the last equality follows from Proposition 8.1, p. 11 in Harrison (1985).

\section{Proof of Proposition 3}

Using the conditional probabilities defined in (46) and (47) we can write the value of debt $D_{2}\left(F_{\tau_{c}^{-}}\right)$as:

$$
\begin{aligned}
D_{2}\left(F_{\tau_{c}}\right)= & \mathbb{E}_{\tau_{c}^{-}}^{\mathbb{Q}}\left[D_{3}\left(\mathbf{1}_{\left\{\tau_{b}>\tau_{c}\right\}}, F_{\tau_{c}}\right) \mathbf{1}_{\left\{y_{\tau_{c}}>0\right\}}+(1-\alpha)(1-\theta) V_{\tau_{c}} \mathbf{1}_{\left\{y_{\tau_{c}}<0\right\}}\right] \\
= & \pi_{2}^{\mathbb{Q}}\left(\tau_{b}>\tau_{c} \mid \mathcal{F}_{2, \tau_{c}^{-}}\right) D_{3}\left(\mathbf{1}_{\left\{\tau_{b}>\tau_{c}\right\}}, F_{\tau_{c}}\right) \\
& +(1-\alpha)(1-\theta) v_{b} F_{\tau_{c}} \int_{-\infty}^{0} \frac{d y_{\tau_{c}}}{\sqrt{2 \pi \sigma^{2} L}} e^{-\left(\frac{1}{2 \sigma^{2} L}\right)\left[y_{\tau_{c}}-\left(y_{\tau_{c}-L}+m L\right)\right]^{2}} e^{y_{\tau_{c}}} \\
= & N\left(\frac{\log \left(\underline{\Psi} e^{-\xi L} / v_{b}\right)+m L}{\sqrt{\sigma^{2} L}}\right) D_{3}\left(\mathbf{1}_{\left\{\tau_{b}>\tau_{c}\right\}}, F_{\tau_{c}}\right) \\
& +(1-\alpha)(1-\theta) \underline{\Psi} F_{\tau_{c}} e^{\left(m-\xi+\frac{\sigma^{2}}{2}\right) L} N\left(\frac{-\log \left(\underline{\Psi} e^{-\xi L} / v_{b}\right)-\left(m+\sigma^{2}\right) L}{\sqrt{\sigma^{2} L}}\right),
\end{aligned}
$$

where the debt value $D_{3}\left(y_{\tau_{c}-L}, \mathbf{1}_{\left\{\tau_{b}>\tau_{c}\right\}}, \bar{F}, \tau_{c}\right)$ is given in Proposition 2, and where the last equality uses the densities in equations (46) and (47). 


\section{Proof of Proposition 4}

We conjecture that the regime- 1 bond price is homogeneous degree- 1 in its arguments, and therefore can be specified as:

$$
D_{1}\left(\widehat{V}_{t}, F_{t}\right)=F_{t} d\left(\Psi_{t}=\left(\widehat{V}_{t} / F_{t}\right)\right)
$$

After plugging the following partial derivatives

$$
\begin{aligned}
D_{1, \widehat{V}}\left(\widehat{V}_{t}, F_{t}\right) & =d_{\Psi} \\
D_{1, \widehat{V} \widehat{V}}\left(\widehat{V}_{t}, F_{t}\right) & =\left(1 / F_{t}\right) d_{\Psi \Psi} \\
D_{1, F}\left(\widehat{V}_{t}, F_{t}\right) & =d-\Psi d_{\Psi},
\end{aligned}
$$

into the PDE (58), we find that this scaling feature reduces the PDE to a nonlinear ODE:

$$
\begin{aligned}
0= & -(r+\xi) d+(c+\xi)+\frac{\sigma^{2}}{2} \Psi^{2} d_{\Psi \Psi}+ \\
& \Psi d_{\Psi}\left[(\mu+\xi)-\left(\frac{1}{d}\right)(\beta(\Psi-\underline{\Psi})+(1-\theta) c+\xi)\right] .
\end{aligned}
$$

By construction, the boundary condition at $\Psi_{t}=\underline{\Psi}$ is specified as:

$$
d\left(\Psi_{t}=\underline{\Psi}\right)=\left(\frac{D_{2}\left(F_{\tau_{c}}\right)}{F_{\tau_{c}}}\right) .
$$

In contrast, there is no exogenously imposed boundary as $\Psi_{t} \rightarrow \infty$. Instead, it is a natural boundary derived from the ODE in equation (D.37). Specifically, one can show that $d(\Psi)$ possesses a Taylor series expansion about $\Psi=\infty$ of the form:

$$
d(\Psi)=\sum_{j=0}^{\infty} d_{j} \Psi^{-j}
$$


The implication is that $\lim _{\Psi_{t} \rightarrow \infty} d\left(\Psi_{t}\right)$ approaches a constant, and therefore that:

$$
\lim _{\Psi_{t} \rightarrow \infty} d_{\Psi}\left(\Psi_{t}\right)=0
$$

Intuitively, this equation captures the fact that the bond price per unit face value goes to a constant as $\Psi \rightarrow \infty$.

\section{Proof of Proposition 5}

Recall from equation (63) that, for dates $t \in\left(\tau_{c}, \tau_{b}\right)$, the value of equity conditional upon the manager's information set can be written as:

$$
S\left(y_{t}, F_{t}\right)=F_{t} \mathbf{1}_{\left(y_{t}>0\right)}\left\{(1-\theta) v_{b}\left(e^{y_{t}}-e^{-\omega y_{t}}\right)-\left(\frac{c(1-\theta)+\xi}{r+\xi}\right)\left(1-e^{-\omega y_{t}}\right)\right\} t \geq \tau_{c} .
$$

For these dates, creditors do not know $y_{t}$, but only the lagged value $y_{t-L}$, and the fact that the process $\left\{y_{s}\right\}>0 \forall s \in\left(\tau_{c}, t\right)$, which for conciseness, we express as $\tau_{b}>t$. Thus, the value of equity conditional upon the creditor's information set is:

$$
\widehat{S}\left(y_{t-L}, F_{t}\right)= \begin{cases}\int_{0}^{\infty} \pi_{3}^{\mathbb{Q}}\left(y_{t} \mid \tau_{b}>t, y_{t-L}\right) S\left(y_{t}, F_{t}\right) d y_{t} & \text { if } \tau_{c} \leq t<\tau_{c}+L \\ \int_{0}^{\infty} \pi_{4}^{\mathbb{Q}}\left(y_{t} \mid \tau_{b}>t, y_{t-L}\right) S\left(y_{t}, F_{t}\right) d y_{t} & \text { if } t \geq \tau_{c}+L\end{cases}
$$

where $\pi_{3}^{\mathbb{Q}}\left(y_{t} \mid \tau_{b}>t, y_{t-L}\right)$ is given by equation (D.4) in Lemma 2 , and $\pi_{4}^{\mathbb{Q}}\left(y_{t} \mid \tau_{b}>t, y_{t-L}\right)$ is given in equation (D.1) in Lemma 1.

For times $t<\tau_{c}$, creditor's valuation of equity is given by the sum of risk-neutral expected cash flows due to shareholders prior to date- $\tau_{c}$, and the value of equity at date $\tau_{c}$ :

$$
\widehat{S}\left(\widehat{V}_{t}, F_{t}\right)=\mathbb{E}_{t}^{\mathbb{Q}}\left[\int_{t}^{\tau_{c}} d T e^{-r(T-t)}\left[(1-\theta)(r-\mu) \widehat{V}_{t+L}+\beta\left(\widehat{V}_{t}-\underline{\Psi} F_{T}\right)\right]+e^{-r\left(\tau_{c}-t\right)} \widehat{S}_{\tau_{c}} \mid \mathcal{F}_{t}\right]
$$


where $\widehat{S}_{\tau_{c}}=\widehat{S}\left(y_{\tau_{c}-L}=\log \left(\underline{\Psi} e^{-\xi L} / v_{b}\right), F_{\tau_{c}}\right)$ can be determined from equation (D.41):

$$
\begin{aligned}
\widehat{S}_{\tau_{c}} & =\int_{0}^{\infty} d y_{\tau_{c}} \pi\left(y_{\tau_{c}} \mid y_{\tau_{c}-L}=\log \left(\underline{\Psi} e^{-\xi L} / v_{b}\right)\right) S\left(y_{\tau_{c}}, F_{\tau_{c}}\right) \\
& =(1-\theta) \underline{\Psi} F_{\tau_{c}} e^{L\left(m-\xi+\left(\sigma^{2} / 2\right)\right)} N\left[\frac{y_{\tau_{c}-L}+m L+\sigma^{2} L}{\sqrt{\sigma^{2} L}}\right]-\left(\frac{c(1-\theta)+\xi}{r+\xi}\right) F_{\tau_{c}} N\left[\frac{y_{\tau_{c}-L}+m L}{\sqrt{\sigma^{2} L}}\right] \\
& +\left[\left(\frac{c(1-\theta)+\xi}{r+\xi}\right)-(1-\theta) v_{b}\right] F_{\tau_{c}} e^{-\omega y_{\tau_{c}-L}} e^{L\left(\left(\omega^{2} \sigma^{2} / 2\right)-\omega m\right)} N\left[\frac{y_{\tau_{c}-L}+m L-\omega \sigma^{2} L}{\sqrt{\sigma^{2} L}}\right],
\end{aligned}
$$

with $y_{\tau_{c}-L}=\log \left(\underline{\Psi} e^{-\xi L} / v_{b}\right)$.

With the value of $\widehat{S}_{\tau_{c}}$ obtained in equation (66), we can determine the outsiders' valuation of equity $S_{t}$ for $t<\tau_{c}$ by solving the expectation in equation (65). Because $e^{-r t} \widehat{S}\left(\widehat{V}_{t}, F_{t}\right)+$

$\mathrm{E}_{t}\left[\int_{0}^{t} d T e^{-r T}\left[(1-\theta)(r-\mu) \widehat{V}_{T+L}+\beta\left(\widehat{V}_{T}-\underline{\Psi} F_{T}\right)\right]\right]$ is a $\mathbb{Q}$-martingale, the expectation in equation (65) reduces to the following PDE:

$$
\begin{aligned}
0= & -r \widehat{S}+\mu \widehat{V} \widehat{S}_{\widehat{V}}+\frac{\sigma^{2}}{2} \widehat{V}^{2} \widehat{S}_{\widehat{V} \widehat{V}}+(1-\theta)(r-\mu) \widehat{V} e^{m L}+\beta(\widehat{V}-\underline{\Psi} F) \\
& +\widehat{S}_{F}\left[-\xi F+\left(\frac{F}{D_{1}(\widehat{V}, F)}\right)[((1-\theta) c+\xi) F+\beta(\widehat{V}-\underline{\Psi} F)]\right]
\end{aligned}
$$

\section{Proof of Proposition 6}

Given the scaling feature of our framework, we look for a solution of the form:

$$
\widehat{S}\left(\widehat{V}_{t}, F_{t}\right)=F_{t} \widehat{s}\left(\Psi=\widehat{V}_{t} / F_{t}\right)
$$


Using the relations

$$
\begin{aligned}
\widehat{S}_{\widehat{V}}(\widehat{V}, F) & =\widehat{s}_{\Psi}(\Psi) \\
\widehat{S}_{\widehat{V} \widehat{V}}(\widehat{V}, F) & =\left(\frac{1}{F}\right) \widehat{s}_{\Psi \Psi}(\Psi) \\
\widehat{S}_{F}(\widehat{V}, F) & =\widehat{s}(\Psi)-\Psi \widehat{s}_{\Psi}(\Psi),
\end{aligned}
$$

we find that the PDE in equation (67) simplifies to the ODE:

$$
\begin{aligned}
0= & -r \widehat{s}+\mu \Psi \widehat{s}_{\Psi}+\frac{\sigma^{2}}{2} \Psi^{2} \widehat{s}_{\Psi \Psi}+(1-\theta)(r-\mu) \Psi e^{m L}+\beta(\Psi-\underline{\Psi} F) \\
& +\left(\widehat{s}(\Psi)-\Psi \widehat{s}_{\Psi}(\Psi)\right)\left[-\xi+\left(\frac{1}{d(\Psi)}\right)[((1-\theta) c+\xi)+\beta(\Psi-\underline{\Psi})]\right] .
\end{aligned}
$$

By construction, the boundary condition at $\Psi_{t}=\underline{\Psi}$ is specified as:

$$
\widehat{s}(\Psi=\underline{\Psi})=\frac{\widehat{S}_{\tau_{c}}}{F_{\tau_{c}}} .
$$

In contrast, there is no exogenously imposed boundary as $\Psi_{t} \rightarrow \infty$. Instead, it is a natural boundary derived from the ODE in equation (D.48). Specifically, one can show that $\widehat{s}(\Psi)$ possesses a Taylor series expansion about $\Psi=\infty$ of the form:

$$
\widehat{s}(\Psi)=\sum_{j=-1}^{\infty} s_{j} \Psi^{-j}
$$

The implication is that $\lim _{\Psi_{t} \rightarrow \infty} \widehat{s}\left(\Psi_{t}\right)$ approaches a linear function:

$$
\lim _{\Psi_{t} \rightarrow \infty} \widehat{s}\left(\Psi_{t}\right)=s_{-1} \Psi
$$


Plugging this conjecture into equation (D.48), we find that the constant equals:

$$
s_{-1}=(1-\theta) e^{m L}+\beta /(r-\mu)
$$

Thus, we have

$$
\lim _{\Psi_{t} \rightarrow \infty} \widehat{s}_{\Psi}\left(\Psi_{t}\right)=(1-\theta) e^{m L}+\beta /(r-\mu)
$$

which implies the boundary condition

$$
\lim _{\Psi_{t} \rightarrow \infty} \widehat{s}_{\Psi \Psi}\left(\Psi_{t}\right)=0
$$




\section{E Bond prices in Regime 3 for times $t \in\left(\tau_{c}, \tau_{c}+L\right)$}

For times $t \in\left(\tau_{c}, \tau_{c}+L\right)$, we can express the value of debt as a sum of two components:

$$
D_{3}\left(\mathbf{1}_{\left\{\tau_{b}>t\right\}}, y_{t-L}, F_{t}\right)=D_{3,1}\left(\mathbf{1}_{\left\{\tau_{b}>t\right\}}, y_{t-L}, F_{t}\right)+D_{3,2}\left(\mathbf{1}_{\left\{\tau_{b}>t\right\}}, y_{t-L}, F_{t}\right)
$$

The first component is the present value at time- $t$ of the claim to coupon and principal

payments $(c+\xi) F_{T} d T$ made during the interval $d T$ for times $T \in(t, \infty)$ if default has not yet occurred (i.e., $t<\tau_{b}$ ):

$$
\begin{aligned}
D_{3,1}\left(\mathbf{1}_{\left\{\tau_{b}>t\right\}}, y_{t-L}, F_{t}\right) & =\mathbb{E}\left[\int_{t}^{\infty} d T e^{-r(T-t)}(c+\xi) F_{t} e^{-\xi(T-t)} \mathbf{1}_{\left(\tau_{b}>T\right)}\right] \\
& =(c+\xi) F_{t} \mathbf{1}_{\left\{\tau_{b}>t\right\}} d_{3,1}\left(y_{t-L}\right)
\end{aligned}
$$

where

$$
d_{3,1}\left(y_{t-L}\right)=\int_{t}^{\infty} d T e^{-(r+\xi)(T-t)} \pi^{\mathbb{Q}}\left(\tau_{b}>T \mid \tau_{b}>t, y_{t-L}\right)
$$

The second component is the present value at time- $t$ of the claim to recovery $(1-\alpha)(1-\theta) V_{\tau_{b}}$ if default occurs during the interval $(T, T+d T)$, for times $T \in(t, \infty)$, given by:

$$
\begin{aligned}
D_{3,2}\left(\mathbf{1}_{\left\{\tau_{b}>t\right\}}, y_{t-L}, F_{t}\right) & =\mathbb{E}\left[\int_{t}^{\infty} d T e^{-r(T-t)}(1-\alpha)(1-\theta) V_{T} \delta\left(\tau_{b}=T\right)\right] \\
& =(1-\alpha)(1-\theta) v_{b} F_{t} \mathbf{1}_{\left\{\tau_{b}>t\right\}} d_{3,2}\left(y_{t-L}\right)
\end{aligned}
$$

where

$$
\begin{aligned}
d_{3,2}\left(y_{t-L}\right) & =\int_{t}^{\infty} d T e^{-(r+\xi)(T-t)} \pi^{\mathbb{Q}}\left(\tau_{b}=T \mid \tau_{b}>t, y_{t-L}\right) \\
& =1-(r+\xi) d_{3,1}\left(y_{t-L}\right) .
\end{aligned}
$$


To price $d_{3,1}\left(y_{t-L}\right)$, we need to identify $\pi^{\mathbb{Q}}\left(\tau_{b}>T \mid \tau_{b}>t, y_{t-L}\right)$. To do so, we note:

$$
\begin{gathered}
\pi^{\mathbb{Q}}\left(\tau_{b}>T \mid \tau_{b}>t, y_{t-L}\right)=\int_{0}^{\infty} d y_{\tau_{c}} \int_{0}^{\infty} d y_{t} \pi^{\mathbb{Q}}\left(\tau_{b}>T, y_{\tau_{c}}, y_{t} \mid \tau_{b}>t, y_{t-L}\right) \\
=\int_{0}^{\infty} d y_{\tau_{c}} \int_{0}^{\infty} d y_{t} \pi^{\mathbb{Q}}\left[\tau_{b}>T \mid \tau_{b}>t, y_{t}\right] \pi^{\mathbb{Q}}\left[y_{t} \mid \tau_{b}>t, y_{\tau_{c}}\right] \pi^{\mathbb{Q}}\left[y_{\tau_{c}} \mid \tau_{b}>t, y_{t-L}\right] \\
=\int_{0}^{\infty} d y_{t} \pi^{\mathbb{Q}}\left[\tau_{b}>T \mid \tau_{b}>t, y_{t}\right] \pi_{3}^{\mathbb{Q}}\left[y_{t} \mid \tau_{b}>t, y_{t-L}\right]
\end{gathered}
$$

where we have defined

$$
\pi_{3}^{\mathbb{Q}}\left[y_{t} \mid \tau_{b}>t, y_{t-L}\right]=\int_{0}^{\infty} d y_{\tau_{c}} \pi^{\mathbb{Q}}\left[y_{t} \mid \tau_{b}>t, y_{\tau_{c}}\right] \pi^{\mathbb{Q}}\left[y_{\tau_{c}} \mid \tau_{b}>t, y_{t-L}\right]
$$


These densities can be determined using:

$$
\begin{aligned}
& \pi^{\mathbb{Q}}\left[\tau_{b}>T \mid \tau_{b}>t, y_{t}\right]=\mathbf{1}_{\left\{y_{t}>0\right\}} \times \\
& {\left[N\left(\frac{y_{t}+m(T-t)}{\sqrt{\sigma^{2}(T-t)}}\right)-e^{-\frac{2 y_{t} m}{\sigma^{2}}} N\left(\frac{-y_{t}+m(T-t)}{\sqrt{\sigma^{2}(T-t)}}\right)\right]} \\
& \pi^{\mathbb{Q}}\left[y_{t} \mid \tau_{b}>t, y_{\tau_{c}}\right]=\frac{\pi^{\mathbb{Q}}\left[y_{t}, \tau_{b}>t \mid y_{\tau_{c}}\right]}{\pi^{\mathbb{Q}}\left[\tau_{b}>t \mid y_{\tau_{c}}\right]} \\
& \pi^{\mathbb{Q}}\left[y_{t}, \tau_{b}>t \mid y_{\tau_{c}}\right]=\mathbf{1}_{\left\{y_{t}>0\right\}} \mathbf{1}_{\left\{y_{\tau_{c}}>0\right\}} \times \\
& {\left[\begin{array}{l}
\frac{1}{\sqrt{2 \pi \sigma^{2}\left(t-\tau_{c}\right)}} \exp \left\{\left(\frac{-1}{2 \sigma^{2}\left(t-\tau_{c}\right)}\right)\left[y_{t}-y_{\tau_{c}}-m\left(t-\tau_{c}\right)\right]^{2}\right\} \\
-e^{-\frac{y \tau_{c} \sigma^{m}}{\sigma^{2}}} \frac{1}{\sqrt{2 \pi \sigma^{2}\left(t-\tau_{c}\right)}} \exp \left\{\left(\frac{-1}{2 \sigma^{2}\left(t-\tau_{c}\right)}\right)\left[y_{t}+y_{\tau_{c}}-m\left(t-\tau_{c}\right)\right]^{2}\right\}
\end{array}\right]} \\
& \pi^{\mathbb{Q}}\left(\tau_{b}>t \mid y_{\tau_{c}}\right)=\mathbf{1}_{\left\{y_{\tau_{c}}>0\right\}} \times \\
& {\left[N\left(\frac{y_{\tau_{c}}+m\left(t-\tau_{c}\right)}{\sqrt{\sigma^{2}\left(t-\tau_{c}\right)}}\right)-e^{-\frac{2 y_{\tau_{c}} m}{\sigma^{2}}} N\left(\frac{-y_{\tau_{c}}+m\left(t-\tau_{c}\right)}{\sqrt{\sigma^{2}\left(t-\tau_{c}\right)}}\right)\right]} \\
& \pi^{\mathbb{Q}}\left[y_{\tau_{c}} \mid \tau_{b}>t, y_{t-L}\right]=\frac{\pi^{\mathbb{Q}}\left[\tau_{b}>t \mid y_{\tau_{c}}\right] \pi^{\mathbb{Q}}\left[y_{\tau_{c}} \mid y_{t-L}\right]}{\int_{0}^{\infty} d y_{\tau_{c}} \pi^{\mathbb{Q}}\left[\tau_{b}>t \mid y_{\tau_{c}}\right] \pi^{\mathbb{Q}}\left[y_{\tau_{c}} \mid y_{t-L}\right]} \\
& \pi^{\mathbb{Q}}\left[y_{\tau_{c}} \mid y_{t-L}\right]=\sqrt{\frac{1}{2 \pi \sigma^{2}\left(\tau_{c}-(t-L)\right)}} \times \\
& \exp \left\{\left(\frac{1}{2 \sigma^{2}\left(\tau_{c}-(t-L)\right)}\right)\left[y_{\tau_{c}}-y_{t-L}-m\left(\tau_{c}-(t-L)\right)\right]^{2}\right\} \text {. }
\end{aligned}
$$


As shown by Duffie and Lando (2001), the default intensity $\lambda_{3, d}^{\mathbb{Q}}\left(t, y_{t-L}\right)$ satisfies

$$
\begin{aligned}
\lambda_{3, d}^{\mathbb{Q}}\left(t, y_{t-L}\right) & =\left.\frac{\sigma^{2}}{2} \frac{\partial}{\partial y_{t}} \pi_{3}^{\mathbb{Q}}\left(y_{t} \mid \tau_{b}>t, y_{t-L}\right)\right|_{y_{t}=0} \\
& =\left(\frac{\int_{0}^{\infty} d y_{\tau_{c}} \pi^{\mathbb{Q}}\left[y_{\tau_{c}} \mid y_{t-L}\right] \frac{y_{\tau_{c}}}{\sqrt{2 \pi \sigma^{2}\left(t-\tau_{c}\right)^{3}}} e^{\left(\frac{-1}{2 \sigma^{2}\left(t-\tau_{c}\right)}\right)\left[y_{\tau_{c}}+m\left(t-\tau_{c}\right)\right]^{2}}}{\int_{0}^{\infty} d y_{\tau_{c}} \pi^{\mathbb{Q}}\left[\tau_{b}>t \mid y_{\tau_{c}}\right] \pi^{\mathbb{Q}}\left[y_{\tau_{c}} \mid y_{t-L}\right]}\right)
\end{aligned}
$$

For the special case $t=\left(\tau_{c}+L\right)$, this equation reduces to $\lambda_{3, d}^{\mathbb{Q}}\left(t, y_{t-L}\right)$ given in equation (32). However, for other values of $t$, in contrast to the time-independent default intensity in Regime 4, the default intensities in Regime 3 are time dependent. 